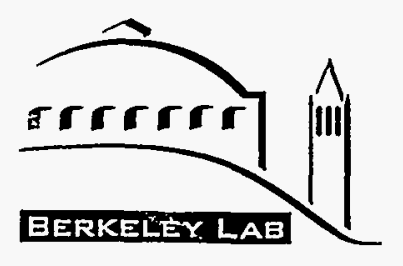

\title{
Guidelines for Generators to Meet HWHF Acceptance Requirements for Hazardous, Radioactive, and Mixed Wastes at Berkeley Lab
}

\author{
Environment, Health and Safety Division \\ Ernest Orlando Lawrence Berkeley National \\ Laboratory \\ Waste Management Group
}

Revision 3

June 1996
University of California
Berkeley, CA 94720

Prepared for the U.S. Department of Energy under Contract No. DE-AC03-76SF00098 


\section{Guidelines for Generators to Meet HWHF Acceptance Requirements for Hazardous, Radioactive, and Mixed Wastes at Berkeley Lab}

PUB-3092

Revision 3

June 1996

Prepared By:

Rich Albert

TEID Technical Writer

Information and Computing

Sciences Division

Reviewed By:

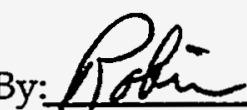

Menet Plobin Wendt, Group Leader

Waste Management Group

Environment, Health \& Safety Division

Approved

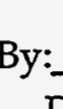

\section{Now}

David McGraw

Division Director

Environment, Health \& Safety Division
$6 / 6 / 96$

(Date)

(Date)

Deputy Division Director

Environment, Health \& Safety Division

Brian M. Smith

Waste Management Group

Environment, Health \& Safety Division

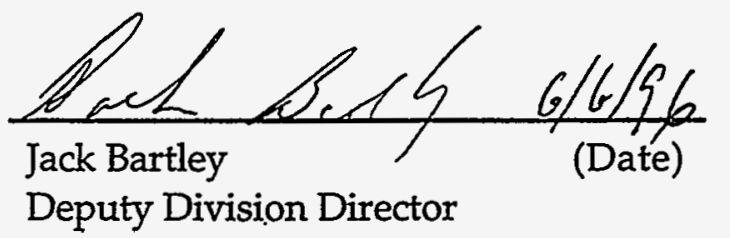

$6-10-96$

(Date)

Klaus Berkner (Date)

Deputy Director, Operations

Berkeley Lab 


\section{DISCLAIMER}

Portions of this document may be illegible in electronic image products. Images are produced from the best available original document. 

May 15, 1996

TO: $\quad$ Berkeley Lab Employees

FROM: $\quad$ Charles V. Shank, Director

RE: $\quad$ Training for Generators of Hazardous Waste

The Berkeley Lab is committed to responsible management of hazardous and/or radioactive waste, and it is imperative that all waste generators be properly trained in the complexities of waste handling to assure that we comply with environmental laws and regulations.

The first step in waste disposal is to accurately and completely characterize our hazardous/radioactive waste. Waste that does not meet Berkeley Lab's waste acceptance criteria will not be accepted by the Hazardous Waste Handling Facility until it does. The main responsibility for characterizing this waste rests with the generator, who has the process knowledge appropriate for this task. When full confidence in process knowledge is not present the generator has an obligation to arrange for chemical analysis of the waste in question.

I further urge all generators of hazardous waste or effluents to work to reduce the generation of such materials through source reduction and other pollution prevention methodologies. In addition to supporting the above policy, such source reduction helps avoid future liability for waste disposal site cleanup. Another benefit of pollution prevention is to reduce waste management costs, which comprise a significant percentage of our EM program dollars.

The Environment, Health \& Safety (EH\&S) Division has the responsibility of ensuring the waste has been properly characterized before accepting it for disposal, treatment or storage and for providing the generator with regulatory guidance. EH\&S is also responsible for ensuring an appropriate level of quality assurance analysis is in place for Laboratory waste streams.

Responsible management of hazardous wastes is the responsibility of ALL generators. The attached Hazardous Waste Generator Guides, when used in conjunction with the required training, outline how to execute that responsibility.

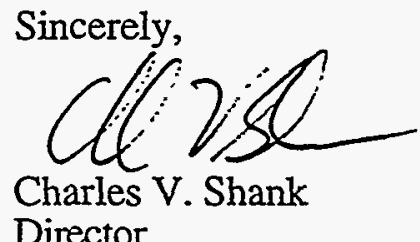

Director 


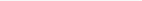




\section{Contents}

Guidelines for Generators to Meet HWHF Acceptance Requirements for Hazardous Wastes at Berkeley Lab

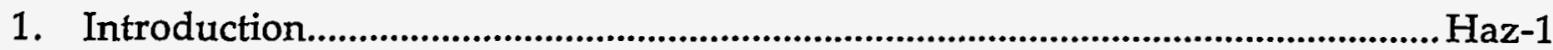

2. Minimization of Hazardous Waste ...................................................................Haz-5

3. Hazardous Waste Characterization...............................................................................

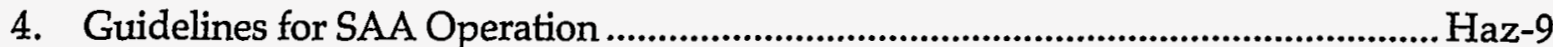

5. Hazardous Waste Containers and Other SAA Items.............................................Haz-11

6. Segregation of Incompatible Wastes .......................................................................13

7 Separation of Incompatible Wastes........................................................................ Haz-14

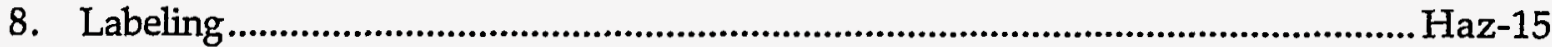

9. Requesting Hazardous Waste Pickup ……………….......................................... Haz-18

10. Compressed Gases and Pressurized Liquids ........................................................... Haz-24

11. Empty Containers..........................................................................................Haz-25

12. Spill Cleanup and Reporting.........................................................................Haz-26

13. Berkeley Lab Chemical Exchange Program..........................................................Haz-27

14. Closing Out an SAA ...................................................................................... Haz-28

\section{Guidelines for Generators to Meet HWHF Acceptance Requirements for Radioactive Wastes at Berkeley Lab}

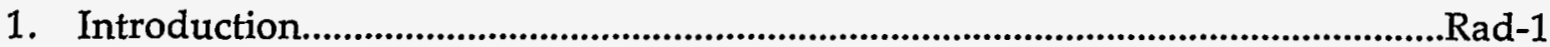

2. Minimization of Radioactive Waste........................................................................

3. Radioactive Waste Characterization..............................................................................

4. Segregation of Radioactive Wastes............................................................................

5. Labeling of Radioactive Waste Containers .................................................................

6. Guidelines for Radioactive Waste Accumulation..........................................................16

7. Requesting Radioactive Waste Pickup .................................................................17-17

8. Guidelines for Specific Radioactive Waste Streams......................................................

\section{Guidelines for Generators to Meet HWHF Acceptance Requirements for Mixed Wastes at Berkeley Lab}

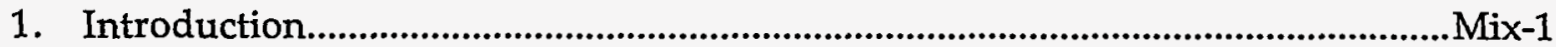

2. Mixed Waste Minimization ...............................................................................................

3. Mixed Waste Characterization...........................................................................................

4. Segregation of Mixed Wastes....................................................................................

5. Separation of Mixed Wastes .......................................................................................

6. Guidelines for Mixed Waste Accumulation....................................................................

7. Mixed Waste Labeling ............................................................................................. Mix-9

8. Requesting Mixed Waste Pickup .................................................................................... 


\section{Appendices}

Appendix 1. Additional Information for Berkeley Lab Waste Generators....................App-1

A. Federal and State of California Toxicity Characteristics......................................App-1

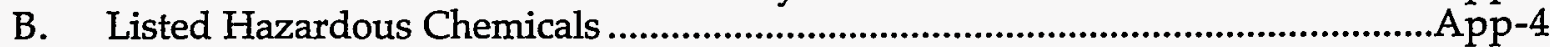

C. List of Extremely Hazardous Chemicals..........................................................App-27

D. Chemical Compatibility Guide ....................................................................App-35

Appendix 2. Waste Acceptance Criteria for Certification Team Review of ..............App-38 Radioactive Waste Tag Information

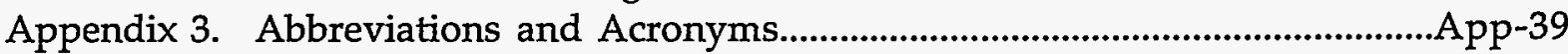

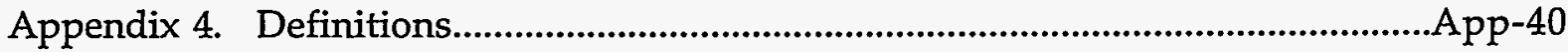

Appendix 5. Compliance Framework for Waste Accumulation at Generator Sites ...App-44

Appendix 6. Governing Documents and References...................................................App-50

\section{Hazardous Waste}

\section{Figures}

Figure H-1. Flowchart for Hazardous Waste Management at Berkeley Lab.............. Haz-2

Figure H-2. Satellite Accumulation Area sign............................................................Haz-9

Figure H-3. Hazardous Waste Label.....................................................................Haz-16

Figure H-4. Hazardous Waste Accumulation Log ................................................Haz-17

Figure H-5. Hazardous Waste Disposal Requisition .............................................Haz-20

Figure H-6. RMA Waste Certification form.................................................................Haz-22

Figure H-7. Laboratory Waste Analysis Request form ............................................ Haz-23

Figure H-8. Process used for empty container disposal.......................................... Haz-25

Radioactive Waste

Figure R-1. Flowchart for Radioactive and Mixed Waste Management

Rad-2 at Berkeley Lab

Figure R-2. Sample LBNL Daily Use Log (RWA Program).....................................Rad-6

Figure R-3. Radioactive Waste Tag ...........................................................................

Figure R-4. Radioactive Waste Tag Continuation Sheet..........................................Rad-13

Figure R-5. Radioactive Waste Accumulation Log ....................................................15

Figure R-6. Radioactive/Mixed Waste Disposal Requisition........................................17

\section{Mixed Waste}

Figure M-1. Flowchart for Radioactive and Mixed Waste Management .......................Mix-2 at Berkeley Lab

Figure M-2. $\quad$ Mixed Waste Satellite Accumulation Area (MWSAA) Sign .....................Mix-8

Figure M-3. Mixed Waste Accumulation Log .........................................................Mix-10

Figure M-4. Radioactive Waste Tag (front) filled out for mixed waste ......................Mix-11

Hazardous Waste

Tables

Table H-1. Approved Containers for Use in Satellite Accumulation Areas............. Haz-11

Table H-2. Satellite Accumulation Area Materials and Equipment..........................Haz-12 


\section{Guidelines for Generators to Meet HWHF Acceptance Requirements for Hazardous Wastes at Berkeley Lab}

\section{Introduction}

This document provides performance standards that you, as a generator of hazardous chemical waste at the Berkeley Lab, must manage your waste to

- $\quad$ protect Berkeley Lab staff and the environment,

- comply with hazardous waste regulations and ensure the continued safe operation of your workplace,

- have your waste transferred to the Hazardous Waste Handling Facility (HWHF), and

- enable the Environment, Health and Safety (EH\&S) Division to properly pick up, manage, and ultimately send your waste off site for recycling, treatment, or disposal.

Figure H-1 is a flowchart that shows how hazardous waste is managed at Berkeley Lab.

If you use hazardous chemicals and generate hazardous wastes, you must establish a Satellite Accumulation Area (SAA) and follow the guidelines in this section of this document. Much of the information in this section also applies to hazardous waste that is accumulated in a Waste Accumulation Area (WAA); supplemental guidelines for WAA operation can be found in PUB3093, Guidelines for Waste Accumulation Areas (WAAs) (see latest revision). To determine the most recent edition of PUB-3093 or any other document referenced in this manual, contact your EH\&S Generator Assistance specialist.

The information in this section also applies to your operations if you generate mixed waste; i.e., waste that is both hazardous and radioactive. For more information on mixed waste management, see "Guidelines for Generators to Meet HWHF Acceptance Requirements for Mixed Wastes at Berkeley Lab" (part of this booklet). 


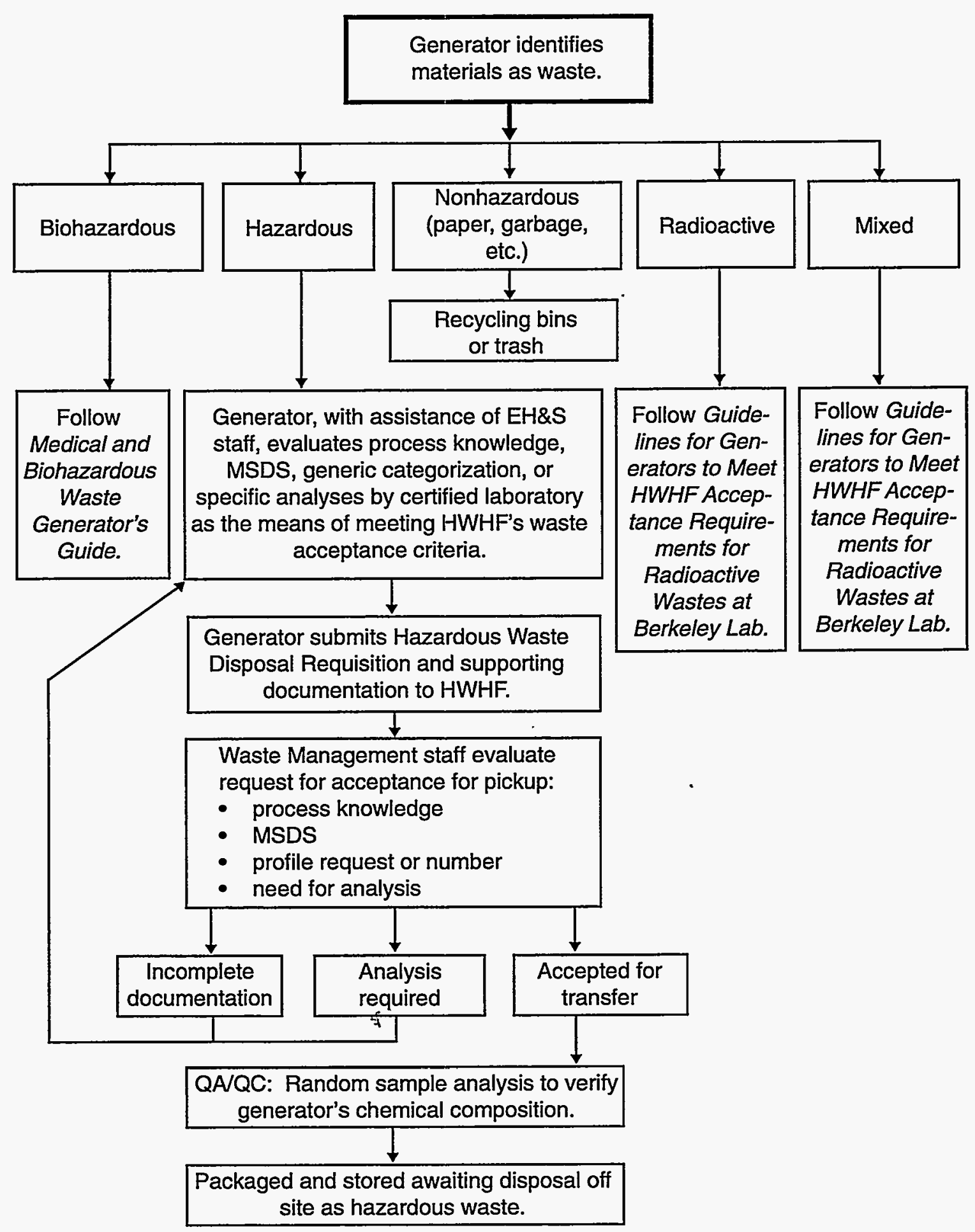

Figure H-1. Flowchart for hazardous waste management at Berkeley Lab 
The performance standards in this section do not apply to

- radioactive wastes that are otherwise nonhazardous. For more information on radioactive waste management, see "Guidelines for Generators to Meet HWHF Acceptance Requirements for Radioactive Wastes at Berkeley Lab" (part of this booklet).

- purely medical and biohazardous wastes. For information on proper management of medical and biohazardous wastes, see PUB-3095, Medical and Biohazardous Waste Generator's Guide (for the latest revision, contact your EH\&S Generator Assistance specialist).

\section{What Is a Hazardous Waste?}

Hazardous waste is defined by both federal and state regulations. Waste falls into two regulatory categories: characteristic and listed. Regulatory designation of chemical components of waste as "characteristic" is based on specific hazardous properties, which may depend on their concentrations. (pH is a good example.) "Listed" waste is derived from chemicals that are specifically listed in the regulations (see last paragraph in this section).

The following general guidelines describe some of the more common characteristics of hazardous waste. If your waste has any of these characteristics, it is regulated and must be handled as hazardous waste.

\section{Characteristics of Hazardous Waste}

Under federal and state law, the four characteristics of a hazardous waste are

- Ignitability. A waste is classified as ignitable if it is

- a liquid with a flash point of less than $140^{\circ} \mathrm{F}$,

- a solid that can ignite spontaneously through the absorption of moisture or through friction, or

- any flammable gas or any oxidizer.

- Corrosivity. A waste is classified as a corrosive if it has a $\mathrm{pH} \leq 2$ or $\geq 12.5$. This applies to aqueous wastes as well as nonaqueous wastes that produce a solution with these $\mathrm{pH}$ values when mixed with an equivalent weight of water. Nonaqueous waste with an acid component and no designation of $\mathrm{pH}$ does not meet HWHF Acceptance Requirements.

- Reactivity. A waste is classified as reactive if it is

- unstable or explosive,

- reacts readily with water, or 
- generates toxic vapors when mixed with water. For example, wastes with certain concentrations of cyanides or sulfides are regulated as hazardous based on generation of toxic vapors when mixed with water.

- Toxicity. A waste is classified as toxic if it poses a hazard to human health or the environment because of

- carcinogenicity,

- acute or chronic toxicity,

- bioaccumulative properties, or

- persistence in the environment.

For example, wastes with certain concentrations of heavy metals or solvents are toxic.

\section{Listed Hazardous Waste}

Although your waste may not exhibit any of the four characteristics listed above, it may be hazardous because one or more of the constituents is specifically listed in federal or state regulations (see Appendix 1). There are many chemicals and mixtures of chemical compounds on these lists that could cause your waste to be classified as hazardous, depending on how they are used. For example, if a "listed" chemical is a participant in a chemical reaction, i.e. a reactant, then the presence of that chemical in the byproduct of the reaction (waste) does not force designation of the waste as hazardous because of the listing. On the other hand, use of "listed" chemicals as solvents for reactants or as cleaning agents dictates designation of the waste as hazardous. Interpretation of the regulations has limited the treatment options, and thereby disposal options, for "listed" waste. Once a "listed" chemical used as a solvent enters a waste stream, it may carry that designation no matter what the fate of the original listed molecule. Furthermore, anything coming in contact with that waste (paper, column packing material, pipet tips), no matter what the final concentration, may also be designated as hazardous.

Avoiding "listed" chemicals is a good way to enhance waste minimization opportunities. For example, substituting ethanol for methanol in many chemical processes might cost more initially, but it could greatly reduce the complications and costs associated with disposal.

If, after reading this section, you are still unsure whether your waste is hazardous, contact your EH\&S Generator Assistance specialist for assistance. 


\section{Minimization of Hazardous Waste}

As a generator of hazardous waste at Berkeley Lab, you must develop and implement waste minimization techniques in your research or support activities. Berkeley Lab is required by federal and state laws enforced by various agencies, and is encouraged by the citizens and government of the City of Berkeley, to maintain an active waste minimization program. The Laboratory's success in this area depends on the contributions of all hazardous waste generators at the Laboratory.

The DOE office that currently supports hazardous waste management at Berkeley Lab (EM, or Environmental Management) will be re-engineered in the next few years. One component of the effort will be to return hazardous waste management costs to the waste-generating organization (principally ER, or Energy Research at Berkeley Lab). To help prepare for this transition, Berkeley Lab is committed to meeting specific waste minimization goals. To increase awareness of the need for minimization, the Waste Management Group will track disposal costs by account number and periodically inform you of the volume and estimated disposal cost of your hazardous waste. These estimated waste management and disposal costs will also be summarized for each Division to facilitate line management participation in waste minimization. In addition, your EH\&S Generator Assistance specialist can provide specific advice and information on ways to reduce the volumes, quantities, and the costs of managing hazardous waste streams.

The major underlying principle of waste minimization is that it makes far more sense not to produce waste in the first place than to develop systems to ensure that generated waste is managed in an environmentally safe manner. What can you do personally? For example, by using chemicals that are not "listed" or by doing your part to reduce the generation of waste, you can help to use materials more effectively, improve the protection of your staff in the workplace, and reduce the impact on the public and the environment. Waste reduction at the source is an economically sensible approach in which you, as a generator, can directly help lower waste management and compliance costs, liabilities, and risks.

The following list highlights some of the things you can do to minimize the amount of hazardous waste you generate at Berkeley Lab:

- Take precautions to prevent contamination of nonhazardous materials with hazardous materials or waste.

- Centralize purchasing of chemicals through one person within your laboratory and purchase chemicals in the smallest quantities needed.

- Rigorously evaluate research procedures to identify less hazardous or nonhazardous reagents that are just as effective for your purposes. In particular, review the use of highly toxic, reactive, carcinogenic, or mutagenic materials to determine if safer alternatives could be used.

- Consider the quantity and type of waste produced when selecting new equipment, and investigate equipment that enables the use of procedures that produce less waste. 
- Review your procedures at least annually to see if quantities of chemicals and/or chemical waste could be reduced.

- When researching a new or alternative procedure, consider the amount and type of waste produced as a factor. For example, practice microscale laboratory techniques whenever possible.

- Use secondary containment, such as dishpans, under bottles of chemicals to minimize the potential waste generated as a result of spills.

- When testing experimental products for private companies, request only the amount needed for research.

- Substitute red liquid (alcohol) thermometers (range up to $150^{\circ} \mathrm{C}$ ) or digital thermometers for mercury thermometers where practicable.

- Substitute biodegradable water-based liquid scintillation fluid for solvent-based fluid, and reduce liquid scintillation fluid volume by using smaller vials.

- Substitute biodegradable water-based solvents for xylene/toluene used in cell preparation and tissue processing.

- $\quad$ Segregate halogenated from nonhalogenated spent solvents.

- Substitute specialty detergents for chromic-acid-based processing cleaners.

- Substitute biodegradable nontoxic detergents for cleaning solvents. When cleaning solvents can not be avoided, reuse spent solvents for initial rinses or general cleaning.

- $\quad$ Reuse gel staining or destaining solutions.

- Use the Laboratory's Chemical Exchange Program to publicize excess chemicals, making them available for transfer to another project. To advertise or locate chemicals and chemical products in good condition in their original container, refer to the Chemical Exchange section of the Chemical Management System database, or contact the EH\&S Waste Minimization specialist at extension 6123 or your Divisional Chemical Inventory Coordinator for assistance.

- Ask your EH\&S Generator Assistance specialist to recommend additional waste minimization techniques that would be practicable for your specific experiments or operations. 


\section{Hazardous Waste Characterization}

Hazardous waste regulations dictate that you, as the generator, are responsible for the complete and accurate characterization of your waste. Precise characterization is also essential to ensure

- safe handling,

- protection of the environment,

- compliance with federal and state packaging requirements,

- compliance with conditions of Berkeley Lab's HWHF Permit,

- compliance with land-disposal restrictions, and

- $\quad$ acceptance of the wastes by appropriate recycling or disposal facilities.

All wastes must be characterized fully, as directed by the criteria in the next section, before they can be accepted for transport to the HWHF. This characterization is essential to ensure that your waste is safely managed through a process designed to enhance waste minimization, safety, and environmental protection.

\section{Process Knowledge}

Because most chemical waste is generated during specific processes in the course of your activities or experiments, you should know the chemical content of a unit of waste from your "knowledge of the process" used to generate that waste. In fact, the individual generating the waste is, in most cases, a more accurate source than certified analytical laboratories for specifying components and their concentrations in a given waste sample. Most hazardous waste generated at the Berkeley Lab can be characterized through process knowledge. However, for this approach is to be considered the most reliable for accurate waste characterization, it must be supported by precise, documented information (see Hazardous Waste Characterization Criteria). To use and justify process knowledge for characterization, you must

- know the hazardous properties of all chemicals used,

- have a thorough understanding of how the chemicals were used,

- understand the chemistry of the reaction to determine if hazardous chemicals were produced where none existed before, and

- know whether the process converted hazardous chemicals to nonhazardous ones.

\section{Hazardous Waste Characterization Criteria}

The first step is to determine whether your waste is hazardous. If your waste is hazardous, it must be characterized by type of hazard, and all hazardous and nonhazardous components must be fully identified. It is important to account for $100 \%$ of the contents of each waste container, including trace amounts of known hazardous components. A common problem is the failure to recognize that water and hydrogen ion $(\mathrm{pH})$, if present, must be listed as components. Hazardous waste characterization to meet performance requirements may be achieved in the following ways: 
- By maintaining records (logs) of accumulations that draw upon knowledge of the procedures and processes that generated the wastes. The logs contain an entry each time a chemical is added to a container (see Figure $\mathrm{H}-4$ in Section 8). To use and justify process knowledge, these entries must be based upon direct information transfer from written research techniques (DIRT), a materials balance (MB), direct assay (DA) and /or a predictable reaction product $(\mathrm{R} x)$.

- By consulting an MSDS for each hazardous component, and listing quantitative information for all nonhazardous components.

- By developing a generic description when the material has a well-known standard composition (e.g., waste alkaline batteries or waste mercury-contaminated glassware).

- By using analytical results from a certified laboratory on known, unchanging waste streams (i.e., a waste profile), or by using complete analytical results from a certified laboratory for each waste. Analytical results from a noncertified laboratory may be used if adequate analytical records and procedures are documented and available to the EH\&S Waste Certification Team.

When you submit your Hazardous Waste Disposal Requisition, each entry on the Requisition should be supported by documentation verifying the entry's composition (i.e., process knowledge, MSDS, standard composition, a waste profile number, or analytical results). If process knowledge is the basis for characterization, indicate the basis (DERT, MB, DA, Rx) under the Process Knowledge checkoff box.

\section{Quality Assurance}

As part of EH\&S's Quality Assurance (QA) program for waste characterization, ten percent of all hazardous wastes, including mixed waste, passing through the Berkeley Lab HWHF are randomly sampled and assayed to verify the accuracy of characterization information on the Waste Disposal Requisitions. In addition, waste streams presenting high risk if characterization is not accurate and special challenges determining the correct characterization are sampled in the field. The performance of individual generators in meeting these QA checks is tracked, and Generator Assistance works with the generators who fail to meet performance standards. Those generators who consistently provide inadequate or incomplete waste-characterization information are placed on a higher sampling regimen until the cause(s) of the mischaracterization is understood and resolved. The cost of the chemical analyses in this situation is charged to the generator's research program. If the generator's characterization of waste targeted for sampling based on waste acceptance performance continues to fail validation for accuracy and integrity, the generator and his/her staff are subjected to process-specific training, and the research program is charged for further waste analyses on the waste in each container in the next two requests for transfer to the HWHF. 


\section{Guidelines for SAA Operation}

A Satellite Accumulation Area (SAA) is an area in an individual laboratory, shop, or other facility designated by the generator for the accumulation of hazardous waste. Hazardous waste regulations require the SAA to be located at or near the point of waste generation and that it be managed by a responsible, trained generator. Even a single small bottle of a hazardous waste requires the establishment of an SAA in your laboratory or work area.

The Facility/Laboratory Supervisor (or designee) is responsible for enforcing proper waste accumulation at the SAA. The Waste Generator is responsible for maintaining the SAA and for keeping detailed records of waste accumulation. If your work area has a pre-existing SAA, ask the responsible person if you can use it. Details for setting up, using, and maintaining an SAA follow.

- Maximum storage allowed is 55 gallons of hazardous waste, including up to 1 quart of extremely hazardous waste.

- If you wish to accumulate more than 10 gallons (and fewer than 55 gallons) of liquid ignitable waste in an SAA, Fire Code requires that your SAA be located in a metal flammables cabinet.

- Waste may accumulate in SAAs for up to 275 days (nine months). A container must be removed from the SAA within three days after reaching the 55-gallon accumulation volume limit.

- The SAA area must be clearly designated using the yellow sign depicted in Figure H-2. If there is uncertainty regarding the boundaries of the SAA, the area should be clearly marked off with tape. Chemicals, empty bottles, or other items should not be stored in your SAA because these items may be mistaken for unlabeled hazardous waste. Good housekeeping practices should be implemented to provide for easy access to your SAA.

\section{SAA}

SATELLITE ACCUMULATION AREA

FOR HAZARDOUS WASTE RESPONSIBLE PARTY:

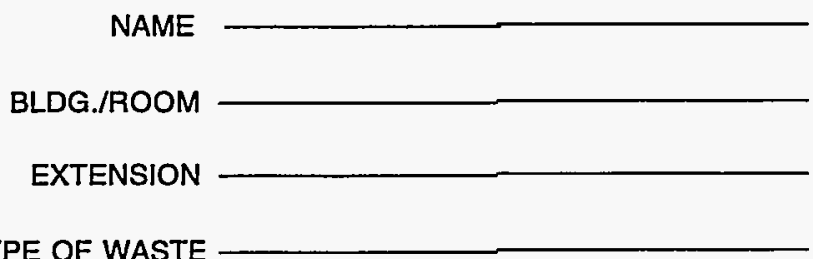

DO NOT ADD WASTE TO THIS SAA WITHOUT PRIOR AUTHORIZATION FROM THE RESPONSIBLE PARTY

Questions: Call the EH\&S Generator Assistance representative

Figure H-2. Satellite Accumulation Area sign. 
- The SAA must be at or near the site where the waste is generated so that the SAA can be controlled by staff while working. Current interpretation of the "at or near" requirement is that your SAA must be located in the room where the waste is generated, or in an immediately adjacent room (with no intervening hallway). The intent of this requirement is to provide virtually full-time monitoring of the SAA by the individual(s) generating the waste.

- Fire Code requires that the SAA be located away from all exit doors or areas where it could hamper exiting in the event of a fire or spill. Appropriate spill cleanup materials should be located near your SAA, especially if large amounts of wastes are accumulated.

- Applicable procedures and directions, including these guidelines, should be readily accessible at the site. Other information regarding the generation and management of your hazardous waste can be kept elsewhere in your laboratory or facility.

- To prevent accidents and injuries, liquid corrosive wastes should be accumulated in polyethylene or plastic containers that are known to be compatible with acids or bases.

- Secondary containment is required for all liquid hazardous wastes and all wastes accumulated in glass containers. The secondary containers must be compatible with the chemical they contain. Examples of secondary containers for SAAs include water troughs or photographic chemical trays. Pail skids make excellent secondary containment for five-gallon or smaller containers.

- Glass containers can be used to accumulate up to 1 pint of Class $1 \mathrm{~A}$ liquid ignitable waste (flash point $\angle 73^{\circ} \mathrm{F}$ and boiling point $<100^{\circ} \mathrm{F}-$-e.g., ethyl ether) or up to 1 quart of Class $1 \mathrm{~B}$ ignitable waste (flash point $<73^{\circ} \mathrm{F}$ and boiling point $>100^{\circ} \mathrm{F}$-e.g., acetone, alcohols). Larger quantities of such wastes (e.g., solvents) must be accumulated in red 2- or 5-gallon safety cans or other approved plastic or metal containers with self-closing lids.

- Primary waste containers must be tightly closed at all times except when you are adding waste. Fire Code requires that large containers ( $>1$ quart) for the accumulation of liquid and solid ignitable wastes (e.g., solvents or solvent-contaminated rags) have self-closing lids that are sufficiently tight to restrict the supply of oxygen.

- Add waste carefully to avoid spills. Any materials used to clean up small amounts of spilled liquid hazardous waste are also considered to be hazardous waste.

- Prepare and label all primary waste containers with red-and-white Hazardous Waste labels. Labels must be complete and correct at all times (See Section 10, "Labeling", for details).

- Tables $\mathrm{H}-1$ and $\mathrm{H}-2$ (next section) contain information on ordering items essential to the proper management and operation of your SAA.

Waste containers can be picked up by EH\&S only if they are properly packaged and labeled and all other documentation is complete and correct. 


\section{Hazardous Waste Containers and Other SAA Items}

You should set up your SAA and obtain waste containers and other items for SAA management based on the guidelines given in Table $\mathrm{H}-1$.

Table H-1. Approved Containers for Use in Satellite Accumulation Areas

\begin{tabular}{|c|c|c|}
\hline Waste Type & Approved Container & $\begin{array}{l}\text { How to } \\
\text { Obtain }\end{array}$ \\
\hline Liquid wastes (large quantities) & 55-gal DOT 17E drum & $\begin{array}{l}\text { Contact } \\
\text { EH\&S }\end{array}$ \\
\hline Solid wastes (large quantities) & 55-gal DOT $17 \mathrm{H}$ drum & $\begin{array}{l}\text { Contact } \\
\text { EH\&S }\end{array}$ \\
\hline Small individual waste containers & $\begin{array}{l}\text { Polypropylene tote box } \\
\text { (useful for secondary } \\
\text { containment) }\end{array}$ & $\begin{array}{l}\text { Stores item } \\
8115-66258\end{array}$ \\
\hline Liquid wastes, bulk, nonflammable & 5-gallon plastic carboy & $8125-45694$ \\
\hline Liquid wastes, bulk, nonflammable & 5-gallon glass carboy & $8125-27825$ \\
\hline Liquid wastes, bulk, flammable & $\begin{array}{l}\text { Red metal or plastic safety } \\
\text { can (used safety cans are } \\
\text { available from EH\&S) }\end{array}$ & $\begin{array}{l}7960-30361 \\
\text { (2-gallon) } \\
7960-30344 \\
\text { (5-gallon) }\end{array}$ \\
\hline $\begin{array}{l}\text { Liquid wastes, bulk, halogenated } \\
\text { solvents }\end{array}$ & $\begin{array}{l}\text { Stainless steel 2- or } \\
5 \text {-gallon can }\end{array}$ & $\begin{array}{l}\text { Contact } \\
\text { EH\&S }\end{array}$ \\
\hline Oily wastes, nonignitable, bulk & Protectoseal oily waste can & $\begin{array}{l}7960-30353 \\
(6 \text { gallons }) \\
7960-30354 \\
(14 \text { gallons })\end{array}$ \\
\hline $\begin{array}{l}\text { Asbestos and asbestos-containing } \\
\text { materials }\end{array}$ & $\begin{array}{l}\text { Double plastic bags labeled } \\
\text { ASBESTOS }\end{array}$ & $\begin{array}{l}\text { Stores item } \\
8105 \\
\text { series (see } \\
\text { Table H-2) }\end{array}$ \\
\hline Mercury & $\begin{array}{l}\text { Do not remove mercury } \\
\text { from original device or } \\
\text { equipment. }\end{array}$ & Call EH\&S \\
\hline PCB-containing wastes & Call EH\&S for details. & \\
\hline Water-reactive metals & $\begin{array}{l}\text { Closed container filled with } \\
\text { mineral oil }\end{array}$ & \\
\hline
\end{tabular}


The items listed in Table $\mathrm{H}-2$ will also be useful in managing your SAA.

Table H-2. Satellite Accumulation Area Materials and Equipment

\begin{tabular}{|l|l|l|}
\hline \multicolumn{1}{|c|}{ SAA Item } & \multicolumn{1}{|c|}{ Comment } & \multicolumn{1}{|c|}{$\begin{array}{c}\text { Berkeley Lab } \\
\text { Stores No. }\end{array}$} \\
\hline Hazardous Waste Label & Red and White, 6" $\times 6^{\prime \prime}$ & $4280-72601$ \\
SAA sign & Yellow; see Figure H-2 & $4280-72514$ \\
Plastic developing tray & $8^{\prime \prime} \times 10^{\prime \prime}$ & $6750-29165$ \\
Plastic developing tray & $14^{\prime \prime} \times 7^{\prime \prime}$ & $6750-29166$ \\
Polyethylene plastic bag & $6^{\prime \prime} \times 8^{\prime \prime}$ & $8105-27697$ \\
Polyethylene plastic bag & $12^{\prime \prime} \times 18^{\prime \prime}$ & $8105-27699$ \\
Polyethylene plastic bag & $16^{\prime \prime} \times 20^{\prime \prime}$ & $8105-47511$ \\
Polyethylene plastic bag & $24^{\prime \prime} \times 30^{\prime \prime}$ & $8105-47512$ \\
Plastic trash container liner & $12^{\prime \prime} \times 8^{\prime \prime} \times 22^{\prime \prime}, 0.002$ in. & $8105-59166$ \\
Pail skid (for 2 5-gallon containers) & $6^{\prime \prime} \times 20^{\prime \prime} \times 26^{\prime \prime}, 0.002^{\prime \prime}$ & Lab Safety Supply \\
& Order Item \#YB-13557- & Janesville, WI \\
Small Pail Skid & $1-800-356-0783$ \\
Polyethylene bottle & 16 oz, wide mouth & $8125-42044$ \\
Polyethylene bottle & 32 oz, narrow mouth & $8125-27820$ \\
Polyethylene bottle & 32 oz, wide mouth & $8125-42045$ \\
Polyethylene bottle & $1 / 2$ gal, narrow mouth & $8125-27821$ \\
Polyethylene jug & 1 gal, integral handle & $8125-27827$ \\
Glass bottle & $1 / 2$ gal, narrow mouth & $8125-27777$ \\
Glass bottle & 1 gal, narrow mouth & $8125-27778$ \\
\hline
\end{tabular}




\section{Segregation of Incompatible Wastes}

Segregation means taking action to prevent the mixing of chemically unrelated or incompatible materials in the same container. Segregation is important for three reasons: safety, recyclability, and disposability.

- When chemicals are mixed without regard to compatibility, safety hazards can result. In some cases, the resulting mixture could explode or produce toxic gases. A safe rule for mixing chemicals is: When in doubt, don't mix.

- Certain chemicals can be recycled at great financial savings, but small amounts of contamination with other chemicals may render the original chemical unrecyclable. For example, waste oil is recyclable, but a few tablespoons of halogenated solvent in a 55gallon barrel of waste oil will render that barrel of oil unrecyclable.

- $\quad$ Some chemicals can be managed and disposed of relatively inexpensively.

Contamination with another chemical, however, may make the waste very difficult and expensive to manage. For example, some wastes can be sent to a landfill, while others require incineration. Mixing wastes together can limit disposal options and increase waste management costs.

A simple and effective way you can reduce waste management and disposal costs is to set up your operation to properly segregate your wastes as they are collected. The following guidelines will help you to properly segregate your hazardous waste.

- Segregate nonhalogenated waste solvents (acetone, alcohol, etc.) from halogenated (containing chlorine, fluorine, bromine, or iodine) solvents. This practice increases the recyclability of the wastes. It also helps the LBL maintain calculated offsite exposures for accident scenarios within limits that are acceptable to DOE.

- Keep waste oil free of contamination by halogenated solvents or water (for the reasons listed in the preceding bullet).

- Keep acids and acid plating solutions free of cyanides.

- Segregate acids and caustics contaminated with metals from those without metal contamination.

- Segregate radioactive wastes from hazardous wastes. Contamination of hazardous waste with even a small amount of radioactive materials can result in the generation of mixed waste. This results in very large increases in waste management costs (by a factor of more than 100). 


\section{Separation of Incompatible Wastes}

In addition to segregation, physical separation will help you to prevent the inadvertent mixing of incompatible materials. Separation is achieved using distance or chemically resistant barriers such as secondary containers. To prevent accidents caused by inadvertent mixing, chemically incompatible wastes can not be accumulated in the same secondary containment bin. In addition, SAAs, MWSAAs (mixed waste SAAs), and Radioactive Waste Collection Areas should be physically separated to minimize chances of accidental cross-contamination.

Separate hazardous wastes using the following guidelines:

- $\quad$ Separate all spontaneously ignitable and explosive wastes from everything else. Package separately to contain and isolate any ignition that may occur. Explosives are not handled at the HWHF. Appendix 1 of this document provides several lists of potentially explosive chemicals.

Note: If you discover a potential explosive in your laboratory, contact the Fire Department at extension 7911 immediately.

- $\quad$ Separate strong oxidizers from all fuels and package separately.

- Separate all extremely hazardous chemical gases and compressed gases from potential fire hazards.

- Separate peroxide-forming chemicals from all other combustible materials and package separately.

- Separate acids from bases and package separately.

- Separate all water reactives from everything else. Package each group separately in a sealed container and protect from water. Place a WATER REACTIVE warning on the package. EH\&S can not transport reactive wastes that are incorrectly packaged.

- Separate extremely hazardous noncorrosive materials from corrosive materials.

- Separate extremely toxic chemicals and poisons from all other wastes.

Appendix 1 of this booklet provides more detailed information on various categories of hazardous chemicals and chemical compatibility. 


\section{Labeling}

When you determine that an item is hazardous waste, you must fill out and attach a Hazardous Waste label (Figure H-3, Berkeley Lab Stores Cat. \# 4280-72601) to the waste container. The Hazardous Waste label identifies the waste generator and the contents of the container, provides information on the hazardous characteristic(s) of the waste, and establishes the waste generation date. Each primary waste container must have a label attached, indicating the composition of the material. A manufacturer's label does not serve this purpose, even if proper hazard information is on the label.

All entries on the Hazardous Waste label must be legible. It is recommended that entries be made with a permanent marker or a pen containing permanent ink. Pens with water-soluble ink or pencils should not be used to fill out Hazardous Waste labels. For large primary waste containers such as carboys, the Hazardous Waste label should be affixed to an area of the container that is easily visible for inspection and emergency response purposes. A waste container too small for a label can be placed in a zip-lock plastic bag with a Hazardous Waste label affixed to the bag.

Figure H-3 gives general instructions on filling out the Hazardous Waste label. The Contents section of the label can be completed using one of the following three approaches:

1. By chemical name. If the material is a mixture, provide concentrations of all constituents, including nonhazardous constituents. If this information will not fit on the Hazardous Waste label, provide a more generic description (see item 3 below) and attach a Hazardous Waste Accumulation Log (see Figure H-4).

2. By manufacturer and specific product (for example, trade name or number, catalog number, etc.), including all hazardous materials listed in the MSDS for the specific product. Chemical identification information of manufactured products may also be found in the Aldrich Catalog of Fine Chemicals, the NIOSH Registry of Toxic Effects of Chemical Substances, and The Merck Index: An Encyclopedia of Chemicals, Drugs, and Biologicals.

3. By complete generic description of the material, only if the material is a mixture with a well-known standard composition. The description should indicate whether the material is new, has exceeded its shelf life, is spent, etc. If the material is a process waste, such as a cleaning agent or an etching bath, list all of the potential contaminants from the process in addition to the known constituents-for example, "chromic acid dip-tank waste with copper." For machine coolants, identify the metals for which the coolants were used.

The generic description must be sufficiently complete to adequately characterize the waste material. For example, "photochemicals" is insufficient because a wide variety of chemicals is used in photoprocessing. The description must be more specific, such as "alkaline photo developer" or "photo fixer with chromate bleach."

Each waste container used for multiple types of wastes (e.g., more than one type of solvent) must have attached to it a record of waste accumulation (for example, a Hazardous Waste 
Accumulation Log; see Figure $\mathrm{H}-4$ ). Each time you place waste in a container, enter the date, your initials, and the type and amount of waste being added. This information is used to prepare a summary description of the container contents for the Hazardous Waste Disposal Requisition. For example, a solvent-collection container used to collect multiple solvents must have a supporting Hazardous Waste Accumulation Log and cannot be identified generically.

If you generate wastes such as oily paper towels while performing repetitive cleaning operations at your bench, you may accumulate your wastes in a large ziplock plastic bag with a Hazardous Waste Label attached. The Accumulation Start Date on the label must be filled in with the words "Daily Accumulation," and you must empty the contents into a nearby SAA at the end of each working shift.

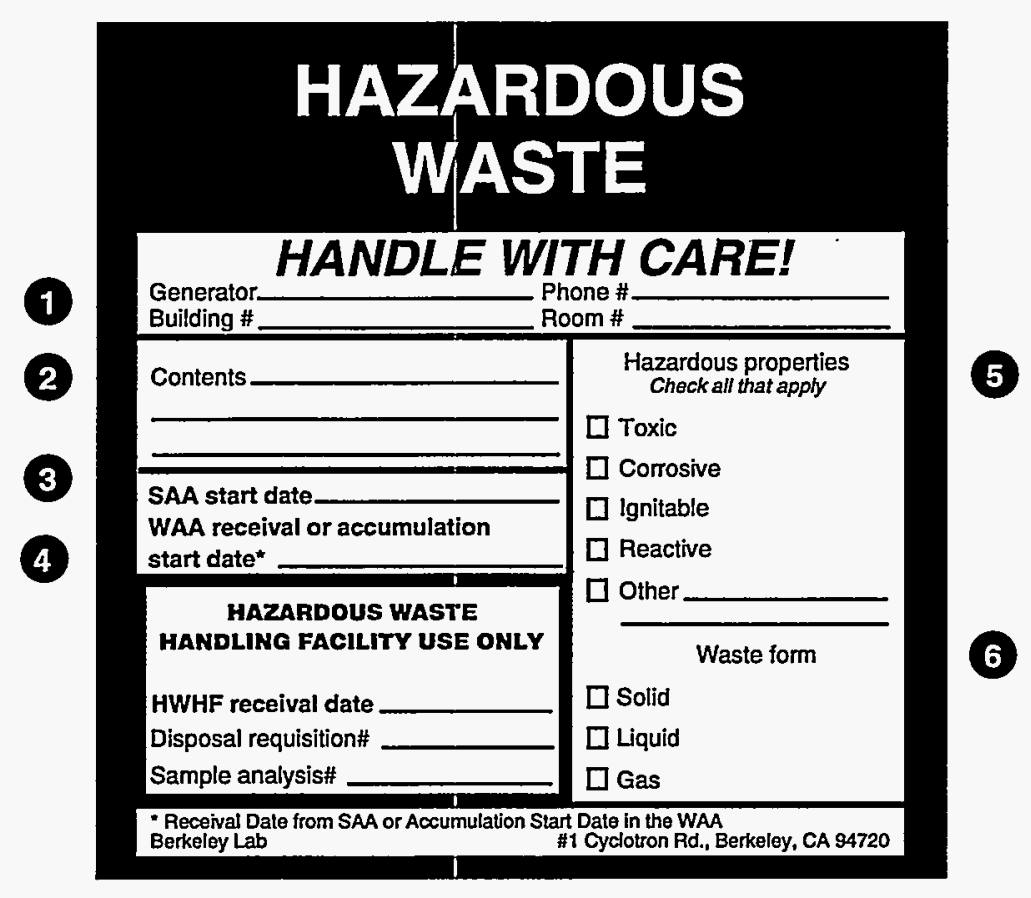

(1) Generator: Enter name, building, phone number, and room number of person generating the waste.

(2) Contents: Give chemical name, material name, or waste stream description. Describe composition of waste.

(3) SAA start date: Enter date waste is first placed in container (SAAs). Leave blank for WAAs.

(4) WAA receival or accumulation start date: Enter date waste from SAA is received at WAA, or date waste is first placed in a container at a WAA collection point.

(5) Hazardous properties: Check appropriate boxes.

6 Waste form: Check appropriate box.

Figure H-3. Hazardous Waste Label 


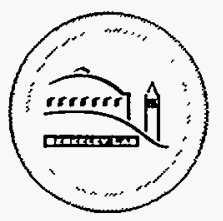

BERKELEY LAB

HAZARDOUS WASTE ACCUMULATION LOG

Container Description:

\begin{tabular}{|c|c|c|c|}
\hline $\begin{array}{c}\text { Date } \\
\text { Added }\end{array}$ & Description of What Was Added & Amount & Initials \\
\hline & & & \\
\hline & & & \\
\hline & & & \\
\hline & & & \\
\hline & & & \\
\hline & & & \\
\hline & & & \\
\hline & & & \\
\hline & & & \\
\hline & & & \\
\hline & & & \\
\hline & & & \\
\hline & & & \\
\hline & & & \\
\hline & & & \\
\hline & & & \\
\hline & & & \\
\hline & & & \\
\hline & & & \\
\hline & & & \\
\hline & & & \\
\hline & & & \\
\hline
\end{tabular}

No. $R$

(HWHF 12/19/95 RA)

Figure H-4. Hazardous Waste Accumulation Log 


\section{Requesting Hazardous Waste Pickup}

When you are approaching either the storage quantity or time limits (275 days) or when you wish to have your hazardous waste picked up by EH\&S, fill out a Hazardous Waste Disposal Requisition (Figure H-5) and fax it, along with any supporting documentation, to EH\&S at extension 4838. This fax number is dedicated to the transmission of Waste Disposal Requisitions. When faxing the Hazardous Waste Disposal Requisition, you must list each individual container on the requisition. Detailed instructions for filling out the Requisition appear on the second page of the Requisition. Please allow 5-7 business days for processing and pickup when determining the date to fax your Hazardous Waste Disposal Requisition. Waste that is not adequately characterized or that does not meet HWHF acceptance criteria can not be transferred to the HWHF.

After EH\&S has received your faxed Hazardous Waste Disposal Requisition, Waste Management Group staff will check your documents to ensure that your waste meets the acceptance criteria described in this document. If the waste does not meet the criteria and discrepancies cannot be resolved through phone discussions with the EH\&S Waste Certification Team, a Nonconformance and Corrective Action Report (NCAR) may be issued to your Division ES\&H Coordinator, and your EH\&S Generator Assistance representative may contact you to offer assistance.

Hazardous wastes generated in a Radiological Material Area (RMA) must be certified by the generator to be free of radioactive contamination before the waste can be removed. By signing the RMA Waste Certification form (see Figure $\mathrm{H}-6$ ), you are certifying that your hazardous waste is free of radioactivity.

If you cannot certify that your waste is free of radioactivity (other than naturally occurring radioactive material, or NORM), additional testing and analysis of the waste will be needed. If your waste requires analysis, please allow an extra two to four weeks for pickup. That is, if you cannot certify that your waste is free of radioactivity, fax your Hazardous Waste Disposal Requisition to EH\&S early enough to comply with the 275-day accumulation time limit and the 55-gallon (or 1-quart) volume limit.

Discovery of inaccurately characterized waste by a regulatory agency could result in fines and/or criminal penalties for the Laboratory and could jeopardize the operation of the HWHF and of the specific research project involved. Generators who make errors in characterization that could compromise the Laboratory's commitment to protect the environment, the safety of colleagues or EH\&S staff may be required to pay for certified analytical information for all of their hazardous waste.

\section{Information Required on the Hazardous Waste Disposal Requisition}

A list of examples of waste types is given below, along with the information to be provided on the Hazardous Waste Disposal Requisition form (see Figure H-5). Also listed are laboratory analyses that may be needed for each waste type. Waste Management Group staff may request additional analysis for characterization of a particular waste.

- Acids and Bases. List acid or base strength in appropriate units (normality, molarity, percent by weight, or $\mathrm{pH}$ ). Identify all metals present and give their concentrations. 
- $\quad$ Plating or Heavy Metal Solutions. Identify all metals present and give their concentrations. List cyanide concentration if cyanide is present. Cyanide analysis is required for all aqueous solutions, acids, or bases generated in areas where cyanide is used.

- Nonchlorinated or Mixed Organic Solvents. List all constituents of the mixture. Analysis for halogenated hydrocarbon concentrations may be required. List flash point if known. The flash point should be determined if can be estimated from the flammability of the each solvent in the mixture is unknown.

- Oils. List all constituents, and flash point if known. Analyses for volatile halocarbon solvents, PCBs, percent oil, and flash point (if the oil has volatile components) may be required. All hydrocarbon-based oils with unknown constituents should must be analyzed.

- Coolants. List all constituents. Analyses may be required for volatile halocarbon solvents, percent oil, and/or metal contaminants (beryllium, uranium, nickel, etc.), depending on use.

- $\quad$ Solid Wastes and Sludges. Give composition of sludges and solid wastes. The composition of flocculants and sludges in liquid waste must be provided.

- Unknowns. Before hazardous waste can be transported to the HWHF, all hazardous and nonhazardous components must be identified by the generator, and all unknowns must be analyzed by a certified laboratory. A copy of the laboratory report should accompany the Hazardous Waste Disposal Requisition form when it is faxed to the Waste Management Group.

If you cannot characterize your waste properly from the original label or from your documented knowledge of the processes used to generate a given hazardous waste, you may need to resort to specific analyses for waste characterization. To initiate this process, fill out and submit a Laboratory Waste Analysis Request Form (see Figure H-7). Your EH\&S Generator Assistance specialist can help you in this process, but the cost of analysis for unknown components may be charged to the research project. 
LBL Hazardous Waste Disposal Requisition FAX 4838

HAS USE ONIX

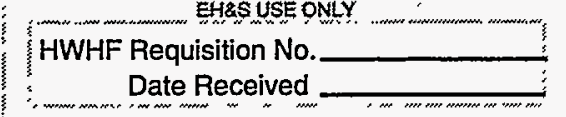

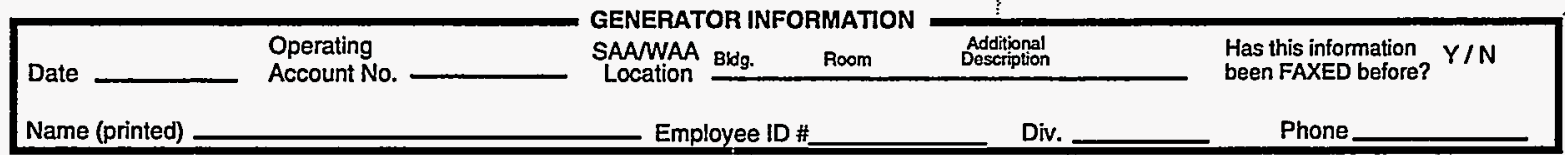

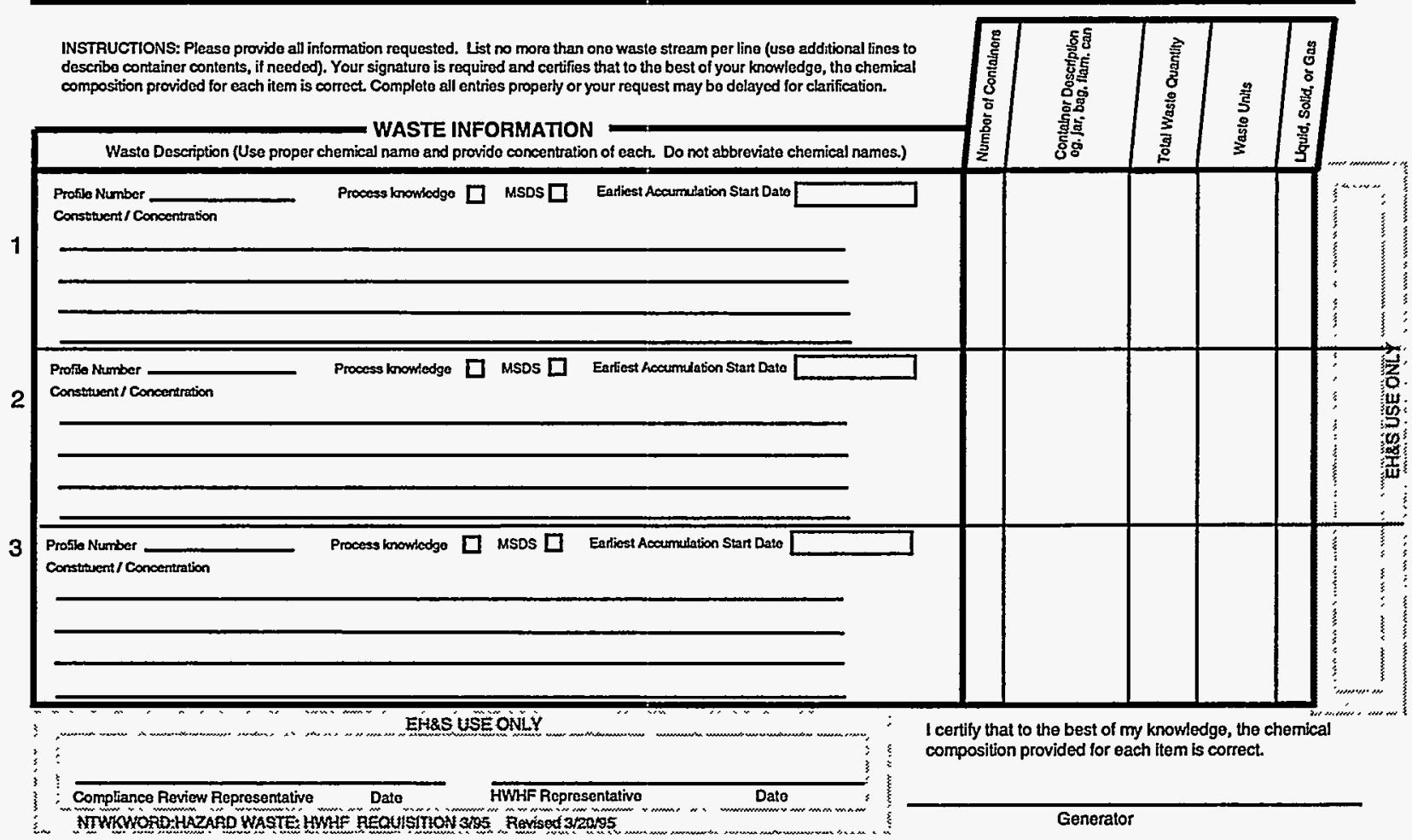

Figure H-5. Hazardous Waste Disposal Requisition 


\section{How to Fill Out This Form}

\section{Generator Information}

Operating Account No: Fill in the account number you charge to for this project.

Has this information been FAXED before? Circle $Y$ only if this is a second submission for the waste described in this requisition.

Name: Fill in your name.

Employee ID number: Fill in your 6-digit employee ID number.

Division: Fill in the Division responsible for the waste-generating project.

Phone: Fill in your phone number.

Date: Fill in the date that you FAX this requisition to EH\&S.

Waste Location: List the building and room number where the waste is located. Use the "Additional Description" for waste that is not adequately located by building and room (for example, waste stored in a yard adjoining a building).

\section{Waste Information}

Waste Description: List one waste stream per line. Use the proper chemical name of the waste. Provide any additional information that may be helpful in describing the waste. List each constituent (hazardous and nonhazardous) and concentration.

Earliest Accumulation Start Date List the first date waste was placed in any container described on this line.

Number of Containers: List the number of containers of this type of waste.

Container Description: Using this column, list (in either metric or English units) the container size and description.

Total Waste Quantity and Waste Units Add up the volume of waste described under "Container Description" and list it here. Report solids by weight.

Liquid, Solid, or Gas Fill in "L," "S," or "G," as appropriate.

Basis for waste, characterization: If you check box for use of "Process Knowledge," mark beneath the box the source ot that knowledge (DERT, MB, DA, Rx).

\section{Supporting Documentation Requirements}

Each waste container must have the contents described on the Hazardous Waste label, andsupporting documentation must be attached to the container in a plastic pouch $O R$ be on file at the HWHF Supporting documentation can be one or more of the following: (A) Process knowledge of wastes whose composition is documented by the procedures generating them; (B) records of accumulation - a log that contains an entry each time waste is added to a container; (C) an MSDS for all chemicals/materials used in an experiment or process; (D) an MSDS for spent or unused materials; $(E)$ a generic description when the material has a well-known standard composition (e.g., waste alkaline batteries or waste mercufy contaminated glassware); (F) analytical results, or (G) Radioactive Waste Tag (for mixed waste only).

Waste Profiling: If the paperwork submitted adequately supports the description of the waste stream, and the waste stream will not change over time, HWHF staff will assign a waste stream profile number. If not, HWHF staff will contact the generator for clarification and/or to arrange for laboratory analysis of the waste stream. Once a profile number is assigned, the generator enters it under the supporting document code/profile number column on the requisition form.

\section{Pickup and Transportation}

A Berkeley Lab Hazardous Waste Disposal Requisition form must be FAXED to the HWHF. Ext. 4838 is dedicated to this purpose. Keep two copies of the requisition form; attach one copy to the containers to be picked up, and put the other copy in your file or work binder as a generator record..

Figure H-5 (continued). Hazardous Waste Disposal Requisition instructions 


\section{LAWRENCE BERKELEY LABORATORY ENVIRONMENT , HEALTH \& SAFETY DIVISION RMA WASTE CERTIFICATION FORM}

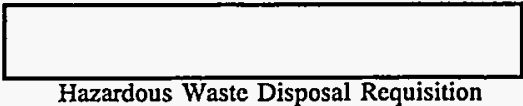

Hazardous Waste Disposal Requisition Number (for EH\&S use only)

\section{Generator able to certify waste as nonradioactive}

Based on my process knowledge of the waste documented on the Hazardous Waste Disposal Requisition, I certify that the waste is neither radioactive nor radioactively contaminated.

Generator unable to certify waste as nonradioactive:

(Anaiytical results will be required prior to pickup or disposal.)

Based on my process knowledge of the waste documented on the Hazardous Waste Disposal Requisition, Lam unable to certify that the waste is not radioactive or radioactively contaminated for the following reason(s):

\section{Radiation Survey-EH\&S use only}

If the waste is from a RMA, survey the container and check the appropriate box "Meets Release Criteria" or "Unrelea per EH\&S Procedure 868). Analytical results will be required prior to pickup or disposal.

\section{$\square$ NORM \\ $\square$ Meets Release Criteria \\ $\square$ Unreleasable}

Surveyed by: Signature Date:

Instrument used: Serial Number: Background: Result:

Instrument used: Serial Number: Background: Result:

Comments

Form No. WM 820-02, 5/96

Figure H-6. RMA (Radioactive Material Area) Waste Certification form 


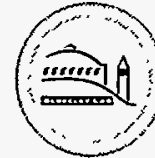

BERKELEY LAB

LABORATORY WASTE ANALYSIS REQUEST FORM

HWHF REQ. NO.
SAMPLE I.D._-
OPERATING ACCOUNT NQ
DATE OF REQUEST $, \quad, \quad$,

\section{For EH\&S use only}

Sample Taken By:

Method of Sampling:

Date Sampled:

Type of Container

SLSPECTED CHEMICAL, COMPOSIION \& DESCRIPTION OF PROOESS QR EXPERIMENT ORIGN IN DETAI, (E.G., PHOTOGRAPHC, ETCHING, HUMAN GENOME, CHROMATOGRAPHY, ETC.)

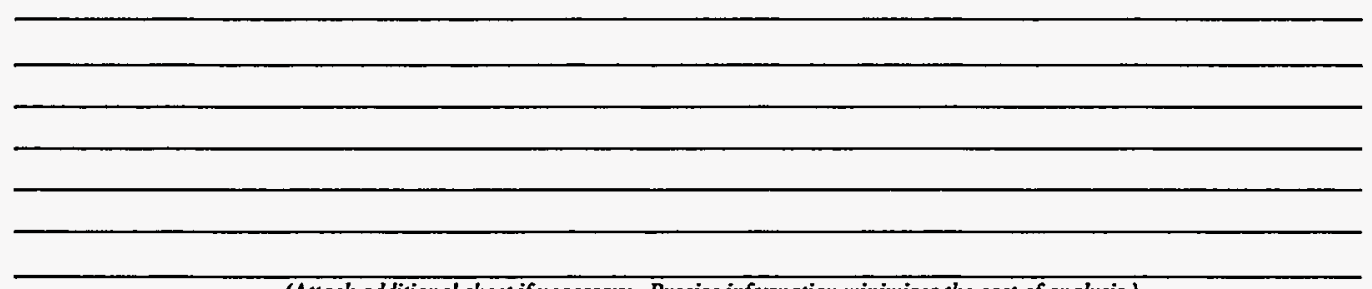

(Attach additional sheet if necessary. Precise information minimizes the cost of analysis.)

\section{INDICATE THE SUPPORTING DOCUMENT THAT IS ATTACHED}

MSSD for each constituent

Formulation(s)

Chemical composition

Record of how the waste was accumulated in the container (date, what was added, the amount and initials for each addition)

D Other

THE SAMPLE IS POTENTIALLY:

$\square$ carcinogenic $\square$ corrosive explosive flammable an oxidizer poisonous radioactive reactive RADIOACTIVEINFORMATION

Radionuclide(s):

Activity:

Methods of Assay:

Performed By: Date:

(HWHF 623/93 RA)

Figure H-7. Laboratory Waste Analysis Request Form 


\section{Compressed Gases and Pressurized Liquids}

Compressed gas cylinders containing hazardous gases are not accepted at the HWHF for disposal. Depending on the type of gas contained in the cylinder, other disposal options are available for users of these materials.

When purchasing hazardous compressed gases, users should assure that the cylinders can be returned to the manufacturer once they are empty. All users should carefully evaluate their processes and order only as much gas as they will need. Users should attempt to use all gas in any cylinder where hazardous gases are involved, since a compressed gas cylinder is exempt from regulation as a hazardous waste when the pressure in the container approaches atmospheric pressure. Typical residual pressure that should remain in the cylinder at the end of its use is a positive pressure of at least $25 \mathrm{psig}$. Maintaining such residual pressure is important to keep the cylinder from becoming contaminated with atmospheric gases.

If you have a cylinder to be disposed of when it is not empty and cannot be returned to the supplier, the cylinder must be processed at the point of generation for shipment off site to an appropriate disposal facility. To start this process, fill out a Hazardous Waste Disposal Requisition and fax it to the Waste Management Group. For cylinders that cannot be returned to the manufacturer, the user is charged for disposal costs. If there is a question on whether a particular gas cylinder might pose a disposal problem, please call the Procurement specialist at extension 6220 or the EH\&S Waste Management Group at extension 5877 before making a purchasing decision. 


\section{Empty Containers}

Certain empty containers that previously contained hazardous materials are exempt from hazardous waste regulations and can be discarded as trash. If you are able to discard your container, please call extension 6571 to ensure that the container is deleted from the chemical inventory database. Figure $\mathrm{H}-8$ shows the process used to determine if a container is considered "empty" and thus is exempt from regulation.

\section{EMPTY CONTAINER DISPOSAL (FOR CONTAINERS 5 GALLONS OR LESS IN SIZE)}

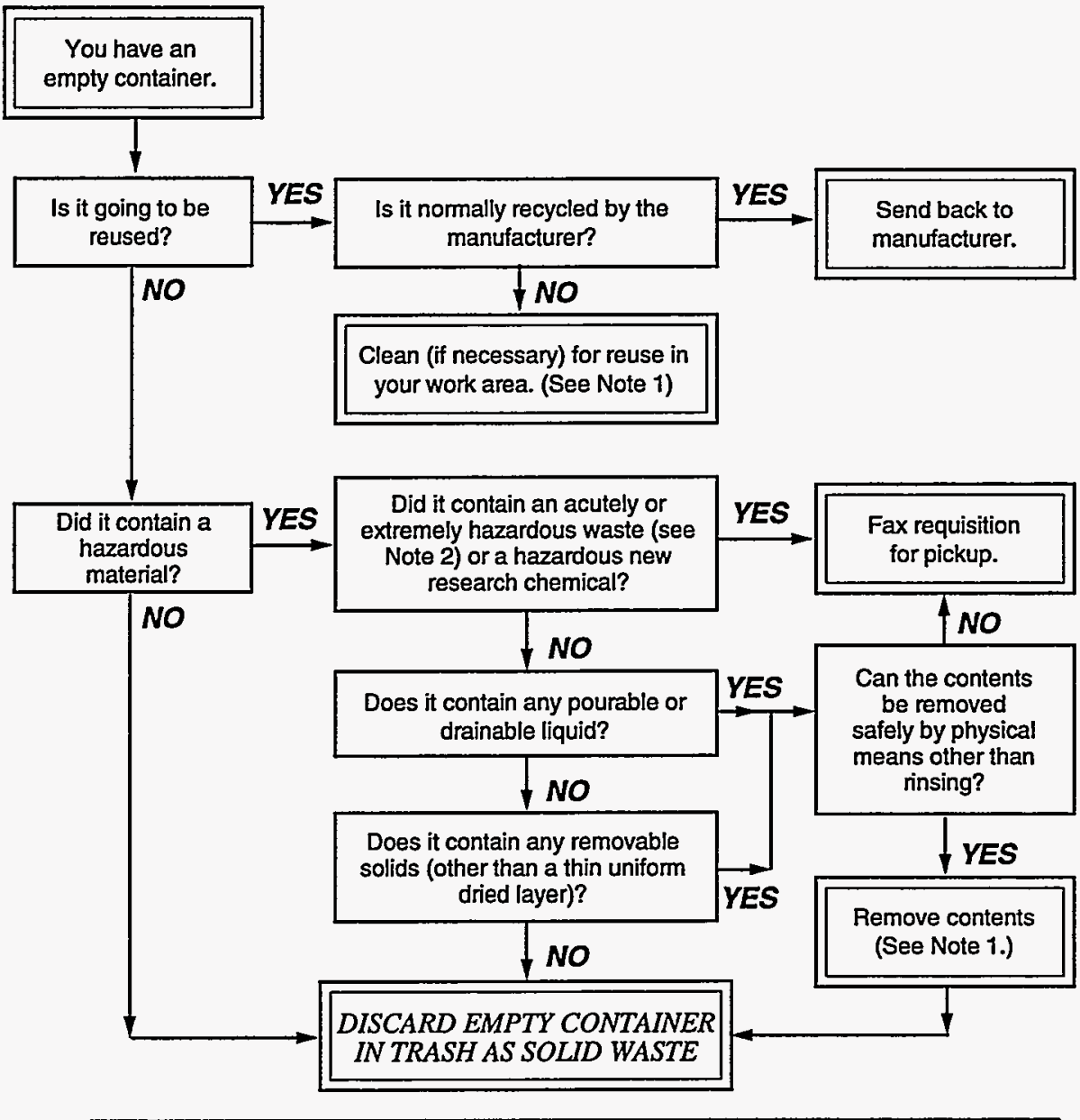

Note 1: All hazardous waste residues must be packaged for transfer to the HWHF. Note 2: A list of acutely and extremely hazardous wastes is in EH\&S Procedure $\mathbf{8 2 0 . 1 1}$ posted by your Building Manager.

*UNCERTAIN? Contact your Generator Assistance Specialist.

Figure H-8. Process used for empty container disposal 


\section{Spill Cleanup and Reporting}

If a hazardous material or hazardous waste spill occurs, the primary response should be to protect human health and the environment. Spills are categorized as either small spills or large spills.

A small spill is defined as one in which all of the following apply:

- The nature and hazards of the spilled material are known.

- The material is not a perceived threat to human health or the environment.

- The spill is small enough to be cleaned up safely by one or two people within one hour.

- All necessary personal protective equipment and cleanup equipment are available.

If a small spill occurs, the responsible program individual should immediately determine the source, type, and amount of spilled material and follow the procedure outlined in the relevant contingency plan for cleaning up a spill of that type of hazardous material or waste. If there is any uncertainty about safely managing the spill, the responsible individual must call the following number immediately:

From ICS phones: 7911 (LBNL Fire Department). $\quad$ From Campus phones: $\quad$ 9-911.

All small spills should be reported immediately to the Divisional ES\&H Coordinator and the Berkeley Lab Emergency Coordinator, who will determine whether the spill is reportable to DOE or regulatory agencies. If the spill is reportable, EH\&S personnel will handle all notifications and reporting.

A large spill is defined as one in which any of the following apply:

- The nature of the material and the potential hazards are not known or are in question.

- The spill is perceived as an immediate actual or potential threat to public health or the environment.

- Necessary personal protective equipment or cleanup equipment is not available.

- More than two people would be required to clean up the spill safely within one hour.

In the event of a large spill or fire, the Fire Department must be called immediately:

\begin{tabular}{llll}
\hline From ICS phones: & 7911 (LBNL Fire Department). & From Campus phones: & 9-911.
\end{tabular}

Provide the Fire Department with the following information: 
- Location of spill.

- Source of spill.

- Type of material.

- Amount of spilled material.

- $\quad$ Any exposure to personnel.

The Berkeley Lab Fire Department will contact all EH\&S personnel necessary to respond to any large spill.

\section{Berkeley Lab Chemical Exchange Program}

Occasionally you will need to discard laboratory reagent chemicals because of excess inventory, expired shelf life, or lack of any further need for the chemical. It is a good idea to review the chemicals in your area at least annually to determine if you have chemicals that should be removed.

If you have identified excess chemicals, you should determine if they can be reused or if they must be disposed of as waste. If the chemicals appear to have further use by virtue of condition, amount, or age, you should consider using the Berkeley Lab Chemical Exchange Program to find a new user for your chemicals.

Surplus chemicals can be listed on the sitewide Chemical Management System (CMS) database. For information on CMS, call extension 4171 or 6571 . In addition, you can call the EH\&S Waste Minimization Specialist at extension 6123 for assistance. The Waste Minimization Specialist will assist in the listing of chemicals and provide information for exchange, storage, and disposal. 


\section{Closing Out an SAA}

If you currently operate an SAA and will be leaving Berkeley Lab or relocating to another area of the Laboratory, you are responsible for assuring that any waste that has accumulated in your area is properly identified, characterized, and disposed of as part of your routine relocation or checkout process.

If you leave waste behind when you relocate, the next person to use the area will be unable to perform this identification and characterization. Managing your waste before your departure is especially important if you work in a Radiological Material Area (RMA), because subsequent occupants will not be able to certify the waste as being free of radioactivity. Extra time and cost will be involved in evaluating this waste.

If you know you are going to move, you should plan to process your waste for pickup prior to your departure. The following points are important to consider when closing out an SAA:

- If you are relocating to another part of Berkeley Lab, do the new occupants of your former area know where to locate you if necessary?

- Have you informed your Division ES\&H Coordinator and your Building Manager that you are closing out an SAA?

- Have all wastes in your SAA been properly identified, characterized, and labeled?

- Are all wastes in your SAA properly segregated and stored?

- Have you filled out and submitted a Hazardous Waste Disposal Requisition for all wastes in your SAA?

- Is your SAA in an RMA? If so, has all waste that you have generated been certified by you to be free of known radioactive contamination?

- Have all wastes from your SAA been picked up by EH\&S?

- Are there any hazardous materials you will leave behind or will not be moving? If so, have they been considered for reuse or recycling?

- If you are terminating your employment with Berkeley Lab, have you completed the employee/supervisor checkout list? 


\section{Guidelines for Generators to Meet HWHF Acceptance Requirements for Radioactive Wastes at Berkeley Lab}

\section{Introduction}

This document provides performance standards that you, as a generator of radioactive waste at the Berkeley Lab, must meet to

- protect Berkeley Lab staff and the environment,

- comply with radioactive waste regulations and ensure the continued safe operation of your workplace,

- have your radioactive waste transferred to the Hazardous Waste Handling Facility (HWHF), and

- enable the Environment, Health and Safety (EH\&S) Division to properly pick up, manage, and ultimately send your waste off site for reuse, recycling, treatment, or disposal.

Figure R-1 is a flowchart that shows how radioactive and mixed waste is managed at the Berkeley Lab.

If you use radioactive materials and generate radioactive waste, you must establish a Radioactive Waste Collection Area and follow the guidelines in this section of this manual.

The information in this section also applies if you generate mixed waste; i.e., waste that is both hazardous and radioactive. For more information on mixed waste management, see "Guidelines for Generators to Meet HWHF Acceptance Requirements for Mixed Wastes at Berkeley Lab" (part of this manual).

The guidelines in this section do not apply to wastes that are hazardous, but are not radioactive. For more information on hazardous waste management, see "Guidelines for Generators to Meet HWHF Acceptance Requirements for Hazardous Wastes at Berkeley Lab" (part of this manual).

The guidelines in this section also do not apply to purely medical and biohazardous wastes. For information on proper management of medical and biohazardous wastes, see the most recent revision of PUB-3095, Medical and Biohazardous Waste Generator's Guide. 


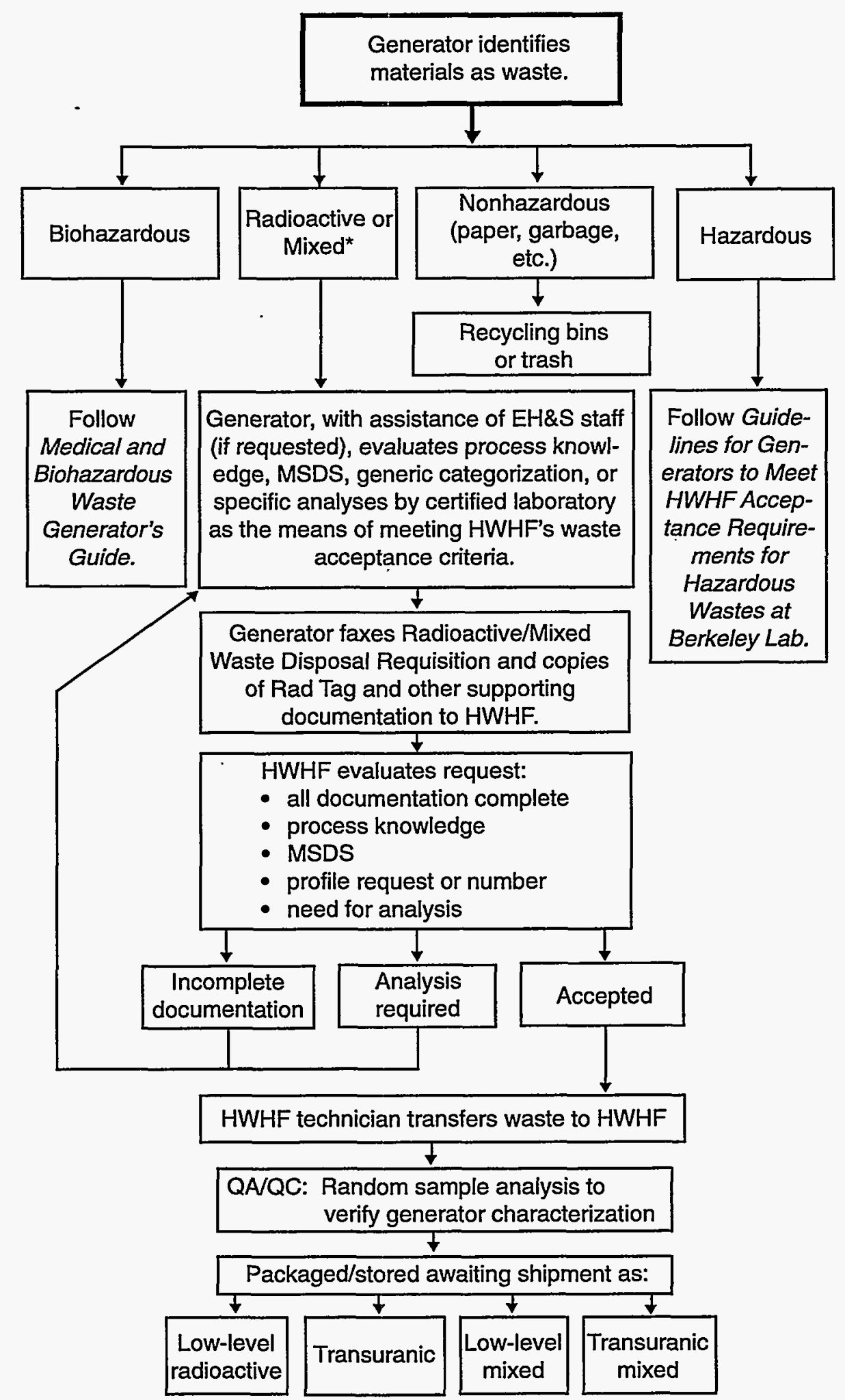

*Containers of mixed waste must have Hazardous Waste labels attached to them at all times.

Figure R-1. Flowchart for radioactive and mixed waste management at Berkeley Lab 
Radioactive waste generated through the Berkeley Lab research and support activities is transferred to the Hazardous Waste Handling Facility (HWHF), managed by the Environment, Health and Safety (EH\&S) Division. The waste is treated, if necessary, and packaged for shipment to one of several treatment, storage, and disposal facilities (TSDFs). Each of the TSDF operators establishes criteria (in conjunction with DOE) for acceptance of radioactive wastes. The performance standards provided in this section are designed to allow the Berkeley Lab to comply with the various waste acceptance criteria of TSDFs doing business with the Laboratory. These standards are also designed to promote compliance with all other regulations covering the management of radioactive wastes.

Further information on proper handling of radioactive wastes is presented in Chapter 20 ("Hazardous Waste Disposal") and in the Radiological Work Authorization (RWA) Section of Chapter 21 ("Radiation Safety") of the most recent version of PUB-3000, the Berkeley Lab Health and Safety Manual.

\section{What Is a Radioactive Waste?}

Radioactive waste is defined by both federal and state agencies. At the Berkeley Lab, a waste is characterized as radioactive if either process knowledge or monitoring and sampling show that radioactive material has been added to the waste. Wastes containing only naturally occurring radioactive material (NORM), such as potassium-bearing compounds with ${ }^{40} \mathrm{~K}$, as the sole radioactive constituent are not considered to be radioactive and should be managed as hazardous or nonhazardous waste, depending on chemical composition. If, after reading this section, you are still unsure whether your waste is radioactive, contact your EH\&S Generator Assistance representative for assistance. 


\section{Minimization of Radioactive Waste}

As a generator of radioactive waste at the Berkeley Lab, you must develop and implement waste minimization techniques in your research or support activities. Berkeley Lab is required by federal guidelines, and is encouraged by the citizens and government of the City of Berkeley, to maintain an aggressive radioactive waste minimization program. The Berkeley community is particularly concerned about radioactive waste production and storage. The Laboratory's success in this area depends on the contributions of all radioactive waste generators to the waste minimization effort at the Laboratory.

The DOE office that currently supports waste management at Berkeley Lab (EM, or Environmental Management) will be re-engineered in the next few years. One component of the effort will be to return radioactive waste management costs to the waste-generating organization (principally ER, or Energy Research at Berkeley Lab). To help prepare for this transition, the Berkeley Lab is committed to meeting specific waste minimization goals. To increase awareness of the need for minimization, the Waste Management Group will track disposal costs by account number and periodically inform you of the volume and estimated disposal cost of your radioactive waste. These estimated waste management and disposal costs will be summarized for each Division to facilitate line-management participation in waste minimization. In addition, your EH\&S Generator Assistance specialist can provide specific advice and information that will allow you to reduce the volumes, quantity, and the costs of managing radioactive waste.

The major underlying principle of waste minimization is that it makes far more sense not to produce waste in the first place than to develop systems to ensure that generated waste is managed in an environmentally safe manner. What can you do personally? By doing your part to reduce the generation of waste, you can use radioactive materials more effectively. By means such as those described below, you can reduce the generation of radioactive waste and improve the protection of your staff in the workplace as well as reduce the impact on the public and the environment. Waste reduction at the source is an economically sensible approach in which you, as a generator, can directly help lower waste management and compliance costs, liabilities, and risks.

The following list highlights a few of the things you can do to minimize the amount of radioactive waste you generate.

- Minimize the gross volume of radioactive wastes by designing your experiments to use the minimum amount of radioactive materials and chemicals practicable.

- Order only the amount of radioactive materials and chemicals you will use.

- Search for nonradioactive substitutes (e.g., immuno-assay reagents, materials labeled with stable isotopes) for radioactive constituents in your experiments.

- Keep the amount of radioactive wastes accumulated in your Laboratory at a minimum.

- Store radioactive wastes separately from hazardous and nonhazardous wastes.

- Do not allow nonhazardous or hazardous materials to be contaminated with radioactive materials or waste.

- Do not add radioactive materials to unknown (uncharacterized) mixtures.

- Carefully segregate your radioactive wastes based on isotopic half life (see Section 4).

- Decontaminate items with surface contamination to meet release limits. (Contact the Radiation Protection Program for advice.) 


\section{Radioactive Waste Characterization}

Radioactive waste characterization should be taken very seriously. The objective of accurate and complete radioactive characterization is to ensure

- safe waste handling,

- protection of the environment,

- compliance with DOE and U.S. DOT packaging requirements,

- compliance with conditions of Berkeley Lab's HWHF

- compliance with land disposal restrictions, and

- $\quad$ acceptance of the wastes by the relevant disposal or recycling facility.

The Hanford Waste Disposal Site requires that radioactive wastes be characterized in great detail. Characterization requirements continue to increase as disposal sites become more selective about the wastes they accept. It is your responsibility as a radioactive waste generator to fully characterize your waste both chemically and radiologically. Detailed guidelines for both radioactive and chemical characterization of radioactive wastes are presented in the following subsections. To ensure that your waste can be safely and reasonably managed by the Waste Management Group, your EH\&S Generator Assistance specialist will advise you of any changes in radioactive waste acceptance criteria for disposal sites or the Berkeley Lab HWHF.

\section{Radioactive Waste Characterization Criteria}

The first step is to determine whether your waste is radioactive or mixed (a mixture of radioactive and hazardous waste). All the hazardous and nonhazardous components in each waste container must be fully identified. If radioactive waste contains a hazardous component, it must be characterized by type of hazard (see Hazardous Waste Characterization Criteria in this manual). It is important to account for $100 \%$ of the contents of each waste container, including trace amounts of known hazardous components, even though you may not consider the concentrations to be sufficient to warrant designation of the waste as hazardous. A common problem is the failure to recognize that water and hydrogen ion $(\mathrm{pH})$, if present, must be listed as components. Radioactive waste characterization to meet performance requirements may be achieved in the following ways:

- By maintaining records (logs) of accumulations that draw upon knowledge of the procedures and processes that generated the wastes. The logs contain an entry each time radioactivity is added to a container (see Figure $\mathrm{R}-5$ on page Rad-15). To use and justify process knowledge, these entries must be based on direct information transfer from written research techniques (DIRT), a materials balance (MB), direct assay (DA) and/or a predictable reaction product $(\mathrm{Rx})$. The Daily Use Log (RWA program; see Figure R-2) may be used for this purpose.

- Use separate accumulation logs for mixed waste; in this case, the hazardous component must meet the characterization requirements for Hazardous Waste (see Hazardous Waste Characterization Criteria in this manual). 
- By using analytical results from a certified laboratory on known, unchanging waste streams (i.e., a waste profile), or by using complete analytical results from a certified laboratory for each waste. Analytical results from a noncertified laboratory may be used if adequate analytical records and procedures are documented and available to the EH\&S Waste Certification Team.

To provide auditable documentation of your characterization methodology, you should complete, sign, and date the Waste Characterization Certification section of the Radioactive/Mixed Waste Disposal Requisition. (See Figure R-6 in Section 7.)

\section{LBNL Daily Use Log}

RWA: 1067

$$
\text { Location: Bldy } 94 / 3
$$

Principal Investigator: Jean Generatur

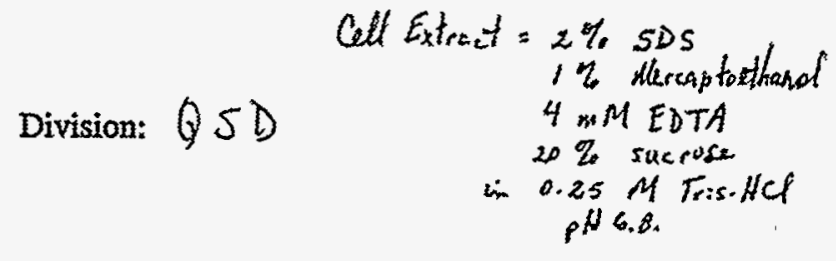

$2 \%$ SDS

4 mM EDTA

$20 \%$ sucruse pH 6.8.

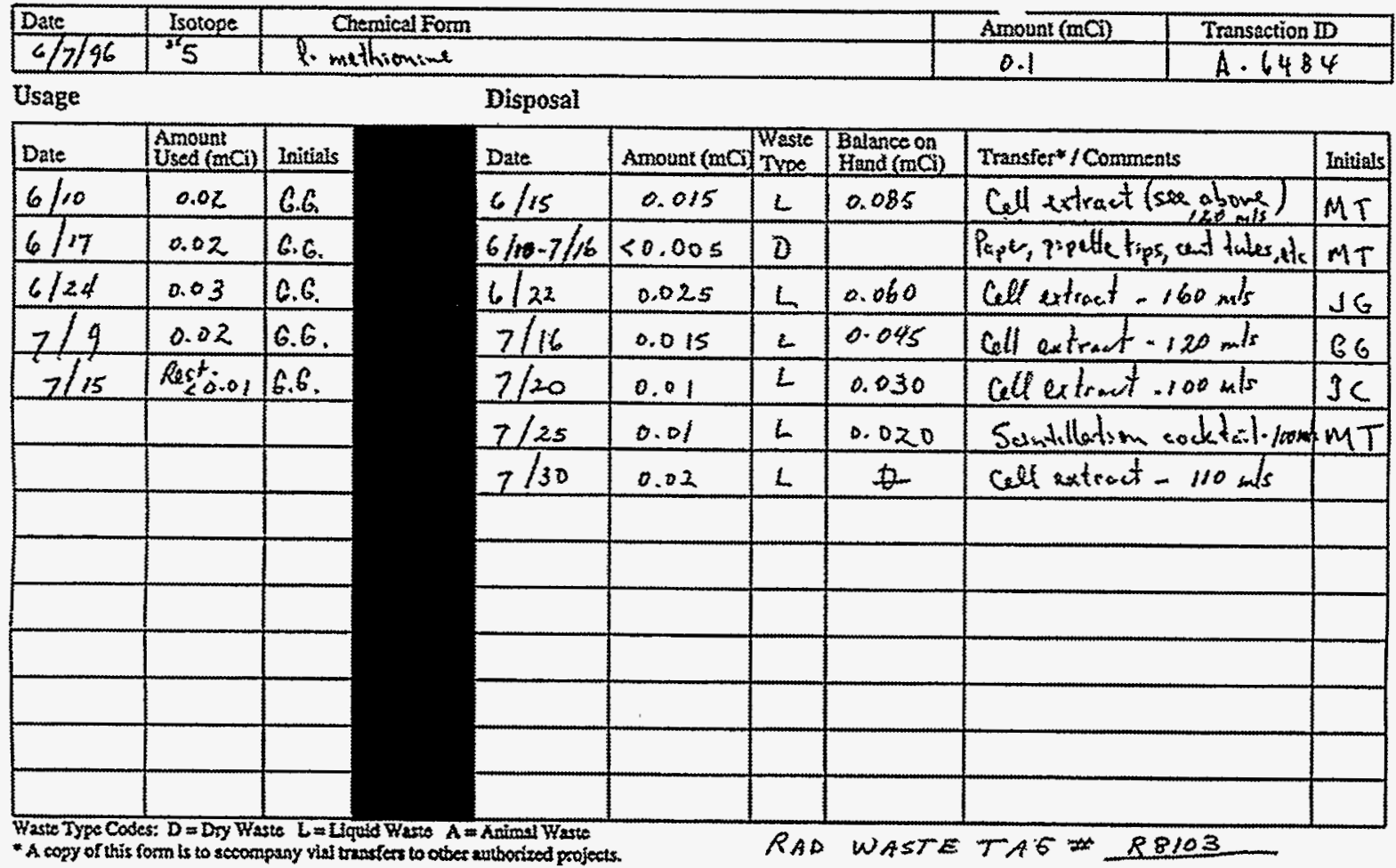

Figure R-2. Sample LBNL Daily Use Log (RWA program) 


\section{Documentation of Experimental Process}

Waste acceptance criteria from radioactive waste disposal sites require that all waste generators be able to validate the chemical and radioactive constituents of their waste by referring to pertinent written procedures, logs of activities, and results of analyses conducted in the course of their experiments. To achieve this requirement, Generator Support will assist generators in diagramming and briefly describing experimental processes and the associated waste streams from research activities involving radioactive materials. Your EH\&S Generator Assistance specialist will assist you in preparing this documentation. This information should provide the basis for characterization of waste based on process knowledge (see below). This process information will be compiled by EH\&S as part of the Berkeley Lab Radioactive Waste Reduction Plan and will be updated annually.

\section{Process Knowledge}

Because most radioactive waste is generated during specific processes in the course of your activities or experiments, you should know the radioactive and chemical content of a unit of waste from your "knowledge of the process" that generated that waste. In fact, the individual who generates the waste is, in most cases, the most accurate source, including certified analytical laboratories, for specifying the components and their concentration in a given waste sample. Most radioactive and mixed waste generated at the Berkeley Lab can be characterized through process knowledge. However, for this approach to be considered the most reliable for accurate waste characterization, it must be supported by precise, documented information. (See Radioactive Waste Characterization Criteria; and, for mixed waste, see Hazardous Waste Characterization Criteria as well.) To use and justify process knowledge for characterization of radioactive and mixed waste, you must

- be able to estimate, with some precision, the radioactive content of a unit of waste, if any;

- know whether the chemicals used in the process were hazardous;

- have a thorough understanding of how the chemicals were used;

- understand the chemistry of the reaction to determine if hazardous chemicals were produced where none existed before; and

- know whether the process converted unlabeled chemicals to radiolabeled ones.

\section{Naturally Occurring Radioactive Material (NORM)}

Wastes containing naturally occurring radioactive material (NORM) as the sole radioactive constituent are disposed of as radioactive waste only if they have been isotopically enriched during Berkeley Lab research or support activities. For example, photographic fixers and other chemical solutions containing ${ }^{40} \mathrm{~K}$ as the only radioactive constituent (in its naturally occurring isotopic abundance) are managed only for hazardous characteristics, if any. 


\section{Quality Assurance}

As part of EH\&S's quality assurance (QA) program for waste characterization, Waste Management Group personnel sample waste at the HWHF to ensure that the generators have accurately and completely characterized their waste. On a routine basis, up to $40 \%$ of incoming waste may be sampled and analyzed under various QA progams. (There are seven different QA programs that require generator characterization to be validated. Some are driven by LBNL's Part B Permit, some are driven by the DOE low-level waste Moratorium procedures, and some are driven by low-level waste certification plans required by our offsite treatment and disposal facilities.) The Waste Management Group tracks performance of individual generators and issues NCARs where generators have made substantial errors. In all cases, Generator Assistance will discuss results of QA sampling and analysis with you.

The Deputy Director for Operations will require generators whose waste is consistently mischaracterized, as determined by QA programs, to provide analytical results from the certified analytical services laboratories under contract to LBL before the Waste Management Group picks up their waste. Sampling must be arranged well in advance of waste pickup and must take into account maximum residence times in the SAAs. This sampling and analysis must be funded by the division owning the waste.

If the generator's characterization continues to fail validation for accuracy and integrity, the Deputy Director for Operations may required the generator and his/her staff to complete process-specific training. Again, any related sampling and analysis required to fully characterize the waste must be funded by the division. 


\section{Segregation of Radioactive Wastes}

To reduce the costs of radioactive waste management at Berkeley Lab, it is important for you to segregate your aqueous radioactive waste streams by half-life of the isotopes to allow yourself and the HWHF to maximize waste reduction in the future. Separate, clearly labeled collection containers should be established, as follows:

- Segregate wastes by half-life:

- Segregate materials containing isotopes with half lives $<3$ hours from all other radionuclides; such materials must be allowed to decay in the workplace for at least 10 half lives ( 30 hours). After ten half-lives, the materials will be checked for contamination according to the governing RWA. This must be approved through the RWA process.

- Segregate wastes containing radionuclides with half lives $>3$ hours and $<15$ days (such as ${ }^{32} \mathrm{P}$ ).

- Segregate wastes containing radionuclides with half lives $>15$ days and $<90$ days (including ${ }^{35} \mathrm{~S}$ and ${ }^{125} \mathrm{I}$ ).

- Segregate wastes containing radionuclides with half lives $>90$ days from all other wastes.

- Segregate low-level and transuranic wastes in separate containers.

- Segregate your scintillation vials according to the type of scintillation fluid used and by isotope (see "Scintillation Vials" in Section 8 below).

- Segregate compactable and noncompactable dry radioactive waste.

If you are unclear on these requirements or the radioactive waste segregation as outlined above is not feasible in your laboratory, please contact your Generator Assistance specialist. 


\section{Labeling of Radioactive Waste Containers}

\section{Chemical Composition of Radioactive Waste}

All radioactive wastes that contain chemicals should be considered potential mixed wastes until the chemical portion has been determined to be nonhazardous. To allow this level of characterization, quantitative information describing all hazardous and nonhazardous constituents must be listed on the Radioactive Waste Tag (Figure R-3), or on a supporting Radioactive/Mixed Waste Accumulation Log or Daily Use Log, keyed by number to the Radioactive Waste Tag. Important information regarding hazardous waste characterization can be found in "Guidelines for Generators to Meet HWHF Acceptance Requirements for Hazardous Wastes at Berkeley Lab" (part of this manual).

\section{Radioactive Content of Radioactive Waste}

The radioactive content of your waste must be known. You may determine the concentration of a radionuclide either by direct methods such as counting, or by indirect methods such as radionuclide material accountability or the use of scaling factors that relate the inferred concentration of one radionuclide to another that is measured, if there is reasonable assurance that the indirect methods can be correlated with actual measurements. For solid waste, make the best possible estimate of radioactive content. User knowledge is the favored approach, but it must be documented.

\section{The Radioactive Waste Tag}

The Radioactive Waste Tag must provide a summary of all chemical and radiological constituents in your waste, identified by name and concentration. All nonhazardous and potentially hazardous chemical constituents must be listed on the tag. Because the information on the Radioactive Waste Tag is a summary, only one entry for each chemical constituent or radionuclide must appear on the Radioactive Waste Tag; the information on the tag must account for $100 \%$ of the waste volume. In addition, one or more of the acronyms (DA, MB, Rx, and DIRT; see page Rad-5) must be entered to describe the characterization method used for each entry on the Radioactive Waste Tag. An example of a correctly prepared Radioactive Waste Tag is shown as Figure R-3.

Each Radioactive Waste Tag is reviewed by the Waste Management Group's Certification Team for correctness. Appendix 2 shows the acceptance criteria used by the Certification Team in reviewing Radioactive Waste Tags.

\section{The Radioactive Waste Tag Continuation Sheet}

In the event the summary chemical and radiological information will not fit on your Radioactive Waste Tag, you may complete your characterization summary using a Radioactive Waste Tag Continuation Sheet (Figure R-4). If you use a Continuation Sheet, check the box next to "D. Continued on Continuation Sheet?" on your Radioactive Waste Tag. Also, fill in the R-number from the Radioactive Waste Tag after the " $\mathrm{R}$ " on the Continuation sheet. If you are not sure that you are properly using the Radioactive Waste Tag Continuation Sheet, your EH\&S Generator Assistance specialist is available for consultation. 


\section{CAUTION}

\section{RADIOACTIVE WASTE}

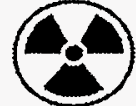

A. Physical Aqueous of Organic $\square$ Scintillation $\square$ Dry $\square$

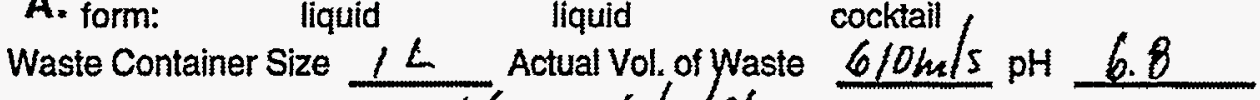
Accumulation log number $167-6 / 7 / 96$

\begin{tabular}{|c|c|}
\hline B. Radioactivity & $\begin{array}{l}\text { C. Chemical Constituents of Waste (i.e., } \\
\text { buffers, salts, etc.) }\end{array}$ \\
\hline & 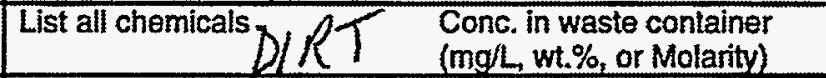 \\
\hline $95 \mu \mathrm{Ci}$ & Sodius doiducy sulfele $\quad 2 \quad$ wt. \% \\
\hline$\mu \mathrm{Ci}$ & Wercaptes thanel \\
\hline$\mu \mathrm{Ci}$ & 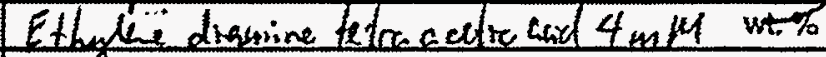 \\
\hline$\mu \mathrm{Cl}$ & Surote 20 \\
\hline$\mu \mathrm{Ci}$ & Tris. $H C l-0.25 \mathrm{~m} M-$ \\
\hline$\mu \mathrm{Cl}$ & an 6.8 \\
\hline$\mu \mathrm{Oi}$ & wt. \% \\
\hline Total: & D. Continued on continuation sheet? \\
\hline
\end{tabular}

E. Constituents Of Dry Waste (i.e., paper, plastic, metal, etc.)

\begin{tabular}{|c|c|c|c|c|c|}
\hline Item & Vol. \% & Item & Vol. \% & llem & Vol. \% \\
\hline & & & & & \\
\hline & & & & & \\
\hline
\end{tabular}

F. Bldg/Rm 94/3 RWA/P67 DivQSSD Acct 3073 Phone 7303

G. I certify I have adequate knowledge of the waste generating process to characterize a. this waste and, to the best of my kriowledgs, the information is zecurate.

Jean Generator

Generator - PAINT NAME

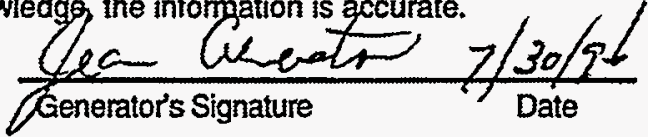

\begin{tabular}{|c|c|}
\hline \multicolumn{3}{|c|}{ WASTE MANAGEMENT GROUP USE ONLY } \\
\begin{tabular}{|c|c|c|}
\hline $\begin{array}{c}\text { Radiation Dose/Rate } \\
\text { Contact }\end{array}$ & mR/hour & instrument serial \#: \\
\hline
\end{tabular}
\end{tabular}

Generator's portion of this tag has been reviewed IAW EH\&S Procedure 827, Sec. 8.

EH\&S Tech performing survey

Pequisition No.

Compactable $\mathrm{O}$

Noncompactable $\quad \square$

Waste Hauler's Signature

CERTIFICATION TEAM WILI DETERMINE CLASSIFICATION

Low level LOW level MIXED TRU - TRU MIXED Induced metals

\begin{tabular}{c} 
KEEP ALL THREE FORMS TOGETHER UNTIL WASTE IS PICKED UP. \\
\hline NO. $\mathrm{A} 4407$
\end{tabular}

Figure R-3. Radioactive Waste Tag (front) 


\section{INSTRUCTIONS}

1. State and Federal waste disposal and transportation regulations require completion of this waste tag.

2. Minimize the gross volume of your waste; separate the noncontaminated materials from the hazardous or radioactive waste.

3. Separate radioactive waste into groupings: low level waste (LLW), transuranic waste (TRU), low level mixed waste (LLMW), and transuranic mixed waste (TRUM). Disposal of mixed waste is the most costly.

4. Keep radioactive waste free of other hazardous substances wherever practical. Identify the hazardous materials used in your research; you may be able to modify your procedure or substitute or neutralize these hazardous components in order to reduce their volume and toxicity. Attempt to keep oxidizers, flammables, poisons, and corrosive substances separate. Any of these substances added to low level waste will change it to the more costly mixed waste.

5. Scintillation vials are collected in a 10-gallon plastic container or in celled cardboard containers inside plastic bags; no metal, adsorbent, or other waste.

6. Segregate radioactive waste based on half-life, as follows:

\begin{tabular}{c} 
Half-life \\
\hline$<3$ hrs \\
$>3$ hrs and $<15$ days \\
$>15$ days and $<90$ days \\
$>90$ days \\
\hline
\end{tabular}

7. For consultation, especially on identifying hazardous materials, call your EH\&S Generator Assistance specialist.

NTWKWORD - OPERATIONS - Rad or Mixed Waste Tag

June 20, 1996

Figure R-3 (continued). Radioactive Waste Tag (reverse side) 


\section{CAUTION}

RADIOACTIVE WASTE

\section{CONTINUATION SHEET}

\begin{tabular}{|c|c|c|c|}
\hline B. Radioactivity & C. Chemical Constituents of Waste \\
(ie. buffers, salts, etc.
\end{tabular}

\begin{tabular}{|llll}
\hline Isotope & Quantity & List all chemicals Conc. in waste container
\end{tabular}

\begin{tabular}{r|r|} 
& (mg/L, wt.\%, or Molarity) \\
\hline$\mu \mathrm{Ci}$ &
\end{tabular}

\begin{tabular}{rr|}
\hline$\mu \mathrm{Ci}$ & wt. \% \\
\hline wt. \% \\
\hline
\end{tabular}

\begin{tabular}{r|r|}
\hline$\mu \mathrm{Ci}$ & wt. \% \\
\hline$\mu \mathrm{Ci}$ & w. \% \\
\hline
\end{tabular}

\begin{tabular}{|r|r|}
\hline$\mu \mathrm{Ci}$ & wt. \% \\
\hline$\mu \mathrm{Ci}$ & wt. \% \\
\hline
\end{tabular}

\begin{tabular}{r|r|}
\hline$\mu \mathrm{Ci}$ & wt. \% \\
\hline & \\
\hline
\end{tabular}

\begin{tabular}{rr|}
\hline$\mu \mathrm{Ci}$ & wt. \% \\
\hline$\mu \mathrm{Ci}$ & wt. \% \\
\hline$\mu$ &
\end{tabular}

\begin{tabular}{rr|}
\hline$\mu \mathrm{Ci}$ & wt. \% \\
\hline$\mu \mathrm{Ci}$ & wt. \% \\
\hline$\mu \mathrm{Ci}$ & wt. \% \\
\hline$\mu \mathrm{Ci}$ & wt. \% \\
\hline$\mu \mathrm{Ci}$ & wt. \% \\
\hline$\mu \mathrm{Ci}$ & wt. \% \\
\hline$\mu \mathrm{Ci}$ & wt. \% \\
\hline$\mu \mathrm{Ci}$ & wt. \% \\
\hline$\mu \mathrm{Ci}$ & wt. \% \\
\hline$\mu \mathrm{Ci}$ & wt. \% \\
\hline$\mu \mathrm{Ci}$ & wt. \% \\
\hline
\end{tabular}

Total :

Additional Comments: \begin{tabular}{lr}
\hline \hline \multicolumn{2}{c}{ KEEP ALL THREE FORMS TOGETHER UNTIL WASTE IS PICKED UP. } \\
\hline \hline No. $R$
\end{tabular} SEE REVERSE SIDE FOR INSTRUCTIONS

Figure R-4. Radioactive Waste Tag Continuation Sheet 


\section{Radioactive Waste Accumulation Log}

When wastes are accumulated in a radioactive waste container through two or more repetitive additions, a history of accumulation must be provided on a Radioactive Waste Accumulation Log or in the RWA notebook in the LBNL Daily Use Log (Figure R-2), and the integrated composition must be summarized on a Radioactive Waste Tag. Separate logs must be kept for radioactive and mixed wastes. For use of this form as a $\log$ for radioactive waste, cross off the word "Mixed" from the title of the log.

When a new accumulation container is started, the Radioactive Waste Tag must be attached with the following sections filled in:

- A ("Physical Form")

- $\quad F$ (all entries)

- $\mathrm{G}$ ("Generator's Name")

Examples of a Radioactive Waste Tag (Figure R-3) and its supporting Radioactive Waste Accumulation Log (Figure R-5) illustrate the fulfillment of this requirement. 


\section{CAUTION}

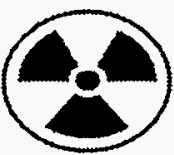

RADIOACTIVE WASTE

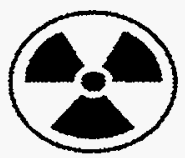

BERKELEY LAB

\section{RADIOACTIVE WASTE ACCUMULATION LOG}

Container Description: $\quad 1<$ bo thle

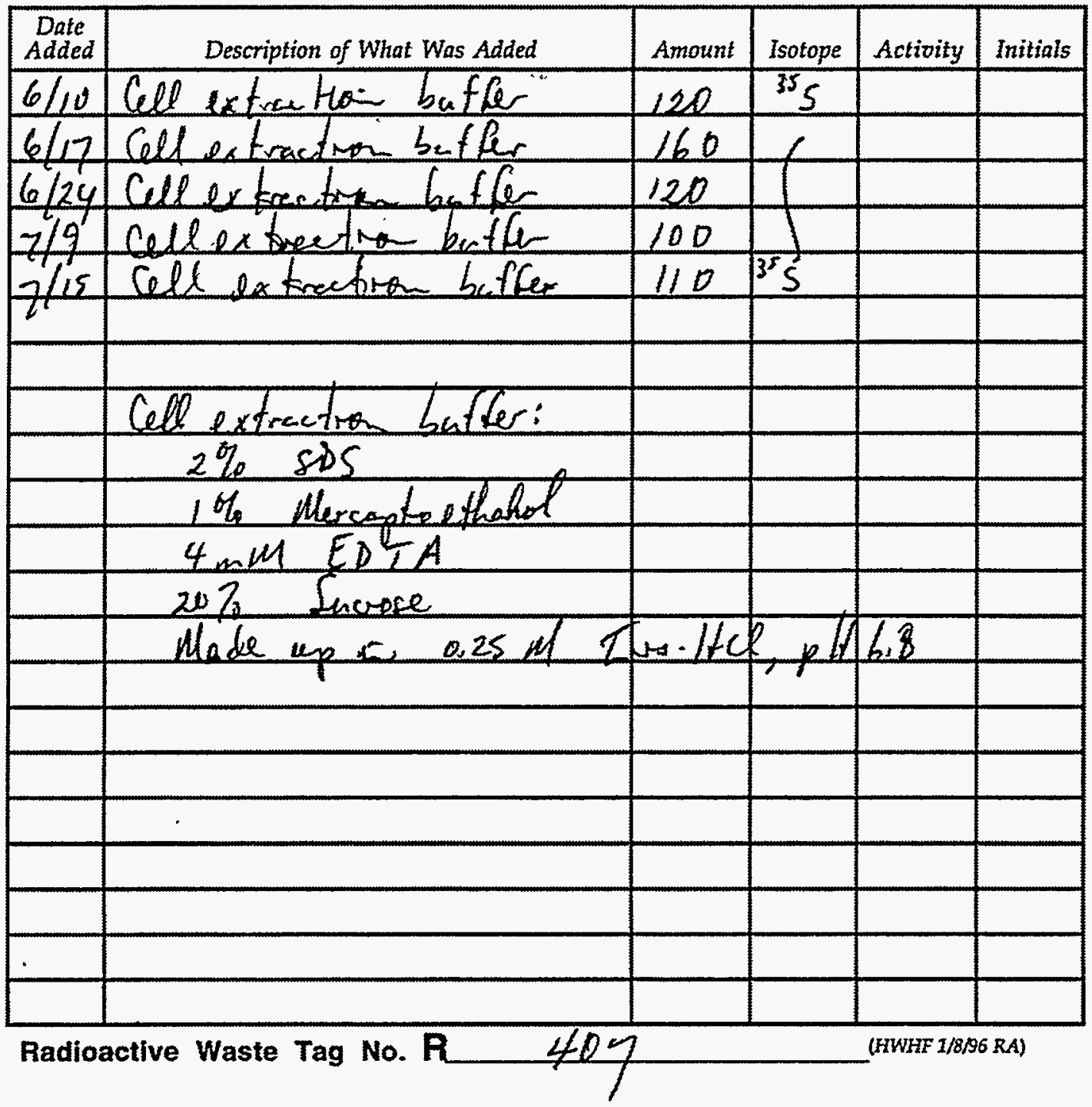

Figure R-5. Radioactive Waste Accumulation Log 


\section{Guidelines for Radioactive Waste Accumulation}

\section{Management of Your Radioactive Waste Collection Area}

You should establish Radioactive Waste Collection Areas for the accumulation of radioactive wastes within your Radioactive Material Area (RMA). The Radioactive Waste Collection Area(s) should be clearly marked off with magenta and yellow tape, and all radioactive waste accumulation should take place within the marked area(s).

- Locate your Radioactive Waste Collection Area away from areas of high foot traffic or emergency equipment, and separated from areas where other types of wastes are accumulated.

- Be scrupulous about good housekeeping in hoods, glove boxes, and laboratories. Avoid overfilling and spills.

- When you are accumulating wastes, you may attach the Radioactive Waste Tag to the secondary containment.

- Do not pour liquid radioactive or mixed waste down the sanitary drain. If this should happen accidentally, immediately call EH\&S Environmental Protection Group, extension 5251.

- $\quad$ Keep a copy of these guidelines near your Radioactive Waste Collection Area.

If you are unsure about guidelines for establishing or managing a Radioactive Waste Collection Area, call your EH\&S Generator Assistance specialist for information or a site consultation.

\section{Radioactive Waste Packaging}

It is very important that you package your waste appropriately for transport to the Berkeley Lab HWHF. Radioactive waste that is not properly packaged will not be picked up by HWHF staff.

- $\quad$ Place all radioactive sharp objects (hypodermic needles, spitzers, scalpels, etc.) in protective containers. Ice cream cartons (available from Stores in pint [Item 811527762], quart [Item 8115-27763], and two-quart [Item 8115-27764] sizes) lined with plastic bags are acceptable.

- Do not place radioactive sharps in medical/biohazardous sharps containers.

- Do not overfill any radioactive or mixed waste container, liquid or dry.

- Make sure that the container is chemically compatible with the contents.

- Store all radioactive liquids in leak-tight containers inside rigid secondary containment. Seal the bottle with duct tape when you are ready to fax the Radioactive/Mixed Waste Requisition to the Waste Management Group.

- You should provide your primary waste containers (ice cream cartons, polyethylene bags, etc.). Most necessary items can be ordered from Berkeley Lab Stores (see Tables $\mathrm{H}-1$ and $\mathrm{H}-2$ of this manual). EH\&S will supply some items, such as 30 -gallon dry compactable waste containers and carboys. 


\section{Requesting Radioactive Waste Pickup}

When your radioactive waste container is filled or when you wish to have your radioactive waste picked up, fax a completed Radioactive/Mixed Waste Requisition form (Figure R-6) to the HWHF (extension 4838), along with a copy of your signed and dated Radioactive Waste Tag and any supporting documentation, such as accumulation logs. If the EH\&S Certification Specialist is satisfied that the tag is filled out completely and accurately, the HWHF will be directed to pick up your waste. You will be contacted by the HWHF if your tag and supporting documentation are not sufficient to adequately characterize your waste. If this phone call does not clarify all issues regarding the appropriate characterization of your waste, a Nonconformance and Corrective Action Report (NCAR) may be issued to your Division ES\&H Coordinator, and your EH\&S Generator Assistance representative may contact you to offer assistance.

\section{LBNL Radioactive/Mixed Waste Disposal Requisition FAX 4838 • Questions: 5251}

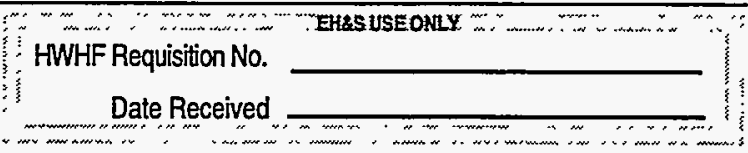

INSTRUCTIONS: Please provide all information requested. List no more than one rad tag number per line.Your signature is required, and certifies that to the best of your knowledge, the chemical and radioactive composition provided for each item on the attached rad tag is correct. Please fax a copy of the radioactive waste tag and accumulation log for each item with this requisition form.

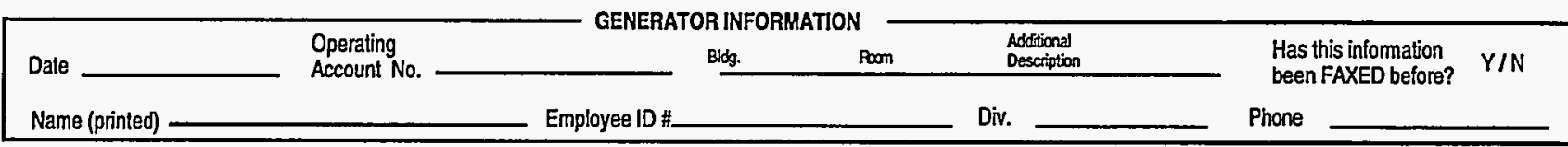

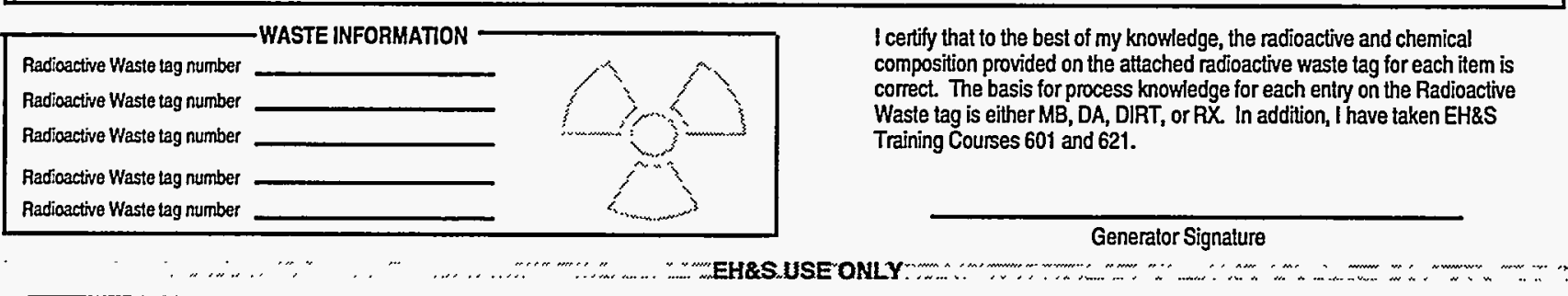

Supporting documentation provided (list all):

\begin{tabular}{|c|c|c|c|c|c|c|c|c|}
\hline \multirow{2}{*}{$\begin{array}{c}\text { Radwaste Tag } \\
\text { number }\end{array}$} & \multicolumn{2}{|r|}{ Certification } & \multicolumn{6}{|c|}{ Compliance } \\
\hline & $\begin{array}{l}\text { Char. } \\
\text { OK? }\end{array}$ & $\begin{array}{l}\text { Char. sampling } \\
\text { (list tests needed) }\end{array}$ & $\begin{array}{c}\text { QA sampling } \\
\text { (list tests needed) }\end{array}$ & $\begin{array}{l}\text { Part B Waste } \\
\text { Stream }\end{array}$ & $\begin{array}{l}\text { EPA/State } \\
\text { Codes }\end{array}$ & $\begin{array}{l}\text { STP Waste } \\
\text { Stream }\end{array}$ & $\begin{array}{l}\text { Pickup? } \\
\text { (Y/N) }\end{array}$ & $\begin{array}{c}\text { Preassigned } \\
\text { Storage Location }\end{array}$ \\
\hline & & & & & & & & \\
\hline & & & & & & & & \\
\hline & & & & & & & & \\
\hline & & & & & & & & \\
\hline & & & & & & & & \\
\hline \multicolumn{4}{|c|}{ Generator training (Course numbers/dates taken): } & \multicolumn{5}{|c|}{ Will acceptance of these waste containers into the HWHF exceed threshold? } \\
\hline
\end{tabular}

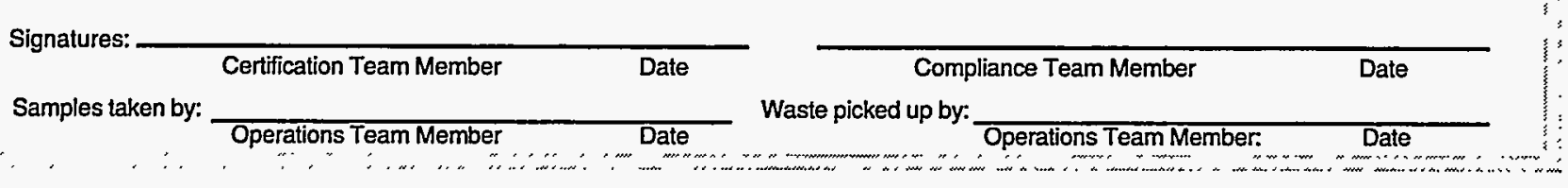

Figure R-6. Radioactive/Mixed Waste Disposal Requisition 


\section{Guidelines for Specific Radioactive Waste Streams}

Before radioactive wastes can be packaged at the HWHF, they must be separated into the proper waste streams. This section describes guidelines unique to each waste stream. If you are unsure about how to separate and package your radioactive waste, please call you EH\&S Generator Assistance specialist.

\section{Solid Compactable Dry Waste}

By definition, dry waste is solid radioactive waste that has less than $1 \%$ free liquids. Keep these wastes inside a cement sack inside a $24^{\prime \prime} \times 38^{\prime \prime}$ polyethylene bag, all placed inside a 15-gallon waste can. EH\&S (extension 5251) provides the Dry Waste 15-gallon can. Cement sacks are available from Berkeley Lab Stores (Item 8105-27692), as are polyethylene bags (Item 8105-51456).

When your dry waste bag is full or ready for pickup, you should seal it with 2-inch duct tape and tie and tape your signed Radioactive Waste Tag and any supporting documentation to the neck of the sealed plastic bag. Double-bag the waste if there is suspected external contamination.

\section{Solid Noncompactable Dry Waste (solid items $>4^{\prime \prime} \times 4^{\prime \prime} \times 4^{\prime \prime}$ with $<1 \%$ liquid)}

Keep these wastes inside a cement sack inside a $24^{\prime \prime} \times 38^{\prime \prime}$ polyethylene bag and seal the plastic bag with 2-inch duct tape.

\section{Induced Metals and Equipment}

An EH\&S representative will package large pieces. Place small pieces in DOT-approved drums or EH\&S-approved polyethylene bags. Label all containers with Radioactive stickers (provided by EH\&S).

\section{Animal Carcasses and Tissues}

Keep carcasses and tissues frozen, contained in double plastic bags. Fill out a separate Radioactive Waste Tag for each bag. Tape or otherwise protect any sharp items, such as claws.

\section{Scintillation Vials}

- Whenever possible, pack scintillation vials in their original celled cardboard containers to minimize the possibility of breakage prior to or during shipment to the HWHF. Place the celled containers in a secondary containment such as a photographic tray.

- If the original celled containers are not available, use 10-gallon plastic containers (provided by EH\&S). Place a 2-mil (minimum thickness) plastic liner in the container. Stores Item $8105-59166$ is acceptable. There should be no metal, absorbent, or other waste in the container. 
- A Radioactive Waste tag must be attached and filled out as specified in the preceding section entitled "Radioactive Waste Tag" to the container for scintillation vial disposal. The chemical characterization of scintillation vial waste must include the chemical in the counting sample and the final concentration; for example; $1 \%$ acetonitrile, $0.01 \mathrm{M}$ $\mathrm{NaOH}$, or $5 \%$ water.

\section{Solid Transuranic Waste}

- $\quad$ Package the waste in 1/2-gallon or smaller ice cream cartons, with lids sealed with 2inch duct tape.

- Place the ice cream carton inside a polyethylene bag sealed with 2-inch duct tape.

- Identify all materials on the Radioactive Waste Tag by material composition (e.g., $50 \%$ paper, $25 \%$ glass, $25 \%$ rubber).

- $\quad$ Sign the Radioactive Waste Tag; tie and tape it (with 2-inch duct tape) to the sealed plastic bag.

- $\quad$ Place the plastic bag inside a 6"-diameter by $12^{\prime \prime}$-high metal can (provided by EH\&S).

\section{Liquid Transuranic Waste}

- Package the waste in LBL-certified glass containers. (Consult with EH\&S on containers.)

- Place the glass containers in the ice cream cartons as described for solid-transuranic waste, and follow the solid waste procedure. 



\section{Guidelines for Generators to Meet HWHF Acceptance Requirements for Mixed Wastes at Berkeley Lab}

\section{Introduction}

This document provides performance standards that you, as a generator of mixed (hazardous and radioactive) waste at the Berkeley Lab, must meet to:

- $\quad$ protect Berkeley Lab staff and the environment,

- comply with hazardous waste regulations and ensure the continued safe operation of your workplace,

- have your waste transferred to the HWHF, and

- enable the Environment, Health and Safety (EH\&S) Division to properly pick up, manage, and ultimately send your waste off site for recycling, treatment, or disposal.

If you use radioactive and hazardous materials and generate mixed wastes, you must establish a Mixed Waste Satellite Accumulation Area (MWSAA) and follow the guidelines listed in this section of the manual. Figure $M-1$ is a flowchart that shows how mixed (and radioactive) waste is managed at the Berkeley Lab.

Because mixed waste is both radioactive and hazardous, you must adhere to the requirements in the two other portions of this manual, entitled "Guidelines for Generators to Meet HWHF Acceptance Requirements for Hazardous Wastes at Berkeley Lab" and "Guidelines for Generators to Meet HWHF Acceptance Requirements for Radioactive Wastes at Berkeley Lab." These requirements include characterization for both chemical and radioactive content and affixing a Hazardous Waste label and a Radioactive Waste tag to each waste container to make it clear that the waste added to the container was mixed. The intent of this section is to provide guidance on the rational integration of requirements for hazardous and radioactive wastes and to point out certain guidelines and requirements that are specific to mixed waste. This section is not meant to provide stand-alone standards for workplace management of mixed waste. It is designed as a supplement to the other sections to avoid redundancy.

Implementation of a mixed waste management system based solely on the information in this section will not meet the performance standards for disposal of mixed waste.

The guidelines in this section do not apply to wastes that are radioactive, but are not hazardous. For information on radioactive waste management, see the "Guidelines for Generators to Meet HWHF Acceptance Requirements for Radioactive Wastes at Berkeley Lab" (part of this manual). 


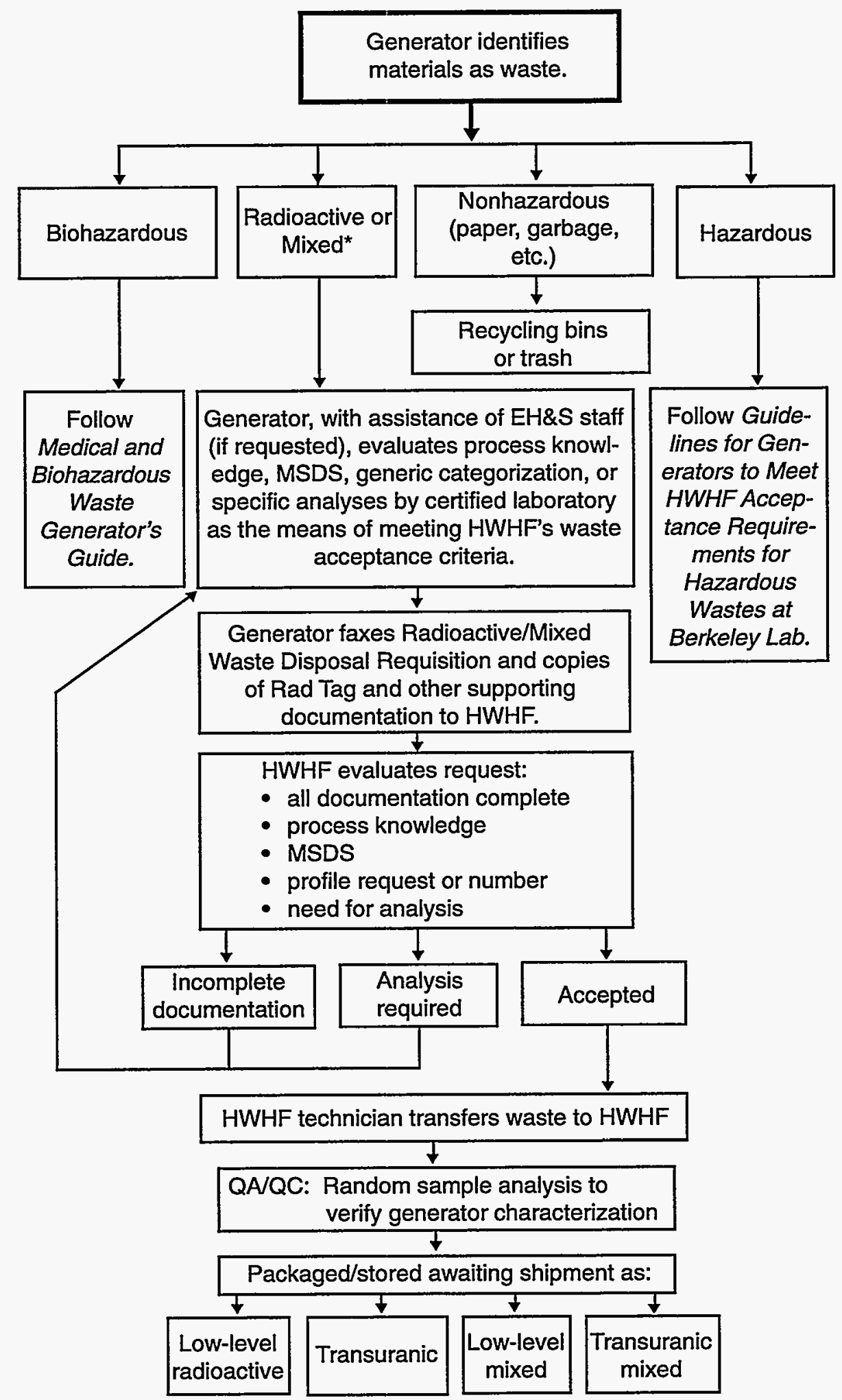

*Containers of mixed waste must have Hazardous Waste labels attached to them at all times.

Figure M-1. Flowchart for Radioactive and Mixed Waste Management at Berkeley Lab 
The guidelines in this section also do not apply to wastes that are hazardous, but are not radioactive. For information on hazardous waste management, see the "Guidelines for Generators to Meet HWHF Acceptance Requirements for Hazardous Wastes at Berkeley Lab" (part of this manual).

The requirements in this section also do not apply to purely medical and biohazardous wastes. For information on proper management of medical and biohazardous wastes, see the most recent revision of PUB-3095, Medical and Biohazardous Waste Generator's Guide. To identify the most recent version of PUB-3095 or any other document referenced in this manual, contact your Generator Assistance specialist.

Mixed waste generated at the Berkeley Lab is transferred to the Hazardous Waste Handling Facility (HWHF), managed by the EH\&S Division. The waste is treated, if necessary, and packaged for storage and ultimate shipment to one of several treatment, storage, and disposal facilities (TSDFs), as specified in the Laboratory's Site Treatment Plan. Each of the TSDFs establishes criteria (in conjunction with $\mathrm{DOE}$ ) for acceptance of mixed wastes. The guidelines listed in this section are designed to ensure that individual generators of mixed waste comply with the waste acceptance criteria of TSDFs so that the Berkeley Lab can dispose of this waste in a responsible and timely manner. The performance standards in this manual are also designed to promote compliance with all other regulations covering the management of mixed wastes at the Berkeley Lab.

Further information on proper handling of mixed wastes is presented in Chapters 20 (Hazardous Waste Disposal) and in the Radiological Work Authorization (RWA) Section of Chapter 21 (Radiation Safety) of the most recent version of PUB-3000, the Berkeley Lab Health and Safety Manual.

\section{What Is a Mixed Waste?}

A waste is mixed if it is classified by federal and state agencies as being both radioactive and hazardous. At Berkeley Lab, a waste is characterized as radioactive if either process knowledge or monitoring and sampling show that radioactive material has been added to the waste. Wastes containing only naturally occurring radioactive material (NORM), such as potassium-bearing compounds with $40 \mathrm{~K}$ as the sole radioactive constituent, are not considered to be radioactive and should be managed as hazardous or nonhazardous waste, depending on chemical composition. More specific information on the proper classification of radioactive wastes can be found in another portion of this manual, entitled the "Guidelines for Generators to Meet HWHF Acceptance Requirements for Radioactive Wastes at Berkeley Lab."

Hazardous waste falls into two regulatory categories: characteristic and listed. Regulatory designation of chemical components of waste as "characteristic" is based on specific hazardous property characteristics (toxicity, reactivity, ignitability, or corrosivity) that may depend on their concentrations ( $\mathrm{pH}$ is a good example). "Listed" waste is derived from chemicals that are specifically listed in the regulations. (See the paragraph entitled "Listed Hazardous Waste" in "Guidelines for Generators to Meet HWHF Acceptance Requirements for Hazardous Wastes at Berkeley Lab.")

If, after reading this manual, you are still unsure whether your waste is mixed, contact your EH\&S Generator Assistance representative for assistance. 


\section{Mixed Waste Minimization}

It is absolutely essential that you minimize the amount of mixed waste you generate in your research. Because the regulations concerning mixed waste treatment and disposal are not yet fully mature, mixed waste management is both difficult and expensive. At the Berkeley Lab, for example, the addition of a small amount of radioactive material to a hazardous waste would increase waste management costs by more than two orders of magnitude! In addition, the total mixed waste storage capacity at the Berkeley Lab's HWHF is extremely limited, and much of the mixed waste must be stored for long periods of time before ultimate treatment and/or disposal will be allowed under a Federal Facilities Compliance Act that governs DOE facilities. The EH\&S Division is doing what it can to alleviate the problems and reduce costs by establishing new treatment capabilities, such as neutralization, for some mixed waste streams, and by instituting "decay in place" policies for short-lived radioactive and mixed wastes. It is important that you also do your share by practicing mixed-waste source reduction in your research to the greatest extent practicable.

Mixed-waste source reduction refers to practices that eliminate the generation of mixed waste. Several ways to accomplish mixed waste source reduction are as follows.

- You can eliminate a mixed waste stream by replacing all radioactive constituents with nonradioactive constituents. For example, immuno-assay or chemical-fluorescence methods might be used in place of radioactive tracers in some applications, with little or no decrease in sensitivity.

- A mixed waste stream can be eliminated by replacing all hazardous constituents with nonhazardous constituents. For example, nonhazardous scintillation fluids can be used in some counting applications, greatly reducing the amount of mixed waste generated.

- You can minimize the volume of an existing mixed waste stream by using microscale chemical techniques and by designing your experiments to use the minimum amount of radioactive materials and chemicals practicable.

In addition, avoidance of "listed" chemicals (Appendix 1) in your research processes enhances opportunities for treatment of mixed waste and eventual disposal as radioactive. This strategy can reduce the volume of the waste, the impact on the environment, and the cost of disposal.

More information relevant to the minimization of mixed wastes can be found in the "Guidelines for Generators to Meet HWHF Acceptance Requirements for Hazardous Wastes at Berkeley Lab" and the "Guidelines for Generators to Meet HWHF Acceptance Requirements for Radioactive Wastes at Berkeley Lab" (other sections of this manual). In addition, specific recommendations for source reduction in your experiment(s) can be found in the Berkeley Lab Mixed Waste Reduction Plan, prepared annually by EH\&S based on input from all routine mixed-waste generators at the Berkeley Lab. Your Generator Assistance specialist will contact you annually to update the Berkeley Lab Mixed Waste Reduction Plan, and to discuss specific source reduction strategies that may be relevant to your research. 


\section{Mixed Waste Characterization}

Proper characterization of mixed waste is mandatory and encompasses all of the challenges of both radioactive waste characterization and hazardous waste characterization. Hazardous waste characterization criteria can be found in the "Guidelines for Generators to Meet HWHF Acceptance Requirements for Hazardous Wastes at Berkeley Lab" (part of this manual). Characterization of radioactive waste is described in detail in the "Guidelines for Generators to Meet HWHF Acceptance Requirements for Radioactive Wastes at Berkeley Lab" (part of this manual).

As with both hazardous and radioactive wastes generated at the Berkeley Lab, an EH\&S Waste Certification specialist will evaluate your characterization information for completeness and accuracy. If questions concerning your characterization or documentation can not be cleared up through a phone conversation, a Nonconformance and Corrective Action Report may be issued to your Division ES\&H Coordinator, and your EH\&S Generator Assistance specialist may contact you to offer assistance.

If , after reading this booklet, you are unsure that you are properly characterizing your mixed waste, please call your EH\&S Generators Assistance specialist for a consultation. 


\section{Segregation of Mixed Wastes}

To avoid inadvertently creating mixed waste and to minimize the costs of mixed waste management at the Berkeley Lab:

- Mixed waste must be segregated from all other types of waste in your laboratory (nonhazardous, hazardous, radioactive, or biohazardous).

- Never add anything but mixed waste to any mixed waste container.

- Segregate mixed waste streams by isotopic half-life to allow the HWHF to maximize mixed waste reductions through "decay in place" practices.

- Established separate containers for low-level radioactive mixed waste and transuranic mixed waste, as indicated in the Segregation of Radioactive Wastes section of the "Guidelines for Generators to Meet HWHF Acceptance Requirements for Radioactive Wastes at Berkeley Lab" (another portion of this manual).

Mixed wastes must also be segregated on the basis of hazardous characteristic to prevent accidents due to the inadvertent mixing of incompatible materials and to maximize treatment and disposal options. Requirements for the segregation of chemically incompatible wastes can be found in the Segregation of Incompatible Wastes section of the "Guidelines for Generators to Meet HWHF Acceptance Requirements for Hazardous Wastes at Berkeley Lab" (another portion of this manual).

If you are unclear on these requirements, or the radioactive waste segregation as outlined above is not feasible in your laboratory, please contact your Generator Assistance specialist.

\section{5. 'Separation of Mixed Wastes}

In addition to segregation, you must use physical separation to prevent the inadvertent mixing of incompatible mixed wastes. Separation is achieved using distance and/or chemically resistant barriers such as secondary containers. Chemically incompatible mixed wastes must not be placed within the same secondary containment bin. In addition, SAAs, MWSAAs, and Radioactive Waste Collection Areas must be physically separated to preclude accidental cross-contamination. More specific information on separation requirements for hazardous (and mixed) waste can be found in the Separation of Incompatible Wastes section of the "Guidelines for Generators to Meet HWHF Acceptance Requirements for Hazardous Wastes at Berkeley Lab" (another portion of this manual). 


\section{Guidelines for Mixed Waste Accumulation}

A Mixed Waste Satellite Accumulation Area (MWSAA) is an area in an individual laboratory, shop, or other facility designated by the generator for the temporary accumulation of mixed waste. You must establish a MWSAA for the accumulation of your mixed wastes within your Radioactive Material Area (RMA). The MWSAA must be clearly identified by a purple MWSAA sign, and all mixed waste accumulation must take place within the designated area. The area must be at or near the point of mixed waste generation and under the control of a responsible, trained generator. Even a single small bottle of mixed waste requires the establishment of a MWSAA.

- Locate your MWSAA away from areas of high foot traffic and emergency equipment, and separated from areas where other types of wastes are accumulated.

- Be scrupulous about good housekeeping in hoods, glove boxes, and laboratories.

- Do not pour liquid mixed waste down the sanitary drain. If this should happen accidentally, immediately call EH\&S Environmental Protection Group, extension 5251.

- You must keep a copy of these Guidelines for Generators to Meet HWHF Acceptance Requirements for Hazardous, Radioactive, and Mixed Wastes at Berkeley Lab near your MWSAA.

If you are unsure about requirements for establishing or managing a MWSAA, call your EH\&S Generator Assistance specialist for information or a site consultation.

With two exceptions, the requirements for operation of a MWSAA are identical to those for operation of an SAA (see the Requirements for SAA Operation section of the "Guidelines for Generators to Meet HWHF Acceptance Requirements for Hazardous Wastes at Berkeley Lab" (another portion of this manual). The two exceptions are as follows:

- The MWSAA must be designated using the purple MWSAA sign shown in Figure M-2.

- When you wish to have your mixed waste picked up, or you are approaching either the quantity or time limits (275 days), you must fax a Radioactive/Mixed Waste Disposal Requisition and supporting documentation to the HWHF at extension 4838. 


\section{MW-SAA}

\section{SATELLITE ACCUMULATION AREA FOR MIXED (HAZARDOUS/RADIOACTIVE) WASTE}

\section{RESPONSIBLE INDIVIDUAL:}

NAME

BLDG/ROOM

PHONE

TYPE OF WASTE

ISOTOPE(S)

DO NOT ADD WASTE TO THIS ACCUMULATION AREA WITHOUT

PRIOR AUTHORIZATION FROM THE RESPONSIBLE INDIVIDUAL

Questions: Call EH\&S Generator Assistance

Figure M-2. Mixed Waste Satellite Accumulation Area (MWSAA) Sign 


\section{Mixed Waste Labeling}

Because mixed waste is both hazardous and radioactive, you must affix both a Hazardous Waste Label and a Radioactive Waste Tag (Figures H-3 and R-3 of this manual, respectively) to each mixed waste container. The tags must be affixed at the time you declare a material to be mixed waste or when you begin to accumulate mixed waste in any container. Details on how to properly fill out these labels and on preparation of supporting documentation can be found in the "Guidelines for Generators to Meet HWHF Acceptance Requirements for Hazardous Wastes at Berkeley Lab" and the "Guidelines for Generators to Meet HWHF Acceptance Requirements for Radioactive Wastes at Berkeley Lab" (other portions of this manual).

\section{Record of Radioactive Mixed Waste Accumulation Log}

When wastes are accumulated in a radioactive mixed waste container through two or more repetitive additions, a history of accumulation must be provided on a Mixed Waste Accumulation Log (see Figure M-3), and the integrated composition must be summarized on a Radioactive Waste Tag. Use of the RWA Materials Use does not suffice as a waste accumulation log in this case because it does account for accumulation of the hazardous component. Separate logs must be kept for radioactive and mixed wastes. For use of this form as a log for mixed waste, cross off the word "Radioactive" from the title.

When a new mixed waste accumulation container is started, affix a Hazardous Waste tag with sections 1, 3, 4, 5, and 6 filled in (see "Labeling" in the hazardous waste section of this manual). Because the waste is also radioactive, attach the Radioactive Waste Tag with sections A ("Physical Form"), F ( all entries), and G (Generator's Name) filled in. The Mixed Waste Accumulation Log or an indication to staff of which mixed waste stream is acceptable should also be attached to each mixed waste container. An example of a Radioactive Waste Tag filled out for mixed waste and a Hazardous Waste Label are shown, respectively, in Figures M-4 (below) and $\mathrm{H}-3$ (in "Guidelines for Generators to Meet HWHF Acceptance Requirements for Hazardous Wastes at Berkeley Lab").

\section{Requesting Mixed Waste Pickup}

When you wish to have your mixed waste picked up, or when you are approaching either the 55gallon or 275-day (9-month) limits for accumulation of mixed waste in an MWSAA, you should fax a Radioactive/Mixed Waste Disposal Requisition (see Figure R-6 in "Guidelines for Generators to Meet HWHF Acceptance Requirements for Radioactive Wastes at Berkeley Lab") and supporting documentation to the HWHF at extension 4838. See Sections 6 and 8 in "Guidelines for Generators to Meet HWHF Acceptance Requirements for Radioactive Wastes at Berkeley Lab" for details on packaging radioctive waste. 


\section{CAUTION}

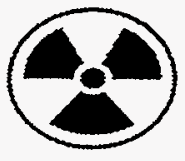

RADIOACTIVE WASTE

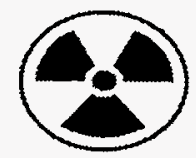

BERKELEY LAB

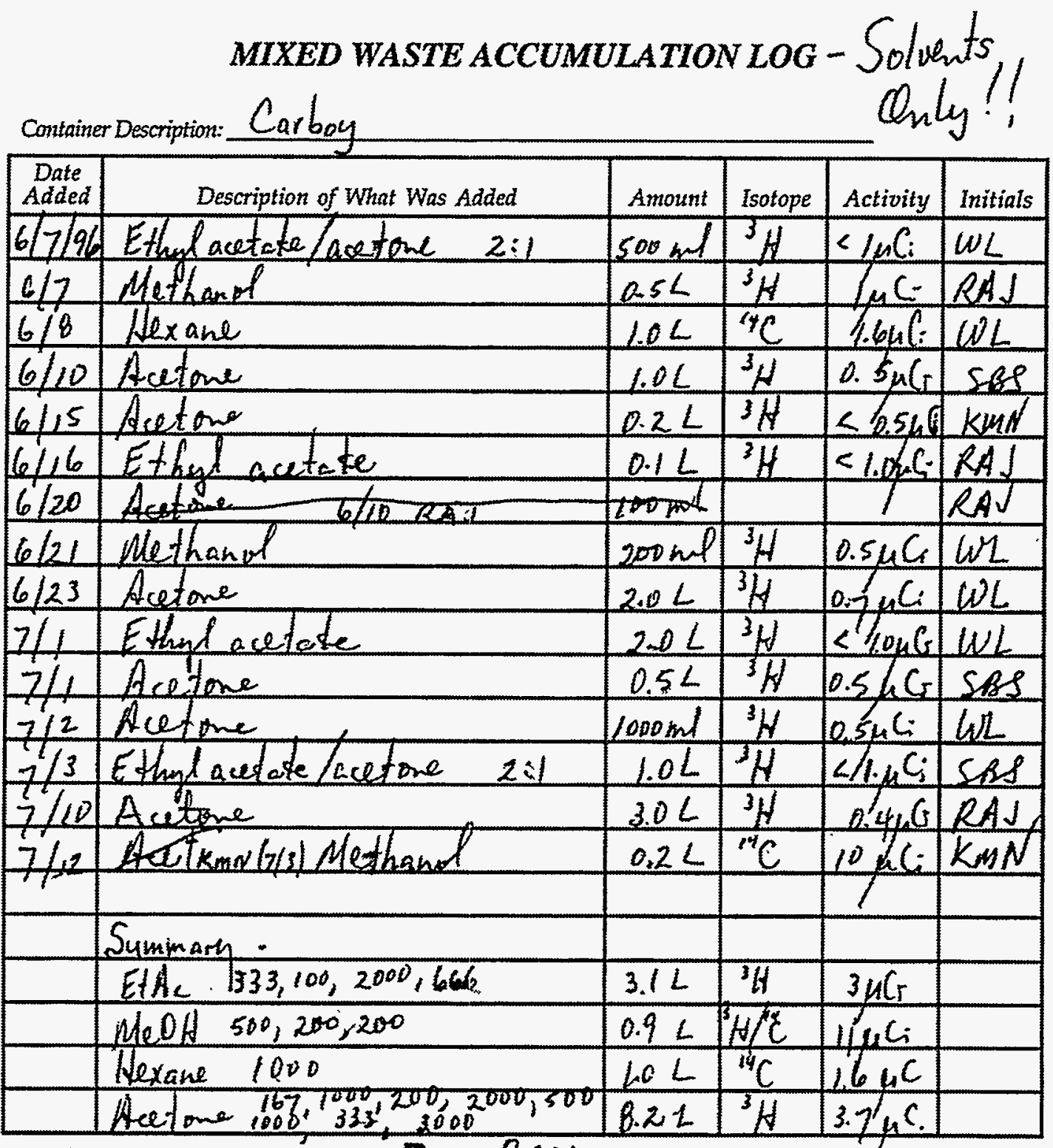

Radioactive Waste Tag No. R 8201

(HW/F 1/8/96 RA)

Figure M-3. Mixed Waste Accumulation Log 


\section{CAUTION

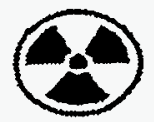 \\ RADIOACTIVE WASTE}

Physical Aqueous

A. form: liquid

Organic
liquid $\begin{gathered}\text { Scintillation } \\ \text { cocktail. }\end{gathered}$

Waste Container Size $15 \mathrm{~L}$ Actual Vol. of Waste $13.2 L$ pH $\mathrm{N} / \mathrm{A}$

Accumulation log number $R \& 201$

\begin{tabular}{|c|c|c|c|c|c|}
\hline \multicolumn{3}{|c|}{ B. Radloactivity } & \multicolumn{3}{|c|}{$\begin{array}{l}\text { C. Chemical Constituents of Waste (l.e., } \\
\text { buffers, salts, etc.) }\end{array}$} \\
\hline & & & List all chemicals & \multicolumn{2}{|c|}{$\begin{array}{l}\text { Conc in wasto container } \\
\text { (mgh, wt.\%, or Molarity) }\end{array}$} \\
\hline$M B$ & 3 & $\mu \mathrm{C}$ & acetate- DIRT & 23 & $14 \% \%$ \\
\hline$M B$ & 211 & $\mathrm{HO}$ & Methanol -MB & 7 & $4 \times 6 \%$ \\
\hline$D A$ & 61.6 & 40 & Dexame & 8 & $\sqrt{4} \%$ \\
\hline$M B$ & 3.7 & $\mu \mathrm{Ci}$ & Aclone & 62 & vW\% \\
\hline & & $\mathrm{HCI}$ & & & w. \% \\
\hline & & HCI & & & wt. \% \\
\hline & & $\mu \mathrm{Ca}$ & & & WL. \% \\
\hline
\end{tabular}

Total: $\quad 19 \quad \mu \mathrm{CI}$

D. Continued on continuation sheet?

E. Constituents of Dry Waste (1.e., paper, plastic, metal, etc.)

\begin{tabular}{|c|c|c|c|c|c|}
\hline Item & Vol. \% & Ilem & Vol.\% & Item & Val. $\%$ \\
\hline & & & & & \\
\hline & & & & & \\
\hline
\end{tabular}

G. I certify I have adequate knowledge of the waste generating process to characterize

G. this waste and, to the best of my knowledge, the information is accurate.

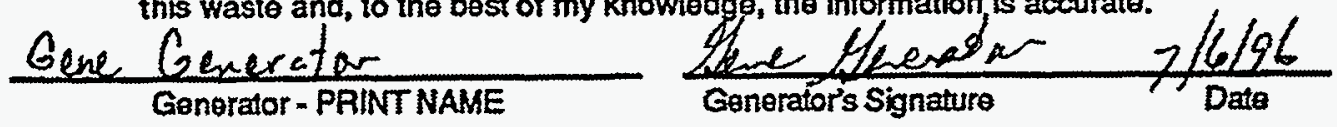

\begin{tabular}{|c|c|c|}
\hline WAST & MANAGEMENT & GROUP USE ONLY \\
\hline $\begin{array}{c}\text { Radiation Dose/Rato @ } \\
\text { Contact }\end{array}$ & mR/hour & Instrument serial \#: \\
\hline
\end{tabular}

Generator's portion of this tag has been reviewed IAW EH\&S Procedure 827, Soc. 8.

EH\&S Tech pertorming survey

Compactable
Requisition No.

Noncompactable 0

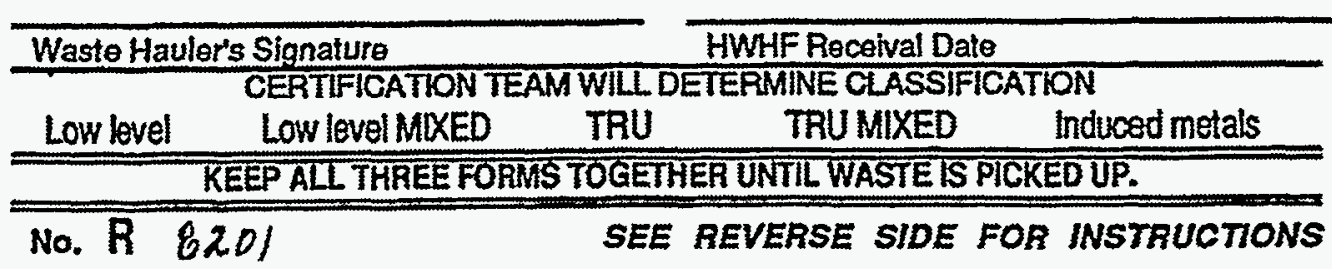

Figure M-4. Radioactive Waste Tag (front) filled out for mixed waste 


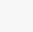




\section{Appendices}

\section{Appendix 1. Additional Information for Berkeley Laboratory Waste Generators}

\section{A. Federal and State of California Toxicity Characteristics}

1. Federal Toxicity Characteristic. If your waste contains any of the following contaminants at or above the regulatory levels listed in the table below, when the waste is extracted (using the standard toxicity characteristic leaching procedure, or TCLP, test), then your waste is hazardous for the toxicity characteristic under federal regulations.

Table A-1. Federal Toxicity Regulatory Levels

\begin{tabular}{lc||lc}
\hline Contaminant & $\begin{array}{c}\text { Regulatory Level } \\
(\mathbf{M g} / \mathrm{L})\end{array}$ & Contaminant & $\begin{array}{c}\text { Regulatory Level } \\
(\mathrm{Mg} / \mathrm{L})\end{array}$ \\
\hline Arsenic & 5.0 & Hexachlorobenzene & 0.13 \\
Barium & 100.0 & Hexachlorobutadiene & 0.5 \\
Benzene & 0.5 & Hexachloroethane & 3.0 \\
Cadmium & 1.0 & Lead & 5.0 \\
Carbon tetrachloride & 0.5 & Lindane & 0.4 \\
Chlordane & 0.03 & Mercury & 0.2 \\
Chlorobenzene & 100.0 & Methoxychlor & 10.0 \\
Chloroform & 6.0 & Methyl ethyl ketone & 200.0 \\
Chromium & 5.0 & Nitrobenzene & 2.0 \\
o-Cresol & 200.0 & Pentachlorophenol & 100.0 \\
m-Cresol & 200.0 & Pyridine & 5.0 \\
p-Cresol & 200.0 & Selenium & 1.0 \\
Cresol & 200.0 & Silver & 5.0 \\
2,4-D & 10.0 & Tetrachloroethylene & 0.7 \\
1,4-Dichlorobenzene & 7.5 & Toxaphene & 0.5 \\
1,2-Dichloroethane & 0.5 & Trichloroethylene & 0.5 \\
1,1-Dichlorethylene & 0.7 & 2,4,5-Trichlorophenol & 400.0 \\
2.4-Dinitrotoluene & 0.13 & 2,4,6-Trichlorophenol & 2.0 \\
Endrin & 0.02 & 2,4,5-TP (Silvex) & 1.0 \\
Heptachlor (and its epoxide) & 0.008 & Vinyl Chloride & 0.2 \\
\hline
\end{tabular}




\section{State of California Toxicity Characteristic}

A material that has any of the following properties exhibits the California toxicity characteristic.

- An acute oral LD50 less than $500 \mathrm{mg} / \mathrm{kg}$

- An acute dermal LD50 less than $4300 \mathrm{mg} / \mathrm{kg}$

- An acute inhalation LD50 less than 10,000 ppm

- An accute aquatic 96 -hour $\mathrm{LC}_{50}$ less than $500 \mathrm{mg} / \mathrm{L}$

- Contains any of the Table A-2 substances exceeding $0.001 \%$ by weight

- Poses a hazard because of its carcinogenicity, acute toxicity, chronic toxicity, bioaccumulative properties, or persistence inthe environment

- Is a federal listed waste

- $\quad$ Exceeds the soluble threshold limit concentration (STLC) or total threshold limit concentration (TTLC) given in Table A-3.

Table A-2

California Toxicity Characteristic Waste Exceeding 0.001\% (Weight)

\begin{tabular}{ll}
\hline 2-acetylaminofluorene & 4-dimethylaminoazobenzene \\
acrylonitrile & ethyleneimine \\
4-aminodiphenyl & alpha-naphthylamine \\
benzidine and its salts & beta-naphthylamine \\
bis(chloromethyl)ether & 4-nitrobiphenyl \\
methyl chloromethyl ether & $\mathrm{N}$-nitrosodimethylamine \\
1,2-dibromo-3-chloropropane & beta-propiolactone \\
$3,3^{\prime}$-dichlorobenzidine and its salts & vinyl chloride \\
\hline
\end{tabular}


Table A-3

California Toxicity Characteristic Waste

Persistent and Bioaccumulative Toxic Substances

\begin{tabular}{|c|c|c|}
\hline & $\begin{array}{c}\text { STLC } \\
\text { mg/liter }\end{array}$ & $\begin{array}{l}\text { TTLC } \\
\mathrm{mg} / \mathrm{kg}\end{array}$ \\
\hline antimony and/or antimony compounds & 15 & 500 \\
\hline arsenic and/or arsenic compounds & 5.0 & 500 \\
\hline asbestos & & $1.0 \%$ \\
\hline barium and/or barium compounds ${ }^{*}$ & 100 & 10,000 \\
\hline beryllium and/or beryllium compounds & 0.75 & 75 \\
\hline cadmium and/or cadmium compounds & 1.0 & 1000 \\
\hline chromium (VI) compounds & 5 & 500 \\
\hline chromium (III) and / or Cr+++ compounds & 560 & 2,500 \\
\hline cobalt and/or cobalt compounds & 80 & 8,000 \\
\hline copper and/or copper compounds & 25 & 2,500 \\
\hline fluoride salts & 180 & 18,000 \\
\hline lead and/or lead compounds & 5.0 & 1,000 \\
\hline lead compounds, organic & & 13 \\
\hline mercury and/or mercury compounds & 0.2 & 20 \\
\hline molybdenum and/or molybdenum compounds & 350 & 3,500 \\
\hline nickel and/or nickel compounds & 20 & 2,000 \\
\hline pentachlorophenol & 1.7 & 17 \\
\hline selenium and or/selenium compounds & 1.0 & 100 \\
\hline silver and / or silver compounds & 5 & 500 \\
\hline thallium and/or thallium compounds & 7.0 & 700 \\
\hline trichloroethylene & 204 & 2040 \\
\hline vanadium and/or vanadium compounds & 24 & 2,400 \\
\hline zinc and /or zinc compounds & 250 & 5,000 \\
\hline polychlorinated biphenyls & 5.0 & 50 \\
\hline nunerous organic perticides & & \\
\hline
\end{tabular}

*Excluding some barium compounds (i.e., barite and solid barium sulfate). 


\section{B. Listed Hazardous Chemicals}

Listed waste is considered hazardous regardless of the concentration of hazardous constituents in each batch.

Listed waste is legally hazardous unless it is "delisted" through a lengthy administrative procedure, as opposed to characteristic waste, which remains hazardous only as long as it is exhibits the characteristics for which it was listed.

A material is a listed waste if it is listed in any of the following:

- Hazardous waste from nonspecific sources (if wastes included in Table B-1)

- Hazardous waste from specific sources (K wastes)

- Acutely toxic wastes ( $P$ wastes included in Table B-2)

- Toxic wastes (U wastes included in Table B-3).

\section{Definition of P-Listed Waste (from 40 CFR Section 261.33)}

(d) Any residue or contaminated soil, water or other debris resulting from the cleanup of a spill into or on any land or water of any commercial chemical product or manufacturing chemical intermediate having the generic name listed in paragraph (e) or (f) of this section [Sec. 261.33], or any residue or contaminated soil, water, or other debris resulting from the cleanup of a spill, into or on any land or water, of any off-specification chemical product and manufacturing chemical intermediate which, if it met specifications, would have the generic name listed in paragraph (e) or (f) of this section.

(e) The commercial chemical products, manufacturing chemical intermediates or off-specification commercial chemical products or manufacturing chemical intermediates referred to in paragraphs (a) through (d) of this section, are identified as acute hazardous wastes $(\mathrm{H})$ and are subject to be the small quantity exclusion defined in 261.5(e).

\section{Definition of U-listed Waste (from 40 CFR Section 261.33)}

(f) The commercial chemical products, manfacturing chemical intermediates, or off-specification commercial chemical products referred to in paragraphs (a) through (d) of this section, are identified as toxic wastes $(T)$, unless otherwise designated and are subject to the small quantity generator exclusion defined in 261.5 (a) and (g). 
Table B-1. Federal Listed Hazardous Waste*

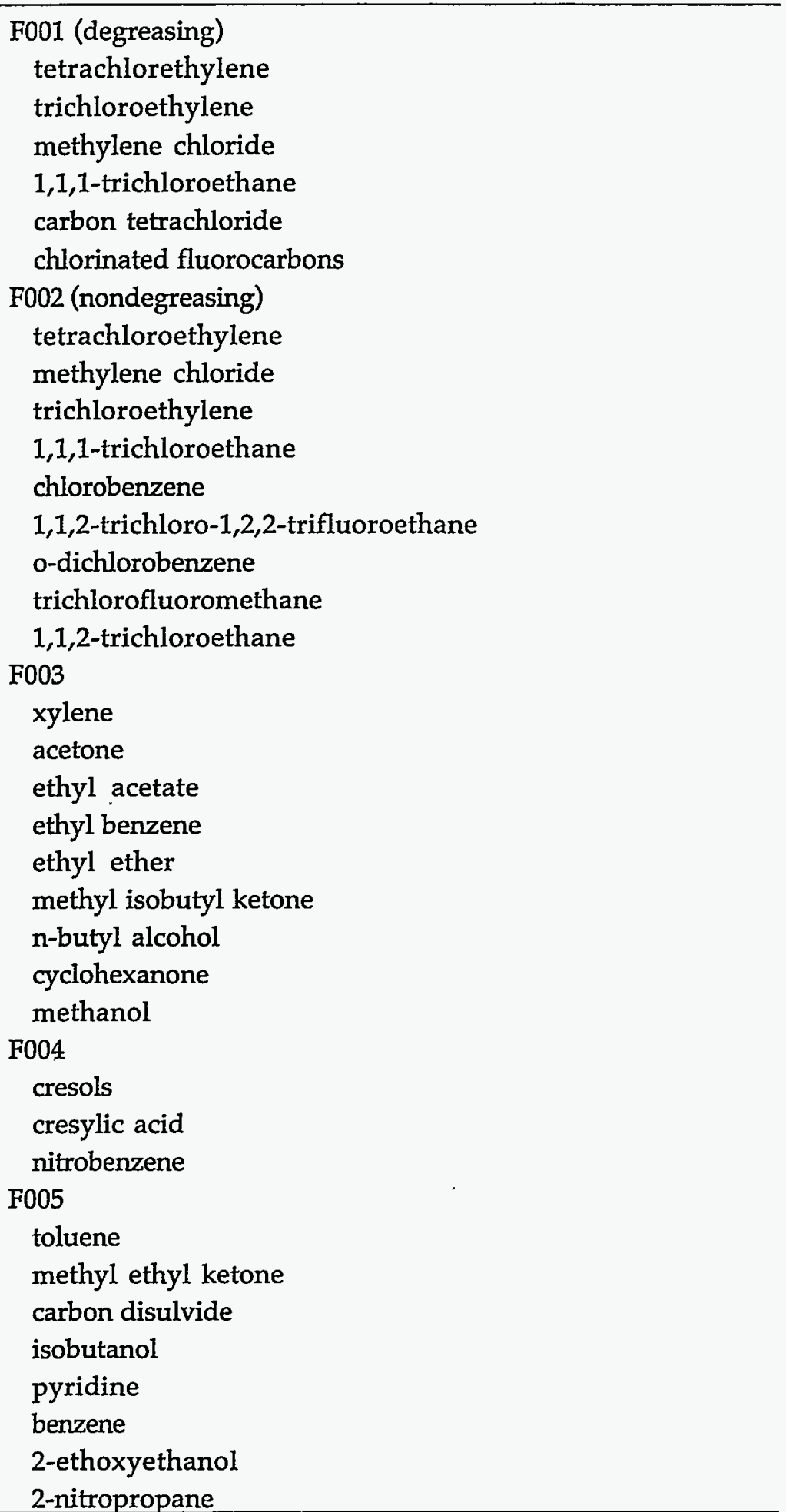

*This summary does not include listed waste from specific sources or industrial processes. 
Table B-2. P-Listed Wastes

\begin{tabular}{|c|c|}
\hline $\begin{array}{l}\text { Hazardous } \\
\text { Waste No. }\end{array}$ & Substance \\
\hline P023 & Acetaldehyde, chloro- \\
\hline $\mathrm{P} 002$ & Acetamide, N-(aminothioxomethyl)- \\
\hline P057 & Acetamide, 2-fluoro- \\
\hline P058 & Acetic acid, fluoro-, sodium salt \\
\hline P002 & 1-Acetyl-2-thiourea \\
\hline P003 & Acrolein \\
\hline P070 & Aldicarb \\
\hline P203 & Aldicarb sulfone. \\
\hline P004 & Aldrin \\
\hline P005 & Allyl alcohol \\
\hline P006 & Aluminum phosphide $(R, T)$ \\
\hline P007 & 5-(Aminomethyl)-3-isoxazolol \\
\hline P008 & 4-Aminopyridine \\
\hline P009 & Ammonium picrate $(R)$ \\
\hline P119 & Ammonium vanadate \\
\hline P099 & Argentate(1-), bis(cyano-C)-, potassium \\
\hline P010 & Arsenic acid $\mathrm{H}_{3} \mathrm{AsO}_{4}$ \\
\hline $\mathrm{P} 012$ & Arsenic oxide $\mathrm{As}_{2} \mathrm{O}_{3}$ \\
\hline P011 & Arsenic oxide $\mathrm{As}_{2} \mathrm{O}_{5}$ \\
\hline P011 & Arsenic pentoxide \\
\hline $\mathrm{P} 012$ & Arsenic trioxide \\
\hline P038 & Arsine, diethyl- \\
\hline P036 & Arsonous dichloride, phenyl- \\
\hline P054 & Aziridine \\
\hline P067 & Aziridine, 2-methyl- \\
\hline P013 & Barium cyanide \\
\hline P024 & Benzenamine, 4-chloro- \\
\hline P077 & Benzenamine, 4-nitro- \\
\hline P028 & Benzene, (chloromethyl)- \\
\hline P042 & 1,2-Benzenediol, 4-[1-hydroxy-2-(methylamino)ethyl]-, (R)- \\
\hline P046 & Benzeneethanamine, alpha,alpha-dimethyl- \\
\hline P014 & Benzenethiol \\
\hline P127 & 7-Benzofuranol, 2,3-dihydro-2,2-dimethyl-, methylcarbamate. \\
\hline P188 & $\begin{array}{l}\text { Benzoic acid, 2-hydroxy-, compd. with (3aS-cis)- 1,2,3,3a,8,8a-hexahydro-1,3a,8- } \\
\text { trimethylpyrrolo [2,3-b]indol-5-yl methylcarbamate ester (1:1). }\end{array}$ \\
\hline P001 & $\begin{array}{l}\text { 2H-1-Benzopyran-2-one, 4-hydroxy-3-(3-oxo-1- phenylbutyl)-, \& salts, when present at } \\
\text { concentrations greater than } 0.3 \%\end{array}$ \\
\hline P028 & Benzyl chloride \\
\hline P015 & Beryllium powder \\
\hline
\end{tabular}


Table B-2. P-Listed Wastes (continued)

\begin{tabular}{|c|c|}
\hline $\begin{array}{l}\text { Hazardous } \\
\text { Waste No. }\end{array}$ & Substance \\
\hline P017 & Bromoacetone \\
\hline P018 & Brucine \\
\hline P045 & 2-Butanone, 3,3-dimethyl-1-(methylthio)-, O-[methylamino)carbonyl] oxime \\
\hline P021 & Calcium cyanide $\mathrm{Ca}(\mathrm{CN})_{2}$ \\
\hline P189 & $\begin{array}{l}\text { Carbamic acid, [(dibutylamino)- thio]methyl-, 2,3-dihydro-2,2-dimethyl- 7- } \\
\text { benzofuranyl ester }\end{array}$ \\
\hline P191 & $\begin{array}{l}\text { Carbamic acid, dimethyl-, 1-[(dimethyl-amino) carbonyl]- 5-methyl-1H- pyrazol-3-yl } \\
\text { ester }\end{array}$ \\
\hline P127 & Carbofuran \\
\hline P022 & Carbon disulfide \\
\hline P095 & Carbonic dichloride \\
\hline P189 & Carbosulfan \\
\hline $\mathrm{P} 023$ & Chloroacetaldehyde \\
\hline P024 & p-Chloroaniline \\
\hline P026 & 1-(o-Chlorophenyl)thiourea \\
\hline P027 & 3-Chloropropionitrile \\
\hline P029 & Copper cyanide \\
\hline P029 & Copper cyanide $\mathrm{Cu}(\mathrm{CN})$ \\
\hline P202 & m-Cumenyl methylcarbamate. \\
\hline P030 & Cyanides (soluble cyanide salts), not otherwise specified \\
\hline P031 & Cyanogen \\
\hline P033 & Cyanogen chloride \\
\hline P033 & Cyanogen chloride $(\mathrm{CN}) \mathrm{Cl}$ \\
\hline P034 & 2-Cyclohexyl-4,6-dinitrophenol \\
\hline P016 & Dichloromethyl ether \\
\hline P036 & Dichlorophenylarsine \\
\hline P037 & Dieldrin \\
\hline P038 & Diethylarsine \\
\hline P041 & Diethyl-p-nitrophenyl phosphate \\
\hline $\mathrm{P} 040$ & O,O-Diethyl O-pyrazinyl phosphorothioate \\
\hline P043 & Diisopropylfluorophosphate (DFP) \\
\hline P004 & $\begin{array}{l}\text { 1,4,5,8-Dimethanonaphthalene, 1,2,3,4,10,10-hexa- chloro-1,4,4a,5,8,8a,-hexahydro-, } \\
\text { (1alpha,4alpha, 4abeta,5alpha,8alpha,8abeta)- }\end{array}$ \\
\hline P060 & $\begin{array}{l}\text { 1,4,5,8-Dimethanonaphthalene, 1,2,3,4,10,10-hexa- chloro-1,4,4a,5,8,8a-hexahydro-, } \\
\text { (1alpha,4alpha, 4abeta,5beta,8beta,8abeta)- }\end{array}$ \\
\hline P037 & $\begin{array}{l}\text { 2,7:3,6-Dimethanonaphth[2,3-b]oxirene, 3,4,5,6,9,9- hexachloro-1a,2,2a,3,6,6a,7,7a- } \\
\text { octahydro-, (1aalpha,2beta,2aalpha,3beta,6beta,6aalpha,7beta, 7aalpha)- }\end{array}$ \\
\hline P051 & $\begin{array}{l}\text { 2,7:3,6-Dimethanonaphth }[2,3-\mathrm{b}] \text { oxirene, } 3,4,5,6,9,9 \text {-hexachloro-1a,2,2a,3,6,6a,7,7a- } \\
\text { octahydro-, (1aalpha,2beta,2abeta,3alpha,6alpha,6abeta,7beta, 7aalpha)-, \& } \\
\text { metabolites }\end{array}$ \\
\hline P044 & Dimethoate \\
\hline
\end{tabular}


Table B-2. P-Listed Wastes (continued)

\begin{tabular}{|c|c|}
\hline $\begin{array}{l}\text { Hazardous } \\
\text { Waste No. }\end{array}$ & Substance \\
\hline P046 & alpha, alpha-Dimethylphenethylamine \\
\hline P191 & Dimetilan. \\
\hline P047 & 4,6-Dinitro-o-cresol, \& salts \\
\hline P048 & 2,4-Dinitrophenol \\
\hline P020 & Dinoseb \\
\hline P185 & 1,3-Dithiolane-2-carboxaldehyde, 2,4-dimethyl-, O- [(methylamino)- carbonyl]oxime. \\
\hline P085 & Diphosphoramide, octamethyl- \\
\hline P111 & Diphosphoric acid, tetraethyl ester \\
\hline P039 & Disulfoton \\
\hline P049 & Dithiobiuret \\
\hline P050 & Endosulfan \\
\hline P088 & Endothall \\
\hline P051 & Endrin \\
\hline P051 & Endrin, \& metabolites \\
\hline P192 & Carbamic acid, dimethyl-, 3-methyl-1- (1-methylethyl)- 1H-pyrazol-5-yl ester. \\
\hline P190 & Carbamic acid, methyl-, 3-methylphenyl ester. \\
\hline P042 & Epinephrine \\
\hline P031 & Ethanedinitrile \\
\hline P194 & $\begin{array}{l}\text { Ethanimidothioc acid, 2-(dimethylamino)-N- [I(methylamino)carbonyl]oxy]-2-oxo-, } \\
\text { methyl ester. }\end{array}$ \\
\hline P066 & Ethanimidothioic acid, N-[[(methylamino)carbonyl]oxy]-, methyl ester \\
\hline P101 & Ethyl cyanide \\
\hline P054 & Ethyleneimine \\
\hline P097 & Famphur \\
\hline P056 & Fluorine \\
\hline P057 & Fluoroacetamide \\
\hline P058 & Fluoroacetic acid, sodium salt \\
\hline P198 & Formetanate hydrochloride. \\
\hline P197 & Formparanate \\
\hline P065 & Fulminic acid, mercury $(2+)$ salt $(R, T)$ \\
\hline P059 & Heptachlor \\
\hline P062 & Hexaethyl tetraphosphate \\
\hline P116 & Hydrazinecarbothioamide \\
\hline P068 & Hydrazine, methyl- \\
\hline P063 & Hydrocyanic acid \\
\hline P063 & Hydrogen cyanide \\
\hline P096 & Hydrogen phosphide \\
\hline P060 & Isodrin \\
\hline P192 & Isolan \\
\hline
\end{tabular}


Table B-2. P-Listed Wastes (continued)

\begin{tabular}{|c|c|}
\hline $\begin{array}{l}\text { Hazardous } \\
\text { Waste No. }\end{array}$ & Substance \\
\hline P202 & 3-Isopropylphenyl $\mathrm{N}$-methylcarbamate. \\
\hline $\mathrm{P} 007$ & $3(2 \mathrm{H})$-Isoxazolone, 5 -(aminomethyl)- \\
\hline P196 & Manganese, bis(dimethylcarbamodithioato-S,S')-, \\
\hline P196 & Manganese dimethyldithiocarbamate. \\
\hline P092 & Mercury, (acetato-O)phenyl- \\
\hline P065 & Mercury fulminate $(\mathrm{R}, \mathrm{T})$ \\
\hline P082 & Methanamine, N-methyl-N-nitroso- \\
\hline P064 & Methane, isocyanato- \\
\hline P016 & Methane, oxybis[chloro- \\
\hline P112 & Methane, tetranitro- $(R)$ \\
\hline P118 & Methanethiol, trichloro- \\
\hline P198 & $\begin{array}{l}\text { Methanimidamide, N,N-dimethyl-N'-[2-methyl-4- [I(methylamino) } \\
\text { carbonyl]oxy]phenyl]- }\end{array}$ \\
\hline P050 & $\begin{array}{l}\text { 6,9-Methano-2,4,3-benzodioxathiepin, 6,7,8,9,10,10- hexachloro-1,5,5a,6,9,9a- } \\
\text { hexahydro-, 3-oxide }\end{array}$ \\
\hline P059 & 4,7-Methano-1H-indene, 1,4,5,6,7,8,8-heptachloro- 3a,4,7,7a-tetrahydro- \\
\hline P199 & Methiocarb \\
\hline P190 & Metolcarb \\
\hline P066 & Methomyl \\
\hline P068 & Methyl hydrazine \\
\hline P064 & Methyl isocyanate \\
\hline P069 & 2-Methyllactonitrile \\
\hline P071 & Methyl parathion \\
\hline P128 & Mexacarbate \\
\hline P072 & alpha-Naphthylthiourea \\
\hline P073 & Nickel carbonyl \\
\hline P073 & Nickel carbonyl $\mathrm{Ni}(\mathrm{CO}) 4,(\mathrm{~T}-4)-$ \\
\hline P074 & Nickel cyanide \\
\hline P074 & Nickel cynaide $\mathrm{Ni}(\mathrm{CN}) 2$ \\
\hline P075 & Nicotine, \& salts \\
\hline P076 & Nitric oxide \\
\hline P077 & p-Nitroaniline \\
\hline P078 & Nitrogen dioxide \\
\hline P076 & Nitrogen oxide NO \\
\hline P078 & Nitrogen oxide NO2 \\
\hline P081 & Nitroglycerine (R) \\
\hline P082 & N-Nitrosodimethylamine \\
\hline P084 & N-Nitrosomethylvinylamine \\
\hline P085 & Octamethylpyrophosphoramide \\
\hline P087 & Osmium oxide $\mathrm{OsO}_{4},(\mathrm{~T}-4)-$ \\
\hline
\end{tabular}


Table B-2. P-Listed Wastes (continued)

\begin{tabular}{|c|c|}
\hline $\begin{array}{l}\text { Hazardous } \\
\text { Waste No. }\end{array}$ & Substance \\
\hline P087 & Osmium tetroxide \\
\hline P088 & 7-Oxabicyclo[2.2.1]heptane-2,3-dicarboxylic acid \\
\hline P194 & Oxamyl \\
\hline P089 & Parathion \\
\hline P034 & Phenol, 2-cyclohexyl-4,6-dinitro- \\
\hline P128 & Phenol, 4-(dimethylamino)-3,5-dimethyl-, methylcarbamate (ester). \\
\hline P199 & Phenol, (3,5-dimethyl-4-(methylthio)-, methylcarbamate \\
\hline P048 & Phenol, 2,4-dinitro- \\
\hline P047 & Phenol, 2-methyl-4,6-dinitro-, \& salts \\
\hline P202 & Phenol, 3-(1-methylethyl)-, methyl carbamate. \\
\hline P201 & Phenol, 3-methyl-5-(1-methylethyl)-, methyl carbamate. \\
\hline P020 & Phenol, 2-(1-methylpropyl)-4,6-dinitro- \\
\hline P009 & Phenol, 2,4,6-trinitro-, ammonium salt ( $\mathrm{R})$ \\
\hline P092 & Phenylmercury acetate \\
\hline P093 & Phenylthiourea \\
\hline P094 & Phorate \\
\hline P095 & Phosgene \\
\hline P096 & Phosphine \\
\hline P041 & Phosphoric acid, diethyl 4-nitrophenyl ester \\
\hline P039 & Phosphorodithioic acid, O,O-diethyl S-[2-(ethylthio)ethyl] ester \\
\hline P094 & Phosphorodithioic acid, O,O-diethyl S-[(ethylthio)methyl] ester \\
\hline P044 & Phosphorodithioic acid, O,O-dimethyl S-[2- (methylamino)-2-oxoethyl] ester \\
\hline P043 & Phosphorofluoridic acid, bis(1-methylethyl) ester \\
\hline P089 & Phosphorothioic acid, O,O-diethyl O-(4-nitrophenyl) ester \\
\hline P040 & Phosphorothioic acid, O,O-diethyl O-pyrazinyl ester 3 \\
\hline P097 & Phosphorothioic acid, O-[4-[(dimethylamino)sulfonyl]phenyl] O,O-dimethyl ester \\
\hline P071 & Phosphorothioic acid, O,O,-dimethyl O-(4- nitrophenyl) ester \\
\hline P204 & Physostigmine. \\
\hline P188 & Physostigmine salicylate. \\
\hline P110 & Plumbane, tetraethyl- \\
\hline P098 & Potassium cyanide \\
\hline P098 & Potassium cyanide $\mathrm{K}(\mathrm{CN})$ \\
\hline P099 & Potassium silver cyanide \\
\hline P201 & Promecarb \\
\hline P203 & Propanal, 2-methyl-2-(methyl-sulfonyl)-, O-[(methylamino)carbonyl] oxime. \\
\hline P070 & Propanal, 2-methyl-2-(methylthio)-, O-[(methylamino)carbonyl]oxime \\
\hline P101 & Propanenitrile \\
\hline P027 & Propanenitrile, 3-chloro- \\
\hline P069 & Propanenitrile, 2-hydroxy-2-methyl- \\
\hline
\end{tabular}


Table B-2. P-Listed Wastes (continued)

\begin{tabular}{|c|c|}
\hline $\begin{array}{l}\text { Hazardous } \\
\text { Waste No. }\end{array}$ & Substance \\
\hline P081 & 1,2,3-Propanetriol, trinitrate ( $R$ ) \\
\hline P017 & 2-Propanone, 1-bromo- \\
\hline P102 & Propargyl alcohol \\
\hline P003 & 2-Propenal \\
\hline P005 & 2-Propen-1-ol \\
\hline P067 & 1,2-Propylenimine \\
\hline P102 & 2-Propyn-1-ol \\
\hline P008 & 4-Pyridinamine \\
\hline P075 & Pyridine, 3-(1-methyl-2-pyrrolidinyl)-, (S)-, \& salts \\
\hline P204 & $\begin{array}{l}\text { Pyrrolo[2,3-b]indol-5-ol, 1,2,3,3a,8,8a-hexahydro- 1,3a,8-trimethyl-, methylcarbamate } \\
\text { (ester), (3aS-cis)-. }\end{array}$ \\
\hline P114 & Selenious acid, dithallium $(1+)$ salt \\
\hline P103 & Selenourea \\
\hline P104 & Silver cyanide \\
\hline P104 & Silver cyanide $\mathrm{Ag}(\mathrm{CN})$ \\
\hline P105 & Sodium azide \\
\hline P106 & Sodium cyanide \\
\hline P106 & Sodium cyanide $\mathrm{Na}(\mathrm{CN})$ \\
\hline P108 & Strychnidin-10-one, \& salts \\
\hline P018 & Strychnidin-10-one, 2,3-dimethoxy- \\
\hline P108 & Strychnine, \& salts \\
\hline P115 & Sulfuric acid, dithallium $(1+)$ salt \\
\hline P109 & Tetraethyldithiopyrophosphate \\
\hline P110 & Tetraethyl lead \\
\hline P111 & Tetraethyl pyrophosphate \\
\hline P112 & Tetranitromethane $(\mathrm{R})$ \\
\hline P062 & Tetraphosphoric acid, hexaethyl ester \\
\hline P113 & Thallic oxide \\
\hline P113 & Thallium oxide $\mathrm{Tl}_{2} \mathrm{O}_{3}$ \\
\hline P114 & Thallium(I) selenite \\
\hline P115 & Thallium(I) sulfate \\
\hline P109 & Thiodiphosphoric acid, tetraethyl ester \\
\hline P045 & Thiofanox \\
\hline P049 & Thioimidodicarbonic diamide $\left[\left(\mathrm{H}_{2} \mathrm{~N}\right) \mathrm{C}(\mathrm{S})\right]_{2} \mathrm{NH}$ \\
\hline P014 & Thiophenol \\
\hline P116 & Thiosemicarbazide \\
\hline P026 & Thiourea, (2-chlorophenyl)- \\
\hline P072 & Thiourea, 1-naphthalenyl- \\
\hline P093 & Thiourea, phenyl- \\
\hline
\end{tabular}


Table B-2. P-Listed Wastes (continued)

\begin{tabular}{ll}
\hline $\begin{array}{l}\text { Hazardous } \\
\text { Waste No. }\end{array}$ & \multicolumn{1}{c}{ Substance } \\
\hline P185 & Tirpate. \\
P123 & Toxaphene \\
P118 & Trichloromethanethiol \\
P119 & Vanadic acid, ammonium salt \\
P120 & Vanadium oxide $\mathrm{V}_{2} \mathrm{O}_{5}$ \\
P120 & Vanadium pentoxide \\
P084 & Vinylamine, N-methyl-N-nitroso- \\
P001 & Warfarin, \& salts, when present at concentrations greater than $0.3 \%$ \\
P205 & Zinc, bis(dimethylcarbamodithioato-S,S')-, \\
P121 & Zinc cyanide \\
P121 & Zinc cyanide Zn(CN) 2 \\
P122 & Zinc phosphide $Z \mathrm{Zn}_{3} \mathrm{P}_{2}$, when present at concentrations greater than $10 \%(\mathrm{R}, \mathrm{T})$ \\
P205 & Ziram. \\
\hline
\end{tabular}


Table B-3. U-Listed Wastes

\begin{tabular}{|c|c|}
\hline $\begin{array}{l}\text { Hazardous } \\
\text { Waste No. }\end{array}$ & Substance \\
\hline U394 & A2213. \\
\hline U001 & Acetaldehyde (I) \\
\hline U034 & Acetaldehyde, trichloro- \\
\hline U187 & Acetamide, N-(4-ethoxyphenyl)- \\
\hline U005 & Acetamide, N-9H-fluoren-2-yl- \\
\hline U240 & Acetic acid, (2,4-dichlorophenoxy)-, salts \& esters 3 \\
\hline U112 & Acetic acid ethyl ester (I) \\
\hline U144 & Acetic acid, lead(2t) salt \\
\hline U214 & Acetic acid, thallium $(1+)$ salt \\
\hline see F027 & Acetic acid, (2,4,5-trichlorophenoxy)- 3 \\
\hline U002 & Acetone (I) \\
\hline U003 & Acetonitrile (I,T) \\
\hline U004 & Acetophenone \\
\hline U005 & 2-Acetylaminofluorene \\
\hline U006 & Acetyl chloride $(C, R, T)$ \\
\hline U007 & Acrylamide \\
\hline U008 & Acrylic acid (I) \\
\hline U009 & Acrylonitrile \\
\hline U011 & Amitrole \\
\hline U012 & Aniline (I,T) \\
\hline U136 & Arsinic acid, dimethyl- \\
\hline U014 & Auramine \\
\hline U015 & Azaserine \\
\hline U365 & H-Azepine-1-carbothioic acid, hexahydro-, S-ethyl ester. \\
\hline U010 & $\begin{array}{l}\text { Azirino[2',3':3,4]pyrrolo[1,2-a]indole-4,7-dione, } 6 \text {-amino-8- } \\
\text { [[(aminocarbonyl)oxy]methyl]-1,1a,2,8,8a, 8b-hexahydro-8a-methoxy-5-methyl-, } \\
\text { [1aS-(1aalpha, 8beta,8aalpha,8balpha)]- }\end{array}$ \\
\hline U280 & Barban. \\
\hline U278 & Bendiocarb. \\
\hline U364 & Bendiocarb phenol. \\
\hline U271 & Benomyl. \\
\hline U157 & Benz[j]aceanthrylene, 1,2-dihydro-3-methyl- \\
\hline U016 & Benz[c]acridine \\
\hline U017 & Benzal chloride \\
\hline U192 & Benzamide, 3,5-dichloro-N-(1,1-dimethyl-2-propynyl) - \\
\hline U018 & Benz[a]anthracene \\
\hline U094 & Benz[a]anthracene, 7,12-dimethyl- \\
\hline U012 & Benzenamine $(I, T)$ \\
\hline U014 & Benzenamine, 4,4'-carbonimidoylbis[N,N-dimethyl- \\
\hline U049 & Benzenamine, 4-chloro-2-methyl-, hydrochloride \\
\hline
\end{tabular}


Table B-3. U-Listed Wastes (continued)

\begin{tabular}{|c|c|}
\hline $\begin{array}{l}\text { Hazardous } \\
\text { Waste No. }\end{array}$ & Substance \\
\hline U093 & Benzenamine, N,N-dimethyl-4-(phenylazo)- \\
\hline U328 & Benzenamine, 2-methyl- \\
\hline U353 & Benzenamine, 4-methyl- \\
\hline U158 & Benzenamine, 4,4'-methylenebis[2-chloro- \\
\hline U222 & Benzenamine, 2-methyl-, hydrochloride \\
\hline U181 & Benzenamine, 2-methyl-5-nitro- \\
\hline U019 & Benzene $(I, T)$ \\
\hline U038 & Benzeneacetic acid, 4-chloro-alpha-(4-chlorophenyl) -alpha-hydroxy-, ethyl ester \\
\hline U030 & Benzene, 1-bromo-4-phenoxy- \\
\hline U035 & Benzenebutanoic acid, 4-[bis(2-chloroethyl)amino]- \\
\hline U037 & Benzene, chloro- \\
\hline U221 & Benzenediamine, ar-methyl- \\
\hline U028 & 1,2-Benzenedicarboxylic acid, bis(2-ethylhexyl) ester \\
\hline U069 & 1,2-Benzenedicarboxylic acid, dibutyl ester \\
\hline U088 & 1,2-Benzenedicarboxylic acid, diethyl ester \\
\hline U102 & 1,2-Benzenedicarboxylic acid, dimethyl ester \\
\hline U107 & 1,2-Benzenedicarboxylic acid, dioctyl ester \\
\hline U070 & Benzene, 1,2-dichloro- \\
\hline U071 & Benzene, 1,3-dichloro- \\
\hline U072 & Benzene, 1,4-dichloro- \\
\hline U060 & Benzene, 1,1'-(2,2-dichloroethylidene)bis[4-chloro- \\
\hline U017 & Benzene, (dichloromethyl)- \\
\hline $\mathrm{U} 223$ & Benzene, 1,3-diisocyanatomethyl- $(R, T)$ \\
\hline U239 & Benzene, dimethyl- $(\mathrm{I}, \mathrm{T})$ \\
\hline U201 & 1,3-Benzenediol \\
\hline U127 & Benzene, hexachloro- \\
\hline U056 & Benzene, hexahydro- (I) \\
\hline U220 & Benzene, methyl- \\
\hline U105 & Benzene, 1-methyl-2,4-dinitro- \\
\hline U106 & Benzene, 2-methyl-1,3-dinitro- \\
\hline U055 & Benzene, (1-methylethyl)- (I) \\
\hline U169 & Benzene, nitro- \\
\hline U183 & Benzene, pentachloro- \\
\hline U185 & Benzene, pentachloronitro- \\
\hline U020 & Benzenesulfonic acid chloride $(C, R)$ \\
\hline U020 & Benzenesulfonyl chloride $(C, R)$ \\
\hline U207 & Benzene, 1,2,4,5-tetrachloro- \\
\hline U061 & Benzene, 1,1'-(2,2,2-trichloroethylidene)bis[4- chloro- \\
\hline U247 & Benzene, 1,1'-(2,2,2-trichloroethylidene)bis[4- methoxy- \\
\hline U023 & Benzene, (trichloromethyl)- \\
\hline
\end{tabular}


Table B-3. U-Listed Wastes (continued)

\begin{tabular}{|c|c|}
\hline $\begin{array}{l}\text { Hazardous } \\
\text { Waste No. }\end{array}$ & Substance \\
\hline U234 & Benzene, 1,3,5-trinitro- \\
\hline U021 & Benzidine \\
\hline U202 & 1,2-Benzisothiazol-3(2H)-one, 1,1-dioxide, \& salts \\
\hline U203 & 1,3-Benzodioxole, 5-(2-propenyl)- \\
\hline U141 & 1,3-Benzodioxole, 5-(1-propenyl)- \\
\hline U090 & 1,3-Benzodioxole, 5-propyl- \\
\hline U278 & 1,3-Benzodioxol-4-ol, 2,2-dimethyl-, methyl carbamate. \\
\hline U364 & 1,3-Benzodioxol-4-ol, 2,2-dimethyl-, \\
\hline U367 & 7-Benzofuranol, 2,3-dihydro-2,2-dimethyl- \\
\hline U064 & Benzo[rst]pentaphene \\
\hline U248 & $\begin{array}{l}2 \mathrm{H}-1 \text {-Benzopyran-2-one, } 4 \text {-hydroxy-3-(3-oxo-1-phenyl- butyl)-, \& salts, when present } \\
\text { at concentrations of } 0.3 \% \text { or less }\end{array}$ \\
\hline U022 & Benzo[a]pyrene \\
\hline U197 & p-Benzoquinone \\
\hline U023 & Benzotrichloride $(C, R, T)$ \\
\hline U085 & 2,2'-Bioxirane \\
\hline U021 & {$\left[1,1^{\prime}\right.$-Biphenyl]-4,4'-diamine } \\
\hline U073 & [1,1'-Biphenyl]-4,4'-diamine, 3,3'-dichloro- \\
\hline U091. & [1,1'-Biphenyl]-4,4'-diamine, 3,3'-dimethoxy- \\
\hline U095 & [1,1'-Biphenyl]-4,4'-diamine, 3,3'-dimethyl- \\
\hline U401 & Bis(dimethylthiocarbamoyl) sulfide. \\
\hline U400 & Bis(pentamethylene)thiuram tetrasulfide. \\
\hline U225 & Bromoform \\
\hline U030 & 4-Bromophenyl phenyl ether \\
\hline U128 & 1,3-Butadiene, 1,1,2,3,4,4-hexachloro- \\
\hline U172 & 1-Butanamine, N-butyl-N-nitroso- \\
\hline U031 & 1-Butanol (I) \\
\hline U159 & 2-Butanone $(\mathrm{I}, \mathrm{T})$ \\
\hline $\mathrm{U} 160$ & 2-Butanone, peroxide $(\mathrm{R}, \mathrm{T})$ \\
\hline U053 & 2-Butenal \\
\hline U074 & 2-Butene, 1,4-dichloro- (I,T) \\
\hline U143 & $\begin{array}{l}\text { 2-Butenoic acid, 2-methyl-, 7-[[2,3-dihydroxy- 2-(1-methoxyethyl)-3-methyl-1- } \\
\text { oxobutoxy]methyl]- 2,3,5,7a-tetrahydro-1H-pyrrolizin-1-yl ester, [1S- } \\
\text { [1alpha(Z),7(2S*,3R*),7aalpha]]- }\end{array}$ \\
\hline U031 & n-Butyl alcohol (I) \\
\hline U392 & Butylate. \\
\hline U136 & Cacodylic acid \\
\hline U032 & Calcium chromate \\
\hline U238 & Carbamic acid, ethyl ester \\
\hline U178 & Carbamic acid, methylnitroso-, ethyl ester \\
\hline
\end{tabular}


Table B-3. U-Listed Wastes (continued)

\begin{tabular}{|c|c|}
\hline $\begin{array}{l}\text { Hazardous } \\
\text { Waste No. }\end{array}$ & Substance \\
\hline U372 & Carbamic acid, 1H-benzimidazol-2-yl, methyl ester. \\
\hline U271 & Carbamic acid, [1-[(butylamino)carbonyl]-1H- benzimidazol-2-yl]-, methyl ester. \\
\hline U375 & Carbamic acid, butyl-, 3-iodo-2-propynyl ester. \\
\hline U280 & Carbamic acid, (3-chlorophenyl)-, 4-chloro-2- butynyl ester. \\
\hline U373 & Carbamic acid, phenyl-, 1-methylethyl ester. \\
\hline U409 & Carbamic acid, [1,2-phenylenebis (iminocarbonothioyl)] bis-, dimethyl ester. \\
\hline U097 & Carbamic chloride, dimethyl- \\
\hline U379 & Carbamodithioic acid, dibutyl, sodium salt. \\
\hline U277 & Carbamodithioic acid, diethyl-, 2-chloro-2-propenyl ester. \\
\hline U381 & Carbamodithioic acid, diethyl-, sodium salt. \\
\hline U383 & Carbamodithioic acid, dimethyl, potassium salt. \\
\hline U382 & Carbamodithioic acid, dimethyl-, sodium salt. \\
\hline U376 & Carbamodithioic acid, dimethyl-, tetraanhydrosulfide with orthothioselenious acid. \\
\hline U114 & Carbamodithioic acid, 1,2-ethanediylbis-, salts \& esters \\
\hline U378 & Carbamodithioic acid, (hydroxymethyl)methyl-, monopotassium salt. \\
\hline U384 & Carbamodithioic acid, methyl-, monosodium salt. \\
\hline U377 & Carbamodithioic acid, methyl,- monopotassium salt. \\
\hline U062 & Carbamothioic acid, bis(1-methylethyl)-, S-(2,3- dichloro-2-propenyl) ester \\
\hline U389 & Carbamothioic acid, bis(1-methylethyl)-, S-(2,3,3- trichloro-2-propenyl) ester. \\
\hline U392 & Carbamothioic acid, bis(2-methylpropyl)-, S-ethyl ester. \\
\hline U391 & Carbamothioic acid, butylethyl-, S-propyl ester. \\
\hline U386 & Carbamothioic acid, cyclohexylethyl-, S-ethyl ester. \\
\hline U390 & Carbamothioic acid, dipropyl-, S-ethyl ester. \\
\hline U387 & Carbamothioic acid, dipropyl-, S-(phenylmethyl) ester. \\
\hline U385 & Carbamothioic acid, dipropyl-, S-propyl ester. \\
\hline U279 & Carbaryl. \\
\hline U372 & Carbendazim. \\
\hline U367 & Carbofuran phenol. \\
\hline U215 & Carbonic acid, dithallium(1+) salt \\
\hline U033 & Carbonic difluoride \\
\hline U156 & Carbonochloridic acid, methyl ester (I,T) \\
\hline U033 & Carbon oxyfluoride $(\mathrm{R}, \mathrm{T})$ \\
\hline U211 & Carbon tetrachloride \\
\hline U034 & Chloral \\
\hline U035 & Chlorambucil \\
\hline U036 & Chlordane, alpha \& gamma isomers \\
\hline U026 & Chlornaphazin \\
\hline U037 & Chlorobenzene \\
\hline U038 & Chlorobenzilate \\
\hline U039 & p-Chloro-m-cresol \\
\hline
\end{tabular}


Table B-3. U-Listed Wastes (continued)

\begin{tabular}{|c|c|}
\hline $\begin{array}{l}\text { Hazardous } \\
\text { Waste No. }\end{array}$ & Substance \\
\hline U042 & 2-Chloroethyl vinyl ether \\
\hline U044 & Chloroform \\
\hline U046 & Chloromethyl methyl ether \\
\hline U047 & beta-Chloronaphthalene \\
\hline U048 & o-Chlorophenol \\
\hline U049 & 4-Chloro-o-toluidine, hydrochloride \\
\hline U032 & Chromic acid $\mathrm{H} 2 \mathrm{CrO} 4$, calcium salt \\
\hline U050 & Chrysene \\
\hline U393 & Copper, bis(dimethylcarbamodithioato-S,S')-, \\
\hline U393 & Copper dimethyldithiocarbamate. \\
\hline U051 & Creosote \\
\hline U052 & Cresol (Cresylic acid) \\
\hline U053 & Crotonaldehyde \\
\hline U055 & Cumene (I) \\
\hline U246 & Cyanogen bromide $(\mathrm{CN}) \mathrm{Br}$ \\
\hline U386 & Cycloate. \\
\hline U197 & 2,5-Cyclohexadiene-1,4-dione \\
\hline U056 & Cyclohexane (I) \\
\hline U129 & Cyclohexane, 1,2,3,4,5,6-hexachloro-, (1alpha,2alpha,3beta,4alpha,5alpha,6beta)- \\
\hline U057 & Cyclohexanone (I) \\
\hline U130 & 1,3-Cyclopentadiene, 1,2,3,4,5,5-hexachloro- \\
\hline U058 & Cyclophosphamide \\
\hline $\mathrm{U} 240$ & $2,4-D$, salts \& esters \\
\hline U059 & Daunomycin \\
\hline U366 & Dazomet. \\
\hline U060 & DDD \\
\hline U0̣61 & DDT \\
\hline U062 & Diallate \\
\hline U063 & Dibenz[a,h]anthracene \\
\hline U064 & Dibenzo[a,i]pyrene \\
\hline U066 & 1,2-Dibromo-3-chloropropane \\
\hline U069 & Dibutyl phthalate \\
\hline U070 & o-Dichlorobenzene \\
\hline U071 & m-Dichlorobenzene \\
\hline U072 & p-Dichlorobenzene \\
\hline U073 & 3,3'-Dichlorobenzidine \\
\hline U074 & 1,4-Dichloro-2-butene $(\mathrm{I}, \mathrm{T})$ \\
\hline U075 & Dichlorodifluoromethane \\
\hline U078 & 1,1-Dichloroethylene \\
\hline U079 & 1,2-Dichloroethylene \\
\hline
\end{tabular}


Table B-3. U-Listed Wastes (continued)

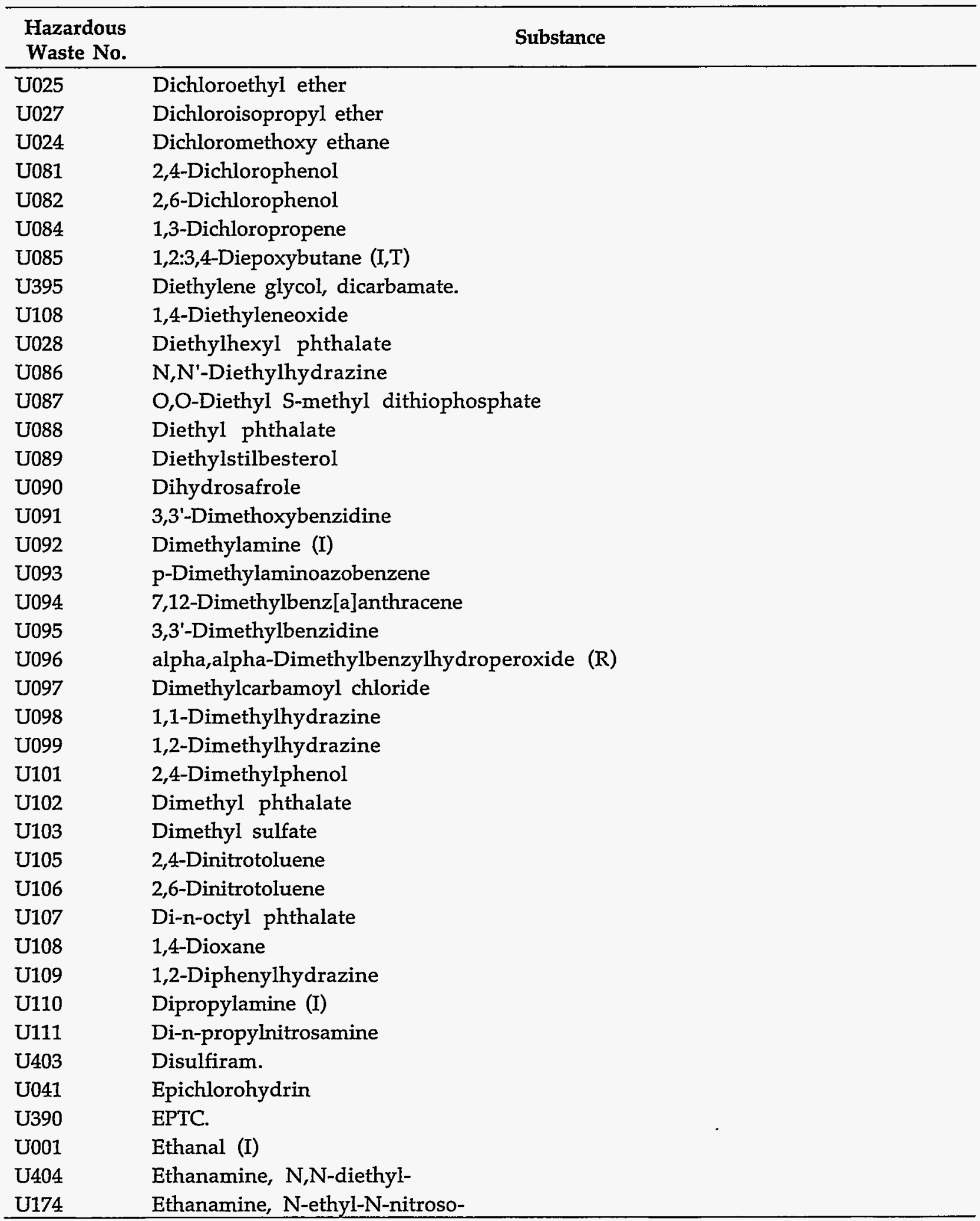


Table B-3. U-Listed Wastes (continued)

\begin{tabular}{|c|c|}
\hline $\begin{array}{l}\text { Hazardous } \\
\text { Waste No. }\end{array}$ & Substance \\
\hline U410 & $\begin{array}{l}\text { Ethanimidothioic acid, N,N'- [thiobis[(methylimino) carbonyloxy]]bis-, dimethyl } \\
\text { ester }\end{array}$ \\
\hline U394 & Ethanimidothioic acid, 2-(dimethylamino)-N-hydroxy-2- oxo-, methyl ester. \\
\hline U155 & 1,2-Ethanediamine, N,N-dimethyl-N'-2-pyridinyl-N'- (2-thienylmethyl)- \\
\hline U067 & Ethane, 1,2-dibromo- \\
\hline U076 & Ethane, 1,1-dichloro- \\
\hline U077 & Ethane, 1,2-dichloro- \\
\hline U131 & Ethane, hexachloro- \\
\hline U024 & Ethane, 1,1'-[methylenebis(oxy)]bis[2-chloro- \\
\hline U117 & Ethane, $1,1^{\prime}$-oxybis-(I) \\
\hline U025 & Ethane, 1,1'-oxybis[2-chloro- \\
\hline U184 & Ethane, pentachloro- \\
\hline U208 & Ethane, 1,1,1,2-tetrachloro- \\
\hline U209 & Ethane, 1,1,2,2-tetrachloro- \\
\hline U218 & Ethanethioamide \\
\hline U226 & Ethane, 1,1,1-trichloro- \\
\hline U227 & Ethane, 1,1,2-trichloro- \\
\hline U359 & Ethanol, 2-ethoxy- \\
\hline U173 & Ethanol, 2,2'-(nitrosoimino)bis- \\
\hline U395 & Ethanol, 2,2'-oxybis-, dicarbamate. \\
\hline U004 & Ethanone, 1-phenyl- \\
\hline U043 & Ethene, chloro- \\
\hline U042 & Ethene, (2-chloroethoxy)- \\
\hline U078 & Ethene, 1,1-dichloro- \\
\hline U079 & Ethene, 1,2-dichloro-, (E)- \\
\hline U210 & Ethene, tetrachloro- \\
\hline U228 & Ethene, trichloro- \\
\hline U112 & Ethyl acetate (I) \\
\hline U113 & Ethyl acrylate (I) \\
\hline U238 & Ethyl carbamate (urethane) \\
\hline U117 & Ethyl ether (I) \\
\hline U407 & Ethyl Ziram. \\
\hline U114 & Ethylenebisdithiocarbamic acid, salts \& esters \\
\hline U067 & Ethylene dibromide \\
\hline U077 & Ethylene dichloride \\
\hline U359 & Ethylene glycol monoethyl ether \\
\hline U115 & Ethylene oxide $(\mathrm{I}, \mathrm{T})$ \\
\hline U116 & Ethylenethiourea \\
\hline U076 & Ethylidene dichloride \\
\hline U118 & Ethyl methacrylate \\
\hline U119 & Ethyl methanesulfonate \\
\hline
\end{tabular}


Table B-3. U-Listed Wastes (continued)

\begin{tabular}{|c|c|}
\hline $\begin{array}{l}\text { Hazardous } \\
\text { Waste No. }\end{array}$ & Substance \\
\hline U396 & Ferbam \\
\hline U120 & Fluoranthene \\
\hline U122 & Formaldehyde \\
\hline U123 & Formic acid $(C, T)$ \\
\hline U124 & Furan (I) \\
\hline U125 & 2-Furancarboxaldehyde (I) \\
\hline U147 & 2,5-Furandione \\
\hline $\mathrm{U} 213$ & Furan, tetrahydro-(I) \\
\hline U125 & Furfural (I) \\
\hline $\mathrm{U} 124$ & Furfuran (I) \\
\hline U206 & Glucopyranose, 2-deoxy-2-(3-methyl-3-nitrosoureido) -, D- \\
\hline U206 & D-Glucose, 2-deoxy-2-[[(methylnitrosoamino)- carbonyl]amino]- \\
\hline U126 & Glycidylaldehyde \\
\hline U163 & Guanidine, N-methyl-N'-nitro-N-nitroso- \\
\hline U127 & Hexachlorobenzene \\
\hline U128 & Hexachlorobutadiene \\
\hline U130 & Hexachlorocyclopentadiene \\
\hline U131 & Hexachloroethane \\
\hline U132 & Hexachlorophene. \\
\hline $\mathrm{U} 243$ & Hexachloropropene \\
\hline U133 & Hydrazine $(R, T)$ \\
\hline U086 & Hydrazine, 1,2-diethyl- \\
\hline U098 & Hydrazine, 1,1-dimethyl- \\
\hline U099 & Hydrazine, 1,2-dimethyl- \\
\hline U109 & Hydrazine, 1,2-diphenyl- \\
\hline U134 & Hydrofluoric acid $(\mathrm{C}, \mathrm{T})$ \\
\hline U134 & Hydrogen fluoride $(C, T)$ \\
\hline U135 & Hydrogen sulfide \\
\hline U135 & Hydrogen sulfide $\mathrm{H} 2 \mathrm{~S}$ \\
\hline U096 & Hydroperoxide, 1-methyl-1-phenylethyl- (R) \\
\hline U116 & 2-Imidazolidinethione \\
\hline U137 & Indeno[1,2,3-cd]pyrene \\
\hline U375 & 3-Iodo-2-propynyl n-butylcarbamate. \\
\hline U396 & Iron, tris(dimethylcarbamodithioato-S,S')-, \\
\hline U190 & 1,3-Isobenzofurandione \\
\hline U140 & Isobutyl alcohol $(\mathrm{I}, \mathrm{T})$ \\
\hline $\mathrm{U} 141$ & Isosafrole \\
\hline $\mathrm{U} 142$ & Kepone \\
\hline U143 & Lasiocarpine \\
\hline U144 & Lead acetate \\
\hline
\end{tabular}


Table B-3. U-Listed Wastes (continued)

\begin{tabular}{|c|c|}
\hline $\begin{array}{l}\text { Hazardous } \\
\text { Waste No. }\end{array}$ & Substance \\
\hline U146 & Lead, bis(acetato-O)tetrahydroxytri- \\
\hline U145 & Lead phosphate \\
\hline U146 & Lead subacetate \\
\hline U129 & Lindane \\
\hline U163 & MNNG \\
\hline U147 & Maleic anhydride \\
\hline U148 & Maleic hydrazide \\
\hline U149 & Malononitrile \\
\hline U150 & Melphalan \\
\hline U151 & Mercury \\
\hline U384 & Metam Sodium. \\
\hline U152 & Methacrylonitrile $(I, T)$ \\
\hline U092 & Methanamine, N-methyl- (I) \\
\hline U029 & Methane, bromo- \\
\hline U045 & Methane, chloro- (I, T) \\
\hline U046 & Methane, chloromethoxy- \\
\hline U068 & Methane, dibromo- \\
\hline U080 & Methane, dichloro- \\
\hline U075 & Methane, dichlorodifluoro- \\
\hline U138 & Methane, iodo- \\
\hline U119 & Methanesulfonic acid, ethyl ester \\
\hline U211 & Methane, tetrachloro- \\
\hline U153 & Methanethiol (I, T) \\
\hline $\mathrm{U} 225$ & Methane, tribromo- \\
\hline U044 & Methane, trichloro- \\
\hline U121 & Methane, trichlorofluoro- \\
\hline U036 & 4,7-Methano-1H-indene, 1,2,4,5,6,7,8,8-octachloro-2, 3,3a,4,7,7a-hexahydro- \\
\hline U154 & Methanol (I) \\
\hline U155 & Methapyrilene \\
\hline U142 & $\begin{array}{l}\text { 1,3,4-Metheno-2H-cyclobuta[cd]pentalen-2-one, 1,1a, 3,3a,4,5,5,5a,5b,6- } \\
\text { decachlorooctahydro- }\end{array}$ \\
\hline U247 & Methoxychlor \\
\hline U154 & Methyl alcohol (I) \\
\hline U029 & Methyl bromide \\
\hline U186 & 1-Methylbutadiene (I) \\
\hline U045 & Methyl chloride (I,T) \\
\hline U156 & Methyl chlorocarbonate (I,T) \\
\hline U226 & Methyl chloroform \\
\hline U157 & 3-Methylcholanthrene \\
\hline U158 & 4,4'-Methylenebis(2-chloroaniline) \\
\hline
\end{tabular}


Table B-3. U-Listed Wastes (continued)

\begin{tabular}{|c|c|}
\hline $\begin{array}{l}\text { Hazardous } \\
\text { Waste No. }\end{array}$ & Substance \\
\hline U068 & Methylene bromide \\
\hline U080 & Methylene chloride \\
\hline U159 & Methyl ethyl ketone (MEK) (I,T) \\
\hline U160 & Methyl ethyl ketone peroxide $(\mathrm{R}, \mathrm{T})$ \\
\hline U138 & Methyl iodide \\
\hline U161 & Methyl isobutyl ketone (I) \\
\hline U162 & Methyl methacrylate (I,T) \\
\hline U161 & 4-Methyl-2-pentanone (I) \\
\hline U164 & Methylthiouracil \\
\hline U010 & Mitomycin C \\
\hline U365 & Molinate. \\
\hline U059 & $\begin{array}{l}\text { 5,12-Naphthacenedione, 8-acetyl-10-[(3-amino-2,3,6- trideoxy)-alpha-L-lyxo- } \\
\text { hexopyranosyl)oxy }]-7,8,9,10 \text {-tetrahydro-6,8,11-trihydroxy-1-methoxy-, (8S-cis) - }\end{array}$ \\
\hline U167 & 1-Naphthalenamine \\
\hline U168 & 2-Naphthalenamine \\
\hline U026 & Naphthalenamine, N,N'-bis(2-chloroethyl)- \\
\hline U165 & Naphthalene \\
\hline U047 & Naphthalene, 2-chloro- \\
\hline U166 & 1,4-Naphthalenedione \\
\hline U236 & $\begin{array}{l}\text { 2,7-Naphthalenedisulfonic acid, 3,3'-[(3,3'- dimethyl[1,1'-biphenyl]-4,4'- } \\
\text { diyl)bis(azo)bis[5- amino-4-hydroxy]-, tetrasodium salt }\end{array}$ \\
\hline U279 & 1-Naphthalenol, methylcarbamate. \\
\hline U166 & 1,4-Naphthoquinone \\
\hline U167 & alpha-Naphthylamine \\
\hline U168 & beta-Naphthylamine \\
\hline $\mathrm{U} 217$ & Nitric acid, thallium(1+) salt \\
\hline U169 & Nitrobenzene $(\mathrm{I}, \mathrm{T})$ \\
\hline U170 & p-Nitrophenol \\
\hline U171 & 2-Nitropropane $(\mathrm{I}, \mathrm{T})$ \\
\hline U172 & N-Nitrosodi-n-butylamine \\
\hline U173 & N-Nitrosodiethanolamine \\
\hline U174 & N-Nitrosodiethylamine \\
\hline U176 & N-Nitroso-N-ethylurea \\
\hline U177 & N-Nitroso-N-methylurea \\
\hline U178 & N-Nitroso-N-methylurethane \\
\hline U179 & N-Nitrosopiperidine \\
\hline U180 & N-Nitrosopyrrolidine \\
\hline U181 & 5-Nitro-o-toluidine \\
\hline U193 & 1,2-Oxathiolane, 2,2-dioxide \\
\hline U058 & 2H-1,3,2-Oxazaphosphorin-2-amine, N,N-bis(2-chloroethyl)tetrahydro-, 2-oxide \\
\hline
\end{tabular}


Table B-3. U-Listed Wastes (continued)

\begin{tabular}{|c|c|}
\hline $\begin{array}{l}\text { Hazardous } \\
\text { Waste No. }\end{array}$ & Substance \\
\hline $\mathrm{U} 115$ & Oxirane $(\mathrm{I}, \mathrm{T})$ \\
\hline U126 & Oxiranecarboxyaldehyde \\
\hline U041 & Oxirane, (chloromethyl)- \\
\hline U182 & Paraldehyde \\
\hline U391 & Pebulate. \\
\hline U183 & Pentachlorobenzene \\
\hline U184 & Pentachloroethane \\
\hline U185 & Pentachloronitrobenzene (PCNB) \\
\hline See F027 & Pentachlorophenol 3 \\
\hline U161 & Pentanol, 4-methyl- \\
\hline U186 & 1,3-Pentadiene (I) \\
\hline U187 & Phenacetin \\
\hline U188 & Phenol \\
\hline U048 & Phenol, 2-chloro- \\
\hline U039 & Phenol, 4-chloro-3-methyl- \\
\hline U081 & Phenol, 2,4-dichloro- \\
\hline U082 & Phenol, 2,6-dichloro- \\
\hline U089 & Phenol, 4,4'-(1,2-diethyl-1,2-ethenediyl)bis-, (E)- \\
\hline U101 & Phenol, 2,4-dimethyl- \\
\hline U052 & Phenol, methyl- \\
\hline U132 & Phenol, 2,2'-methylenebis[3,4,6-trichloro- \\
\hline $\mathrm{U} 411$ & Phenol, 2-(1-methylethoxy)-, methylcarbamate. \\
\hline $\mathrm{U} 170$ & Phenol, 4-nitro- \\
\hline See F027 & Phenol, pentachloro- 3 \\
\hline See F027 & Phenol, 2,3,4,6-tetrachloro- 3 \\
\hline See F027 & Phenol, 2,4,5-trichloro- 3 \\
\hline See F027 & Phenol, 2,4,6-trichloro- 3 \\
\hline U150 & L-Phenylalanine, 4-[bis(2-chloroethyl)amino]- \\
\hline U145 & Phosphoric acid, lead(2+) salt $(2: 3)$ \\
\hline U087 & Phosphorodithioic acid, O,O-diethyl S-methyl ester \\
\hline U189 & Phosphorus sulfide (R) \\
\hline U190 & Phthalic anhydride \\
\hline U191 & 2-Picoline \\
\hline U179 & Piperidine, 1-nitroso- \\
\hline U400 & Piperidine, 1,1'-(tetrathiodicarbonothioyl)-bis- \\
\hline U383 & Potassium dimethyldithiocarbamate. \\
\hline U378 & Potassium n-hydroxymethyl- n-methyldi-thiocarbamate. \\
\hline U377 & Potassium n-methyldithiocarbamate. \\
\hline U192 & Pronamide \\
\hline U194 & 1-Propanamine $(\mathrm{I}, \mathrm{T})$ \\
\hline
\end{tabular}


Table B-3. U-Listed Wastes (continued)

\begin{tabular}{|c|c|}
\hline $\begin{array}{l}\text { Hazardous } \\
\text { Waste No. }\end{array}$ & Substance \\
\hline U111 & 1-Propanamine, $\mathrm{N}$-nitroso- $\mathrm{N}$-propyl- \\
\hline U110 & 1-Propanamine, N-propyl- (I) \\
\hline U066 & Propane, 1,2-dibromo-3-chloro- \\
\hline U083 & Propane, 1,2-dichloro- \\
\hline U149 & Propanedinitrile \\
\hline U171 & Propane, 2-nitro- $(\mathrm{I}, \mathrm{T})$ \\
\hline U027 & Propane, 2,2'-oxybis[2-chloro- \\
\hline U193 & 1,3-Propane sultone \\
\hline See F027 & Propanoic acid, 2-(2,4,5-trichlorophenoxy)- 3 \\
\hline $\mathrm{U} 235$ & 1-Propanol, 2,3-dibromo-, phosphate (3:1) \\
\hline U140 & 1-Propanol, 2-methyl- $(\mathrm{I}, \mathrm{T})$ \\
\hline U002 & 2-Propanone (I) \\
\hline U007 & 2-Propenamide \\
\hline U084 & 1-Propene, 1,3-dichloro- \\
\hline $\mathrm{U} 243$ & 1-Propene, 1,1,2,3,3,3-hexachloro- \\
\hline U009 & 2-Propenenitrile \\
\hline U152 & 2-Propenenitrile, 2-methyl- (I,T) \\
\hline U008 & 2-Propenoic acid (I) \\
\hline U113 & 2-Propenoic acid, ethyl ester (I) \\
\hline U118 & 2-Propenoic acid, 2-methyl-, ethyl ester \\
\hline U162 & 2-Propenoic acid, 2-methyl-, methyl ester $(\mathrm{I}, \mathrm{T})$ \\
\hline U373 & Propham. \\
\hline U411 & Propoxur. \\
\hline U194 & n-Propylamine $(\mathrm{I}, \mathrm{T})$ \\
\hline U083 & Propylene dichloride \\
\hline U387 & Prosulfocarb. \\
\hline U148 & 3,6-Pyridazinedione, 1,2-dihydro- \\
\hline U196 & Pyridine \\
\hline U191 & Pyridine, 2-methyl- \\
\hline U237 & 2,4-(1H,3H)-Pyrimidinedione, 5-[bis(2- chloroethyl)amino]- \\
\hline U164 & $4(1 \mathrm{H})$-Pyrimidinone, 2,3-dihydro-6-methyl-2-thioxo- \\
\hline U180 & Pyrrolidine, 1-nitroso- \\
\hline U200 & Reserpine \\
\hline U201 & Resorcinol \\
\hline U202 & Saccharin, \& salts \\
\hline U203 & Safrole \\
\hline U204 & Selenious acid \\
\hline U204 & Selenium dioxide \\
\hline U205 & Selenium sulfide \\
\hline U205 & Selenium sulfide $\mathrm{SeS}_{2}(\mathrm{R}, \mathrm{T})$ \\
\hline
\end{tabular}


Table B-3. U-Listed Wastes (continued)

\begin{tabular}{|c|c|}
\hline $\begin{array}{l}\text { Hazardous } \\
\text { Waste No. }\end{array}$ & Substance \\
\hline U376 & Selenium, tetrakis(dimethyldithiocarbamate). \\
\hline U015 & L-Serine, diazoacetate (ester) \\
\hline See F027 & Silvex $(2,4,5-\mathrm{TP}) 3$ \\
\hline U379 & Sodium dibutyldithiocarbamate. \\
\hline U381 & Sodium diethyldithiocarbamate. \\
\hline U382 & Sodium dimethyldithiocarbamate. \\
\hline U206 & Streptozotocin \\
\hline U277 & Sulfallate. \\
\hline U103 & Sulfuric acid, dimethyl ester \\
\hline U189 & Sulfur phosphide (R) \\
\hline See F027 & $2,4,5-\mathrm{T} 3$ \\
\hline U402 & Tetrabutylthiuram disulfide. \\
\hline U207 & 1,2,4,5-Tetrachlorobenzene \\
\hline U208 & 1,1,1,2-Tetrachloroethane \\
\hline U209 & 1,1,2,2-Tetrachloroethane \\
\hline U210 & Tetrachloroethylene \\
\hline See F027 & 2,3,4,6-Tetrachlorophenol 3 \\
\hline U213 & Tetrahydrofuran (I) \\
\hline U401 & Tetramethylthiuram monosulfide. \\
\hline U366 & 2H-1,3,5-Thiadiazine- 2-thione, tetrahydro-3,5- dimethyl- \\
\hline U214 & Thallium(I) acetate \\
\hline U215 & Thallium(I) carbonate \\
\hline U216 & Thallium(I) chloride \\
\hline U216 & Thallium chloride Tlcl \\
\hline U217 & Thallium $(I)$ nitrate \\
\hline U218 & Thioacetamide \\
\hline U410 & Thiodicarb. \\
\hline U153 & Thiomethanol (I,T) \\
\hline U402 & Thioperoxydicarbonic diamide, tetrabutyl. \\
\hline U403 & Thioperoxydicarbonic diamide, tetraethyl. \\
\hline U244 & Thioperoxydicarbonic diamide $\left[\left(\mathrm{H}_{2} \mathrm{~N}\right) \mathrm{C}(\mathrm{S})\right]_{2} \mathrm{~S}_{2}$, tetramethyl- \\
\hline U409 & Thiophanate-methyl. \\
\hline U219 & Thiourea \\
\hline $\mathrm{U} 244$ & Thiram \\
\hline U220 & Toluene \\
\hline U221 & Toluenediamine \\
\hline U223 & Toluene diisocyanate $(R, T)$ \\
\hline U328 & o-Toluidine \\
\hline U353 & p-Toluidine \\
\hline $\mathrm{U} 222$ & o-Toluidine hydrochloride \\
\hline
\end{tabular}


Table B-3. U-Listed Wastes (continued)

\begin{tabular}{ll}
\hline Hazardous & \\
Waste No. & \\
\hline U389 & Triallate. \\
U011 & 1H-1,2,4-Triazol-3-amine \\
U227 & 1,1,2-Trichloroethane \\
U228 & Trichloroethylene \\
U121 & Trichloromonofluoromethane \\
See F027 & 2,4,5-Trichlorophenol 3 \\
See F027 & 2,4,6-Trichlorophenol 3 \\
U404 & Triethylamine. \\
U234 & 1,3,5-Trinitrobenzene (R,T) \\
U182 & 1,3,5-Trioxane, 2,4,6-trimethyl- \\
U235 & Tris(2,3-dibromopropyl) phosphate \\
U236 & Trypan blue \\
U237 & Uracil mustard \\
U176 & Urea, N-ethyl-N-nitroso- \\
U177 & Urea, N-methyl-N-nitroso- \\
U385 & Vernolate. \\
U043 & Vinyl chloride \\
U248 & Warfarin, \& salts, when present at concentrations of 0.3\% or less \\
U239 & Xylene (I) \\
U200 & Yohimban-16-carboxylic acid, 11,17-dimethoxy-18-[(3, 4,5-trimethoxybenzoyl)oxy]-, \\
U407 & methyl ester, (3beta, 16beta,17alpha,18beta,20alpha)- \\
U249 & Zinc, bis(diethylcarbamodithioato-S,S')- \\
& Zinc phosphide Zn 3 P, when present at concentrations of 10\% or less \\
\hline
\end{tabular}




\section{List of Extremely Hazardous Chemicals (from 22CCR 66261.126)}

$\begin{array}{llll}\text { Hazard characteristics } & \bullet \mathrm{X}: & \text { toxic } \\ & \bullet \mathrm{C}: & \text { corrosive } \\ & \bullet \mathrm{I}: & \text { ignitible } \\ & \bullet \mathrm{R}: & \text { reactive }\end{array}$

\begin{tabular}{|c|c|}
\hline Waste & Hazard Chars. \\
\hline 2-Acetylaminofluorene, 2-AAF & $\mathrm{X}$ \\
\hline Acetyl chloride & $\mathrm{X}, \mathrm{C}, \mathrm{R}$ \\
\hline Acrolein, Aqualin & $X, I$ \\
\hline Acrylonitrile & $X, I$ \\
\hline Adiponitrile & $\mathrm{X}$ \\
\hline $\begin{array}{l}\text { Aldrin; } 1,2,3,4,10,10 \text {-Hexachloro- } 1,4,4 a, 5,8,8 \mathrm{a} \text {-hexahydro-1,4,5,8-endo- } \\
\text { exodimethanonaphthalene }\end{array}$ & $\bar{x}$ \\
\hline Alkyl aluminum chloride & C,I,R \\
\hline Alkyl aluminum compounds & $\mathrm{C}, \mathrm{I}, \mathrm{R}$ \\
\hline Allyl trichlorosilane & $\mathrm{X}, \mathrm{C}, \mathrm{I}, \mathrm{R}$ \\
\hline Aluminum chloride (anhydrous) & $\mathrm{X}, \mathrm{C}, \mathrm{R}$ \\
\hline Aluminum phosphide, PHOSTOXIN & $\mathrm{X}, \mathrm{I}, \mathrm{R}$ \\
\hline 4-Aminodiphenyl, 4-ADP & $\mathrm{X}$ \\
\hline 2-Aminopyridine & $\mathrm{X}$ \\
\hline Ammonium arsenate & $\mathrm{X}$ \\
\hline Ammonium bifluoride & $\mathrm{X}, \mathrm{C}$ \\
\hline Amyl trichlorosilane (and isomers) & $\mathrm{X}, \mathrm{C}, \mathrm{R}$ \\
\hline Antimony pentachloride & $\mathrm{X}, \mathrm{C}, \mathrm{R}$ \\
\hline Antimony pentafluoride & $\mathrm{X}, \mathrm{C}, \mathrm{R}$ \\
\hline Arsenic & $\mathrm{x}$ \\
\hline Arsenic acid and salts & $\bar{x}$ \\
\hline Arsenic compounds & $\bar{X}$ \\
\hline Arsenic pentaselenide & $\bar{X}$ \\
\hline Arsenic pentoxide, Arsenic oxide & $\bar{x}$ \\
\hline Arsenic sulfide, Arsenic disulfide & $\bar{x}$ \\
\hline Arsenic tribromide, Arsenic bromide & $\bar{X}$ \\
\hline Arsenic trichloride, Arsenic chloride & $\bar{x}$ \\
\hline Arsenic triiodide, Arsenic iodide & $\bar{x}$ \\
\hline Arsenic trioxide, Arsenious oxide & $\bar{x}$ \\
\hline Arsenious acid and salts & $\bar{X}$ \\
\hline Arsines & $\bar{X}$ \\
\hline AZODRIN, 3-Hydroxy-N-cis-crotonamide & $\bar{x}$ \\
\hline Barium cyanide & $\bar{X}$ \\
\hline Benzene hexachloride, $\mathrm{BHC} ; 1,2,3,4,5,6$-Hexachloro-cyclohexane & $\mathrm{X}$ \\
\hline Benzenephosphorous dichloride & $\overline{\mathrm{I}, \mathrm{R}}$ \\
\hline Benzidine and salts & $\mathrm{X}$ \\
\hline Benzotrifluoride, Trifluoromethylbenzene & $X, I$ \\
\hline Benzoyl chloride & $\mathrm{X}, \mathrm{C}, \mathrm{R}$ \\
\hline Benzyl chlorocarbonate, Benzyl chloroformate & $\mathrm{X}, \mathrm{C}, \mathrm{R}$ \\
\hline Beryllium & $X, I$ \\
\hline Beryllium chloride & $\mathrm{X}$ \\
\hline
\end{tabular}




\begin{tabular}{|c|c|}
\hline Waste & Hazard Chars. \\
\hline Beryllium compounds & $\mathrm{X}$ \\
\hline Beryllium copper & $\bar{X}$ \\
\hline Beryllium fluoride & $\mathrm{X}$ \\
\hline Beryllium hydride & $\mathrm{X}, \mathrm{C}, \mathrm{I}, \mathrm{R}$ \\
\hline Beryllium hydroxide & $\mathrm{X}$ \\
\hline Beryllium oxide & $\bar{X}$ \\
\hline $\begin{array}{l}\text { BIDRIN, Dicrotophos, 3-(Dimethylamino)-1-methyl-3-oxo-1-propenyldimethyl } \\
\text { phosphate }\end{array}$ & $\bar{x}$ \\
\hline bis (Chloromethyl) ether, Dichloromethylether, BCME & $\mathrm{X}$ \\
\hline bis (Methylmercuric) sulfate, CEREWET, Ceresan liquid & $\bar{X}$ \\
\hline BOMYL, Dimethyl 3-hydroxyglutaconate dimethyl phosphate & $\mathrm{X}$ \\
\hline Boranes & $\mathrm{X}, \mathrm{I}, \mathrm{R}$ \\
\hline Bordeaux arsenites & $\mathrm{X}$ \\
\hline Boron trichloride, Trichloroborane & $\mathrm{X}, \mathrm{C}, \mathrm{R}$ \\
\hline Boron trifluoride & $\mathrm{X}, \mathrm{C}, \mathrm{R}$ \\
\hline Bromine & $\mathrm{X}, \mathrm{C}, \mathrm{I}$ \\
\hline Bromine pentafluoride & $\mathrm{X}, \mathrm{C}, \mathrm{I}, \mathrm{R}$ \\
\hline Boron trifluoride & $\mathrm{X}, \mathrm{C}, \mathrm{I}, \mathrm{R}$ \\
\hline Brucine, Dimethoxystrychnine & $\mathrm{X}$ \\
\hline n-Butyllithium (and isomers) & $\mathrm{X}, \mathrm{C}, \mathrm{I}, \mathrm{R}$ \\
\hline n-Butyltrichlorosilane & $\mathrm{C}, \mathrm{I}, \mathrm{R}$ \\
\hline Cacodylic acid, Dimethylarsinic acid & $\mathrm{X}$ \\
\hline Cadmium (powder) & $\bar{X}, \mathrm{I}$ \\
\hline Cadmium compounds & $x$ \\
\hline Cadmium cyanide & $\mathrm{X}$ \\
\hline Calcium & $\mathrm{I}, \mathrm{R}$ \\
\hline Calcium arsenate, PENSAL & $\mathrm{X}$ \\
\hline Calcium arsenite & $\mathrm{X}$ \\
\hline Calcium carbide & C,I,R \\
\hline Calcium hydride & $\mathrm{C}, \mathrm{I}, \mathrm{R}$ \\
\hline Calcium hypochlorite, Calcium oxychloride (dry) & $\mathrm{X}, \mathrm{C}, \mathrm{I}, \mathrm{R}$ \\
\hline Calcium phosphide & $\mathrm{X}, \mathrm{I}, \mathrm{R}$ \\
\hline Carbanolate, BANOL, 2-Chloro-4,5-dimethylphenyl methylcarbamate & $\mathrm{X}$ \\
\hline $\begin{array}{l}\text { Carbophenothion, TRITHION, S[[(4-Chloro-phenyl)thio]methyl]0,0-diethyl } \\
\text { phosphorodithioate }\end{array}$ & $\bar{X}$ \\
\hline Chlordane; $1,2,4,5,6,7,8,8$-Octachloro-4,7-methano-3a,4,7,7a-tetra- hydro- indane & $\bar{x}$ \\
\hline $\begin{array}{l}\text { Chlorfenvinphos, Compound 4072, 2-Chloro-1-(2,4-dichlorophenyl) vinyl diethyl } \\
\text { phosphate }\end{array}$ & $\bar{X}$ \\
\hline Chlorine & $\mathrm{X}, \mathrm{C}, \mathrm{I}, \mathrm{R}$ \\
\hline Chlorine dioxide & $\mathrm{X}, \mathrm{C}, \mathrm{I}, \mathrm{R}$ \\
\hline Chlorine pentafluoride & $\mathrm{X}, \mathrm{C}, \mathrm{I}, \mathrm{R}$ \\
\hline Chlorine trifluoride & $\mathrm{X}, \mathrm{C}, \mathrm{I}, \mathrm{R}$ \\
\hline Chloroacetaldehyde & $\mathrm{X}, \mathrm{C}$ \\
\hline alpha-Chloroacetophenone, Phenyl chloromethyl ketone & $\mathrm{X}$ \\
\hline Chloroacetyl chloride & $\mathrm{X}, \mathrm{C}, \mathrm{R}$ \\
\hline
\end{tabular}




\begin{tabular}{|c|c|}
\hline Waste & Hazard Chars. \\
\hline ortho-Chlorobenzylidene malonitrile, OCMB & $\mathrm{X}$ \\
\hline Chloropicrin, Chlorpicrin, Trichloronitromethane & $\mathrm{X}$ \\
\hline Chlorosulfonic acid & $\mathrm{X}, \mathrm{C}, \mathrm{I}, \mathrm{R}$ \\
\hline Chromyl chloride, Chlorochromic anhydride & $\mathrm{X}, \mathrm{C}, \mathrm{I}, \mathrm{R}$ \\
\hline Copper acetoarsenite, Paris green & $\mathrm{x}$ \\
\hline Copper arsenate, Cupric arsenate & $\bar{X}$ \\
\hline Copper arsenite, Cupric arsenite & $\mathrm{X}$ \\
\hline Copper cyanide, Cupric cyanide & $\mathrm{X}$ \\
\hline $\begin{array}{l}\text { Coroxon; ortho,ortho-Diethyl-ortho-(3-chloro-4-methylcoumarin-7-yl) } \\
\text { phosphate }\end{array}$ & $\bar{X}$ \\
\hline $\begin{array}{l}\text { Coumafuryl, FUMARIN, 3-[1-(2-Furanyl)-3-oxobutyl]1-4-hydroxy-2H-1- } \\
\text { benzopyran-2-one }\end{array}$ & $\bar{X}$ \\
\hline $\begin{array}{l}\text { Coumatetralyl, BAYER 25634, RACUMIN 57, 4-Hydroxy-3-(1,2,3,4-tetrahydro-1- } \\
\text { naphthalenyl)-2H-1-benzopyran-2-one }\end{array}$ & $\mathrm{X}$ \\
\hline Crimidine, CASTRIX, 2-Chloro-4-dimethylamino-6-methyl-pyrimidine & $X$ \\
\hline Crotonaldehyde, 2-Butenal & $\bar{X}$ \\
\hline Cyanide salts & $\mathrm{X}$ \\
\hline Cyanogen & $\mathrm{X}, \mathrm{I}, \mathrm{R}$ \\
\hline Cyclohexenyltrichlorosilane & $\mathrm{X}, \mathrm{C}, \mathrm{R}$ \\
\hline Cycloheximide, ACTIDIONE & $\mathrm{X}$ \\
\hline Cyclohexyltrichlorosilane & $\mathrm{X}, \mathrm{C}, \mathrm{R}$ \\
\hline DDVP, Dichlorvos, VAPONA, Dimethyl dichlorovinyl phosphate & $\bar{x}$ \\
\hline Decaborane & $\mathrm{X}, \mathrm{I}, \mathrm{R}$ \\
\hline Demeton, SYSTOX & $\mathrm{X}$ \\
\hline $\begin{array}{l}\text { Demeton-S-methyl sulfone, METAISOSYSTOX-SULFON, S-[2-(ethyl-sulfonyl) } \\
\text { ethyl] O,O-dimethyl phosphorothioate }\end{array}$ & $\bar{x}$ \\
\hline Diborane, Diboron hexahydride & $\mathrm{I}, \mathrm{R}$ \\
\hline 1,2-Dibromo-3-chloropropane, DBCP, Fumazone, nemagon & $\mathrm{X}$ \\
\hline 3,3-Dichlorobenzidine and salts, DCB & $\bar{X}$ \\
\hline 2,4-Dichlorophenoxyacetic acid; 2,4-D & $\bar{X}$ \\
\hline $\begin{array}{l}\text { Dieldrin; 1,2,3,4,10,10-Hexachloro-6,7-epoxy-1,4,4a,5,6,7,8,8a-octahydro-1,4- } \\
\text { endo,exo-5,8-dimethanonaphthalene }\end{array}$ & $\bar{X}$ \\
\hline Diethylaluminum chloride, Aluminum diethyl monochloride, DEAC & $\mathrm{I}, \mathrm{R}$ \\
\hline Diethyl chlorovinyl phosphate, Compound 1836 & $\mathrm{X}$ \\
\hline Diethyldichlorosilane & $\mathrm{X}, \mathrm{C}, \mathrm{I}, \mathrm{R}$ \\
\hline O,O-Diethyl-S-(isopropylthiomethyl) phosphorodithioate & $\mathrm{X}$ \\
\hline Diethylzinc, Zinc ethyl & C,I,R \\
\hline Difluorophosphoric acid & $\mathrm{X}, \mathrm{C}, \mathrm{R}$ \\
\hline Diglycidyl ether, bis(2,3-Epoxypropyl) ether & $\mathrm{X}$ \\
\hline Dimefox, Hanane, Pextox 14, Tetramethylphosphorodiamidic fluoride & $\bar{X}$ \\
\hline Dimethylaminoazobenzene, Methyl yellow & $\mathrm{X}$ \\
\hline Dimethyldichlorosilane, Dichlorodimethylsilane & $\mathrm{X}, \mathrm{C}, \mathrm{I}, \mathrm{R}$ \\
\hline 1,1-Dimethylhydrazine, UDMH & $\mathrm{X}, \mathrm{I}$ \\
\hline Dimethyl sulfate, Methyl sulfate & $\mathrm{X}$ \\
\hline Dimethyl sulfide, Methyl sulfide & $\mathrm{X}, \mathrm{I}, \mathrm{R}$ \\
\hline Dinitrobenzene (ortho, meta, para) & $\mathrm{I}, \mathrm{R}$ \\
\hline
\end{tabular}




\begin{tabular}{|c|c|}
\hline Waste & Hazard Chars. \\
\hline \multicolumn{2}{|l|}{ 4,6-Dinitro-ortho-cresol, DNPC, SINOX, E } \\
\hline Dinitrophenol $(2,3-; 2,4-; 2,6$-isomers $)$ & $\mathrm{I}, \mathrm{R}$ \\
\hline DINOSEB; 2,4-Dinitro-6-sec-butylphenol & $\mathrm{X}$ \\
\hline $\begin{array}{l}\text { Dioxathion, DELNAV; S,S-1,4-dioxane-2,3-diyl bis(O,O-diethyl } \\
\text { phosphorodithioate) }\end{array}$ & $\bar{X}$ \\
\hline Diphenyl, Biphenyl, Phenylbenzene & $\bar{x}$ \\
\hline Diphenylamine chloroarsine, Phenarsazine chloride & $\mathrm{X}$ \\
\hline Diphenyldichlorosilane & $\mathrm{X}, \mathrm{C}, \mathrm{R}$ \\
\hline $\begin{array}{l}\text { Disulfoton, DI-SYSTON; O,O-Diethyl S-[2-(ethylthio) ethyl] } \\
\text { phosphorodithioate }\end{array}$ & $\mathrm{X}$ \\
\hline Dodecyltrichlorosilane & $\overline{X, C, R}$ \\
\hline $\begin{array}{l}\text { DOWCO-139, ZECTRAM, Mexacarbate, 4-(Di-methylamino)-3,5- } \\
\text { dimethylphenyl methylcarbamate }\end{array}$ & $\mathrm{X}$ \\
\hline DYFONATE, Fonofos, O-Ethyl-S-phenylethyl phosphonodithioate & $\bar{X}$ \\
\hline $\begin{array}{l}\text { Endosulfan, THIODAN; } 6,7,8,9,10,10 \text {-Hexachlor-1,5,5a,6,9,9a-hexa-hydro-6,9- } \\
\text { methano-2,4,3-benzo-dioxathiepin-3-oxide }\end{array}$ & $\mathrm{X}$ \\
\hline Endothal, 7-Oxabicyclo[2.2.1]heptane-2,3-dicarboxylic acid & $\bar{X}$ \\
\hline $\begin{array}{l}\text { Endothion, EXOTHION, S-[(5-Methoxy-4-oxo-4H-pyran-2-yl)-methyl] O,O- } \\
\text { dimethyl phosphorothioate }\end{array}$ & $\bar{X}$ \\
\hline $\begin{array}{l}\text { Endrin; } 1,2,3,4,10,10-H e x a c h l o r o-6,7-e p o x y-1,4,4,4 a, 5,6,7,8,8 a-o c t a h y d r o-1,4- \\
\text { endo-endo-5,8-dimethanonaphthalene }\end{array}$ & $\bar{X}$ \\
\hline EPN; O-Ethyl O-para-nitrophenyl phenylphosphonothioate & $\bar{X}$ \\
\hline Ethion, NIALATE; O,O,O',O'-Tetraethyl-S,S-methylenediphosphorodithioate & $\mathrm{X}$ \\
\hline Ethyl chloroformate, Ethyl chlorocarbonate & $\mathrm{X}, \mathrm{C}, \mathrm{I}, \mathrm{R}$ \\
\hline Ethyldichloroarsine, Dichloroethylarsine & $\mathrm{I}, \mathrm{R}$ \\
\hline Ethyldichlorosilane & $\mathrm{X}, \mathrm{C}, \mathrm{I}, \mathrm{R}$ \\
\hline Ethylene cyanohydrin, beta-Hydroxypropionitrile & $\mathrm{I}, \mathrm{R}$ \\
\hline Ethyleneimine, Aziridine, EI & $\mathrm{X}, \mathrm{I}, \mathrm{R}$ \\
\hline Ethyl mercaptan, Ethanethiol & $\mathrm{X}, \mathrm{I}, \mathrm{R}$ \\
\hline Ethylphenyldichlorosilane & $\mathrm{X}, \mathrm{C}, \mathrm{R}$ \\
\hline Ethyltrichlorosilane & $\mathrm{I}, \mathrm{R}$ \\
\hline $\begin{array}{l}\text { Fensulfothion, BAYER 25141, DASANIT, O,O-Di-ethyl-0-[4-(methyl- } \\
\text { sulfinyl)phenyl] phosphorothioate }\end{array}$ & $\bar{X}$ \\
\hline Ferric arsenate & $\mathrm{X}$ \\
\hline Ferrous arsenate, Iron arsenate & $\mathrm{X}$ \\
\hline Fluoboric acid, Fluoroboric acid & $\mathrm{X}, \mathrm{C}$ \\
\hline Fluorine & $\mathrm{X}, \mathrm{C}, \mathrm{R}$ \\
\hline Fluoroacetanilide, AFL 1082 & $\mathrm{X}$ \\
\hline Fluoroacetic acid and salts, Compound 1080 & $\mathrm{X}$ \\
\hline Fluorosulfonic acid, Fluosulfonic acid & $\mathrm{X}, \mathrm{C}, \mathrm{R}$ \\
\hline $\begin{array}{l}\text { FURADAN, NIA 10,242, Carbofuran; 2,3-Dihydro-2,2-dimethyl-7- } \\
\text { benzofuranylmethylcarbamate }\end{array}$ & $\mathrm{X}$ \\
\hline GB, O-Isopropyl methyl phosphoryl fluoride & $\bar{X}$ \\
\hline $\begin{array}{l}\text { Guthion; O,O-Dimethyl-S-4-oxo-1,2,3-benzotriazin-3(4H)-ylmethyl } \\
\text { phosphorodithioate }\end{array}$ & $\bar{X}$ \\
\hline Heptachlor; $1,4,5,6,7,8,8$-Heptachloro-3a,4,7,7a-tetrahydro-4,7-methe & $\mathrm{X}$ \\
\hline
\end{tabular}




\begin{tabular}{|c|c|}
\hline Waste & Hazard Chars. \\
\hline Hexadecyltrichlorosilane & $\mathrm{X}, \mathrm{C}, \mathrm{R}$ \\
\hline Hexyltrichlorosilane & $\mathrm{X}, \mathrm{C}, \mathrm{R}$ \\
\hline Hydrazine, Diamine & $\mathrm{X}, \mathrm{I}$ \\
\hline Hydriodic acid, Hydrogen iodide & $\mathrm{X}, \mathrm{C}, \mathrm{R}$ \\
\hline Hydrobromic acid, Hydrogen bromide & $\mathrm{X}, \mathrm{C}, \mathrm{R}$ \\
\hline Hydrochloric acid, Hydrogen chloride, Muriatic Acid & $\mathrm{X}, \mathrm{C}, \mathrm{R}$ \\
\hline Hydrocyanic acid, Hydrogen cyanide & $\mathrm{X}, \mathrm{I}, \mathrm{R}$ \\
\hline Hydrofluoric acid, Hydrogen fluoride & $\mathrm{X}, \mathrm{C}, \mathrm{R}$ \\
\hline Hydrogen selenide & $X, I$ \\
\hline Hydrogen sulfide & $\overline{X, I}$ \\
\hline Hypochlorite compounds & $\mathrm{X}, \mathrm{C}, \mathrm{I}, \mathrm{R}$ \\
\hline meta-Isopropylphenyl-N-methylcarbamate, Ac 5,727 & $\mathrm{X}$ \\
\hline $\begin{array}{l}\text { Kepone; } 1,1 \mathrm{a}, 3,3 \mathrm{a}, 4,5,5,5 \mathrm{a}, 5 \mathrm{~b}, 6 \text {-Decachloroocta-hydro-1,2,4-metheno-2H- } \\
\text { cyclobuta(cd) pentalen-2-one, Chlorecone }\end{array}$ & $\bar{X}$ \\
\hline Lead arsenate, Lead orthoarsenate & $\mathrm{X}$ \\
\hline Lead arsenite & $\bar{X}$ \\
\hline Lead cyanide & $\bar{X}$ \\
\hline Lewisite, beta-Chlorovinyldichloroarsine & $\mathrm{X}$ \\
\hline Lithium & $\mathrm{C}, \mathrm{I}, \mathrm{R}$ \\
\hline Lithium aluminum hydride, LAH & C,I,R \\
\hline Lithium amide & $\mathrm{C}, \mathrm{I}, \mathrm{R}$ \\
\hline Lithium ferrosilicon & $\mathrm{I}, \mathrm{R}$ \\
\hline Lithium hydride & $\mathrm{C}, \mathrm{I}, \mathrm{R}$ \\
\hline Lithium hypochlorite & $\mathrm{X}, \mathrm{C}, \mathrm{I}, \mathrm{R}$ \\
\hline London purple, mixture of arsenic trioxide, aniline, lime, and ferrous oxide & $\mathrm{X}$ \\
\hline Magnesium & $\overline{I, R}$ \\
\hline Magnesium arsenate & $\mathrm{X}$ \\
\hline Magnesium arsenite & $\bar{x}$ \\
\hline Maleic anhydride & $\mathrm{X}$ \\
\hline Manganese arsenate, Manganous arsenate & $\mathrm{X}$ \\
\hline $\begin{array}{l}\text { MECARBAM; O,O-Diethyl S-(N-ethoxycarbonyl N-methylcarba-moyl-methyl) } \\
\text { phosphorodithioate }\end{array}$ & $\bar{X}$ \\
\hline Medinoterb acetate, 2-tert-Butyl-5-methyl-4,6-dinitro-phenyl acetate & $\bar{X}$ \\
\hline Mercuric chloride, Mercury chloride & $\mathrm{X}$ \\
\hline Mercuric cyanide, Mercury cyanide & $\bar{X}$ \\
\hline Mercury & $\bar{X}$ \\
\hline Mercury compounds & $\bar{X}$ \\
\hline Metal hydrides & $\mathrm{I}, \mathrm{R}$ \\
\hline Methomyl, LANNATE, S-Methyl-N-((methyl-carbamoyl)oxy) thioacetimidate & $\mathrm{X}$ \\
\hline $\begin{array}{l}\text { Methoxyclor; 1,1,1-Trichloro-2, -bis(p-meth- oxyphenyl) ethane, CHEMFLORM, } \\
\text { MARLATE }\end{array}$ & $\bar{x}$ \\
\hline Methoxyethylmercuric chloride, AGALLOL, ARETAN & $\mathrm{X}$ \\
\hline Methylaluminum sesquibromide & $\mathrm{I}, \mathrm{R}$ \\
\hline Methylaluminum sesquichloride & $\mathrm{I}, \mathrm{R}$ \\
\hline Methyl bromide, Bromomethane & $x$ \\
\hline
\end{tabular}




\begin{tabular}{|c|c|}
\hline Waste & Hazard Chars. \\
\hline Methyl chloroformate, Methyl chlorocarbonate & $X, I, R$ \\
\hline Methyl chloromethyl ether, CMME & $\mathrm{X}, \mathrm{I}$ \\
\hline Methyldichloroarsine & $\mathrm{X}$ \\
\hline Methyldichlorosilane & $X, I, R$ \\
\hline 4,4-Methylene bis(2-chloroaniline), MOCA & $\mathrm{X}$ \\
\hline Methyl hydrazine, Monomethyl hydrazine, MMH & $\mathrm{X}, \mathrm{I}$ \\
\hline Methyl isocyanate & $\mathrm{X}, \mathrm{I}$ \\
\hline Methylmagnesium bromide & $\mathrm{C}, \mathrm{I}, \mathrm{R}$ \\
\hline Methylmagnesium chloride & $\mathrm{C}, \mathrm{I}, \mathrm{R}$ \\
\hline Methylmagnesium iodide & $\mathrm{C}, \mathrm{I}, \mathrm{R}$ \\
\hline Methyl parathion; O,O-Dimethyl-O-para-nitrophenyl-phosphorothioate & $\mathrm{X}$ \\
\hline Methyltrichlorosilane & $\mathrm{X}, \mathrm{C}, \mathrm{I}, \mathrm{R}$ \\
\hline Mevinphos, PHOSDRIN, 2-Carbomethoxy-1-methylvinyl dimethylphosphate & $\mathrm{X}$ \\
\hline $\begin{array}{l}\text { Mirex; } 1,1 a, 2,2,3,3 a, 4,5,5,5 a, 5 b, 6-\text { Dodecachlorooctahydro-1,3,4-metheno-1H- } \\
\text { cyclobuta (cd) pentalene, Dechlorane }\end{array}$ & $\bar{X}$ \\
\hline MOCAP, O-Ethyl-S,S-dipropyl phosphorodithioate & $\bar{X}$ \\
\hline alpha-Naphthylamine, 1-NA & $\mathrm{X}$ \\
\hline beta-Naphthylamine, 2-NA & $X$ \\
\hline Nickel arsenate, Nickelous arsenate & $\bar{X}$ \\
\hline Nickel carbonyl, Nickel tetracarbonyl & $\mathrm{X}$ \\
\hline Nickel cyanide & $\bar{X}$ \\
\hline Nitrobenzol, Nitrobenzene & $\mathrm{X}$ \\
\hline 4-Nitrobiphenyl, 4-NBP & $\mathrm{X}$ \\
\hline Nitrophenol (ortho, meta, para) & $\bar{x}$ \\
\hline N-Nitrosodimethylamine, Dimethyl nitrosoamine & $\mathrm{X}$ \\
\hline Nonyltrichlorosilane & $\mathrm{I}, \mathrm{R}$ \\
\hline Octadecyltrichlorosilane & $\mathrm{I}, \mathrm{R}$ \\
\hline Octyltrichlorosilane & $\mathrm{I}, \mathrm{R}$ \\
\hline Oleum, Fuming sulfuric acid & $\mathrm{X}, \mathrm{C}, \mathrm{R}$ \\
\hline Oxygen difluoride & $\mathrm{X}, \mathrm{C}, \mathrm{R}$ \\
\hline Para-oxon, MINTACOL; O,O-Diethyl-O-para-nitrophenyl phosphate & $\mathrm{X}$ \\
\hline Parathion; O,O-Diethyl-O-para-nitrophenyl phosphorothioate & $\mathrm{X}$ \\
\hline Pentaborane & $\mathrm{X}, \mathrm{I}, \mathrm{R}$ \\
\hline Perchloromethyl mercaptan, Trichloromethylsulfenyl chloride & $\mathrm{X}$ \\
\hline Phenyldichloroarsine & $\bar{X}$ \\
\hline Phenylphenol, Orthozenol, DOWICIDE I & $\mathrm{X}$ \\
\hline Phenyltrichorosilane & $\mathrm{I}, \mathrm{R}$ \\
\hline Phorate, THIMET; O,O-Diethyl-S-[(Ethylthio)methyl] phosphorodithioate & $\mathrm{x}$ \\
\hline Phosfolan, CYOLAN, 2-(Diethoxyphosphinylimino)-1,3-dithio-lane & $\mathrm{X}$ \\
\hline Phosgene, Carbonyl chloride & $\mathrm{I}, \mathrm{R}$ \\
\hline $\begin{array}{l}\text { Phosphamidon, DIMECRON, 2-Chloro-2-diethyl-carbamoyl-1-methylvinyl } \\
\text { dimethyl phosphate }\end{array}$ & $\mathrm{X}$ \\
\hline Phosphine, Hydrogen phosphide & $\mathrm{X}, \mathrm{I}$ \\
\hline Phosphorus (white or yellow) & $\mathrm{X}, \mathrm{I}, \mathrm{R}$ \\
\hline Phosphorus oxybromide, Phosphoryl bromide & $\mathrm{X}, \mathrm{C}, \mathrm{R}$ \\
\hline
\end{tabular}




\begin{tabular}{|c|c|}
\hline Waste & Hazard Chars. \\
\hline Phosphorus oxychloride, Phosphoryl chloride & $\mathrm{X}, \mathrm{C}, \mathrm{R}$ \\
\hline Phosphorus pentachloride, Phosphoric chloride & $X, C, I, R$ \\
\hline Phosphorus pentasulfide, Phosphoric sulfide & $\mathrm{X}, \mathrm{C}, \mathrm{I}, \mathrm{R}$ \\
\hline Phosphorus sesquisulfide, tetraphosphorus trisulfide & $\bar{X}, \mathrm{C}, \mathrm{I}, \mathrm{R}$ \\
\hline Phosphorus tribromide & $\mathrm{X}, \mathrm{C}, \mathrm{R}$ \\
\hline Phosphorus trichloride & $\mathrm{X}, \mathrm{C}, \mathrm{R}$ \\
\hline Platinum compounds & $\mathrm{X}$ \\
\hline Polychlorinated biphenyls, PCB, Askarel, aroclor, chlorextol, interteen, pyranol & $\mathrm{X}$ \\
\hline Potassium & C,I,R \\
\hline Potassium arsenate & $\mathrm{X}$ \\
\hline Potassium arsenite & $\mathrm{X}$ \\
\hline Potassium bifluoride, Potassium acid fluoride & $\mathrm{X}, \mathrm{C}$ \\
\hline Potassium cyanide & $\mathrm{X}$ \\
\hline Potassium hydride & C,I,R \\
\hline Propargyl bromide, 3-Bromo-1-propyne & $\bar{X}, \mathrm{I}$ \\
\hline beta-Propiolactone, BPL & $\mathrm{X}$ \\
\hline Propyleneimine, 2-Methylaziridine & $\overline{X, I}$ \\
\hline n-Propyltrichlorosilane & $\mathrm{X}, \mathrm{C}, \mathrm{I}, \mathrm{R}$ \\
\hline $\begin{array}{l}\text { Prothoate, FOSTION, FAC; O,O-Diethyl-S-carboethoxy-ethyl } \\
\text { phosphorodithioate }\end{array}$ & $\mathrm{X}$ \\
\hline Pyrosulfuryl chloride, Disulfuryl chloride & $\mathrm{X}, \mathrm{C}, \mathrm{R}$ \\
\hline Quinone; 1,4-Benzoquinone & $\mathrm{X}$ \\
\hline Schradan, Octamethyl pyrophosphoramide, OMPA & $\mathrm{X}$ \\
\hline Selenium & $\mathrm{X}$ \\
\hline Selenium compounds & $\bar{X}$ \\
\hline Selenium fluoride & $\mathrm{X}$ \\
\hline Selenous acid, Selenious acid and salts & $\mathrm{X}$ \\
\hline Silicon tetrachloride, Silicon chloride & $\mathrm{X}, \mathrm{C}, \mathrm{R}$ \\
\hline Silver acetylide & $\mathrm{I}, \mathrm{R}$ \\
\hline Sodium & $\mathrm{C}, \mathrm{I}, \mathrm{R}$ \\
\hline Sodium aluminum hydride & C,I,R \\
\hline Sodium amide, Sodamide & $\mathrm{C}, \mathrm{I}, \mathrm{R}$ \\
\hline Sodium arsenate & $\mathrm{X}$ \\
\hline Sodium arsenite & $\mathrm{X}$ \\
\hline Sodium bifluoride, sodium acid fluoride & $\mathrm{X}, \mathrm{C}$ \\
\hline Sodium cacodylate, Sodium dimethylarsenate & $\mathrm{x}$ \\
\hline Sodium cyanide & $\mathrm{X}$ \\
\hline Sodium hydride & X,C,I,R \\
\hline Sodium hypochlorite & $X, I, R$ \\
\hline Sodium methylate, Sodium methoxide & $\mathrm{C}, \mathrm{I}, \mathrm{R}$ \\
\hline Sodium peroxide & $\mathrm{X}, \mathrm{I}, \mathrm{R}$ \\
\hline Sodium potassium alloy, $\mathrm{NaK}$, Nack & $\mathrm{C}, \mathrm{I}, \mathrm{R}$ \\
\hline Sodium selenate & $\mathrm{X}$ \\
\hline Strontium arsenate & $X$ \\
\hline Strychnine and salts & $X$ \\
\hline
\end{tabular}




\begin{tabular}{|c|c|}
\hline Waste & Hazard Chars. \\
\hline Sulfotepp, DITHIONE, BLACAFUM, Tetraethyldithio-pyrophosphate, TEDP & $\mathrm{X}$ \\
\hline Sulfur chloride, Sulfur monochloride & $\mathrm{X}, \mathrm{C}, \mathrm{R}$ \\
\hline Sulfur mustard & $\mathrm{X}, \mathrm{C}, \mathrm{R}$ \\
\hline Sulfur pentafluoride & $\mathrm{X}, \mathrm{C}$ \\
\hline Sulfuryl chloride, Sulfonyl chloride & $\mathrm{X}, \mathrm{C}, \mathrm{R}$ \\
\hline Sulfuryl fluoride, Sulfonyl fluoride & $\mathrm{X}, \mathrm{C}, \mathrm{R}$ \\
\hline $\begin{array}{l}\text { SUPRACIDE, ULTRACIDE, S-[(5-Methoxy-2-oxo-1,3,4-thia-diazo13(2H)- } \\
\text { yl)methyl]-O,O-dimethyl phosphorodithioate }\end{array}$ & $\mathrm{X}$ \\
\hline $\begin{array}{l}\text { SURECIDE, Cyanophenphos, O-para-Cyanophenyl-O-ethyl phenyl } \\
\text { phosphonothioate }\end{array}$ & $\bar{X}$ \\
\hline Tellurium hexafluoride & $\overline{X, C}$ \\
\hline $\begin{array}{l}\text { TELODRIN, Isobenzan; } 1,3,4,5,6,7,8,8 \text {-Octachloro-1,3,3a,4,7,7a-hexahydro-4,7- } \\
\text { methanoisobenzofuran }\end{array}$ & $\mathrm{X}$ \\
\hline $\begin{array}{l}\text { TEMIK, Aldicarb, 2-Methyl-2(methylthio) propionaldehyde-O- } \\
\text { (methylcarbamoyl) oxime }\end{array}$ & $\bar{X}$ \\
\hline 2,3,7,8-Tetrachlorodibenzo-para-dioxin, TCDD, Dioxin & $\mathrm{X}$ \\
\hline Tetraethyl lead, TEL (and other organic lead) & $\mathrm{X}, \mathrm{I}$ \\
\hline Tetraethyl pyrophosphate, TEPP & $\mathrm{X}$ \\
\hline Tetramethyl succinonitrile & $\mathrm{X}$ \\
\hline Tetranitromethane & $\mathrm{X}, \mathrm{I}, \mathrm{R}$ \\
\hline Tetrasul, ANIMERT V-101, S-para-Chlorophenyl-2,4,5-trichlorophenyl sulfide & $\mathrm{X}$ \\
\hline Thallium & $\bar{X}$ \\
\hline Thallium compounds & $\bar{X}$ \\
\hline Thallus sulfate, Thallium sulfate, RATOX & $\mathrm{X}$ \\
\hline Thiocarbonylchloride, Thiophosgene & $\mathrm{X}, \mathrm{C}, \mathrm{R}$ \\
\hline Thionazin, ZINOPHOS; O,O-Tetramethylthiuram monosulfide & $\mathrm{X}$ \\
\hline Thionyl chloride, Sulfur oxychloride & $\mathrm{X}, \mathrm{C}, \mathrm{R}$ \\
\hline Thiophosphoryl chloride & $\mathrm{X}, \mathrm{C}, \mathrm{R}$ \\
\hline Titanium tetrachloride, Titanic chloride & $\mathrm{X}, \mathrm{C}, \mathrm{R}$ \\
\hline Toluene-2,4-diisocyanate, TDI & $\mathrm{I}, \mathrm{R}$ \\
\hline Toxaphene, Polychlorocamphene & $\mathrm{X}$ \\
\hline $\begin{array}{l}\text { TRANID, exo-3-Chloro-endo-6-cyano-2-norbornanone-O-(methylcarbamoyl) } \\
\text { oxime }\end{array}$ & $\mathrm{X}$ \\
\hline 2,4,5-Trichlorophenoxyacetic acid; $2,4,5-\mathrm{T}$ & $\mathrm{X}$ \\
\hline Trichlorosilane, Silicochloroform & $\mathrm{X}, \mathrm{C}, \mathrm{I}, \mathrm{R}$ \\
\hline tris(1-Aziridinyl) phosphine oxide, Triethylenephosphoramide, TEPA & $\mathrm{X}$ \\
\hline Vanadium pentoxide, Vanadic acid anhydride & $\mathrm{X}$ \\
\hline Vinyl chloride & $\mathrm{X}, \mathrm{I}$ \\
\hline Vinyltrichlorosilane & $\mathrm{X}, \mathrm{C}, \mathrm{I}, \mathrm{R}$ \\
\hline $\begin{array}{l}\text { WEPSYN 155, WP 155, Triamiphos, para-(5-Amino-3-phenyl-1H-1,2,4-triazol-1- } \\
\text { yl)-N,N,N', N'-tetramethyl phosphonic diamide }\end{array}$ & $\mathrm{X}$ \\
\hline Zinc arsenate & $\bar{X}$ \\
\hline Zinc arsenite & $\bar{x}$ \\
\hline Zinc cyanide & $\mathrm{X}$ \\
\hline Zinc phosphide & $\mathrm{X}, \mathrm{I}, \mathrm{R}$ \\
\hline Zirconium chloride, Zirconium tetrachloride & $\mathrm{X}, \mathrm{C}, \mathrm{R}$ \\
\hline
\end{tabular}




\section{Chemical Compatibility Guide}

Separating chemicals into compatible groups can be a complicated procedure. There are several indepth guides available. For the purposes of packaging chemicals for removal from the Laboratory, EH\&S provides a simplified guide on the following page. The table below summarizes the categories you should use in the "Chemical Compatibility Code" column on the Requisition form. Additional information on proper segregation of chemicals can be found in references such as the Material Safety Data Sheets (MSDSs), Aldrich Catalog Handbook of Fine Chemicals, the NIOSH Registry of Toxic Effects of Chemical Substances, or the Merck Index. Laboratory personnel will be able to segregate most chemicals into safe, compatible groups for shipping or short-term storage. For potentially explosive chemicals, contact Industrial Hygiene at extension 5829 for assistance. Contact the HWHF for questions about separation and segregation of waste.

\section{Chemical Compatibility Codes}

I. Solvents: Flammable Liquids, Combustible Liquids, Halogenated Solvents

II. Flammable Solids: Organics, Metals, Solids that are dangerous when wet, Sulfides, Phosphorous Allotropes, Organometallic Compounds, Inorganics

III. Oxidizers: Nitrates, Chlorates, Perchlorates, Oxides, Oxidizing Acids

IV. Corrosives:

- Acids (Mineral, Organic, Reactive Corrosives);

- Bases (Inorganics, Organics, Hydrazine Solutions)
V. Poisons: Organics, Metallics, Inorganic Cyanides

VI. Potential Reactives (Explosives): Trinitros, Azides, Amides, Monomeric Isocyanates

VII. Other Chemical Waste: Separate organics from inorganics. Separate liquids from solids.

VIII. Debris: Separate organics from inorganics and label packaging with all contaminants present.

Identifying and recognizing the hazards of each chemical is critical in order to handle these materials safely.To meet safety and environmental requirements, the following basic categories must be used for segregating and separating your waste.

\section{Solvents}

A. Flammable Liquids

1. Aliphatic: Acetone, Isopropanol, Methyl Ethyl Ketone, Methanol

2. Aromatic: Toluene, Xylene, Benzene, Propyl Benzene

3. Monohalogenated Solvents: Chlorobenzene, Ethyl Chloride, Acetyl Chloride

4. Monomers: Styrene, Ethylene, Vinyl Acetylene, Vinyl Pyridine

5. Reactives: Isopropyl Ether, Phenyl Manganese Chloride, Hydrazine Anhydrous, Ethyl Ether, Divinyl Ether

B. Combustible Liquids

1. Glycols: Ethylene Glycol Dibutyl Ether, Ethylene Glycol Monomethyl Ether 
2. Mineral Spirits

C. Halogenated Solvents: Carbon Tetrachloride, 1,1,1-Trichloroethane, Ethyl Chloroacetate II. Flammable Solids
A. Organic Flammable Solids: Cellulose Acetate, Nitrocellulose (At least 20\% wet)
B. Flammable Metals: Manganese, Magnesium, Yttrium, Zirconium
C. Flammable Solids (Dangerous when wet): Sodium, Lithium, Calcium, Lithium
Hydride
D. Flammable Sulfides: Sodium Sulfide, Potassium Sulfide, Ammonium Sulfide
E. Phosphorous Allotropes: Phosphorus (Yellow, Red, White), Aluminum Phosphide, Phosphorus Sulfide,

Phosphorus Pentasulfide

F. Organometallic Compounds: Lithium Butoxide, Lithium Metoxide, Sodium Ethoxy, Sodium Butylate,

Potassium Methylate

G. Inorganic Flammable Solids: Sodium Phosphide, Aluminum Hydride, Sodium

Borohydride, Boron Lithium

Aluminum Alloy

III Oxidizers
A. Nitrates: Potassium Nitrate, Calcium Nitrate, Sodium Nitrate, Zinc Nitrate, Thallium Nitrate
B. Chlorates: Potassium Chlorate, Lithium Chlorate, Calcium Chlorate, Strontium Chlorate
C. Perchlorates: Lithium Perchlorate, Magnesium Perchlorate
D. Oxides: Manganese Dioxide, Magnesium Dioxide, Chromium Trioxide, Lead Oxide (Brown)
E. Oxidizing Acids: Nitric Acid (greater than 40\%), Perchloric Acid, Periodic Acid

IV. Corrosives

A. Acids

1. Mineral Acids: Hydrochloric Acid, Sulfuric Acid, Nitric Acid (Less than 40\%), Phosphoric Acid

2. Organic Acids: Acetic Acid, Acetic Anhydride, Acetyl Bromide, Formic Acid, Isopentanoic Acid

3. Reactive Corrosives: Phosphorus Trichloride, Phosphorus Pentachloride, Antimony Trichloride, Phosphoric Anhydride

B. Bases

1. Inorganics: Sodium hydroxide, Potassium Hydroxide, Ammonium Hydroxide, Sodium Hypochlorite

2. Organics: Amino Propyl Diethanolamine, Amino Ethyl Piperazine, Acetyl Iodide, Benzoyl Chloride, Dimethyl Sulfonyl Chloride 


\section{Hydrazine Solutions}

V. Poisons
A. Organics: Phenol, Acrylamide, Benzoin, Benzidine, Aniline
B. Metallics: Arsenic, Lead, Beryllium, Mercury, Selenium
C. Inorganic Cyanides: Potassium Cyanide, Sodium Cyanide, Cyanogen Bromide

VI. Potential Reactives (Explosive)
A. Trinitros: Trinitrophenol (Picric Acid), Trinitrobenzene, Trinitrotoluene (TNT), Trinitromethane
B. Azides: Hydrogen Azide, Ammonium Azide, Barium Azide, Chlorine Azide, Silver Azide
C. Amides: Trinitroaniline (Picramide), Sodamide, Potassium Amide
D. Monomeric Isocyanates: Hydrocyanic Acid, Isothiocyanuric Acid

VII. Other Chemical Waste
A. Separate Organics from Inorganics*
B. Separate Liquids from Solids

VIII. Debris

A. Separate Organics from Inorganics* and label packaging with all contaminants present.

"Inorganic materials contaminated with organic components should be segregated as organic. 


\section{Appendix 2. Waste Acceptance Criteria for Certification Team Review of Radioactive Waste Tag Information}

- The generator must have completed Radioactive and Mixed Waste Generator Training.

- The tag must be legible, completely filled out, signed, and dated. Only one waste container is allowed on each waste tag.

- The tag must present a summary of the constituents of the waste, including radiological, physical, and chemical. Do not use the Radioactive Waste tag as an accumulation log.

- $\quad$ Each isotope must be listed with an activity. Total activity must be entered, based on a summation of the individual isotope entries.

- The basis for radioactive characterization must be indicated for each entry, i.e., DIRT (Direct Information transfer from Research Techniques), MB (Materials Balance), DA (Direct Assay), or Rx (predictable Reaction product).

- For dry compactable waste, an estimate of the physical components must be made, and the constituent percentages must total to $100 \%$.

- For liquid waste, all constituents of the waste must be accounted for, including both hazardous and nonhazardous constituents. For aqueous waste, the percent water must be listed.

- $100 \%$ of the contents of the waste container must be accounted for. The preferred unit for constituent concentrations is wt\%. List only one constituent per line. Use continuation sheet(s) if constituents exceed the number of lines on the tag.

- The pH must be reported for all aqueous waste.

- The basis for chemical characterization must be indicated for each entry (i.e., DIRT, MB, $\mathrm{DA}$, or $\mathrm{Rx}$ ).

- A copy of pertinent accumulation $\log (\mathrm{s})$ must be faxed with the Radioactive/Mixed Waste Disposal Requisition where waste is acumulated through multiple additions to a single waste container.

- Supporting documentation must be available for review by Waste Management on request.

- If the generator knows, or has strong reason to believe, that the waste is both hazardous and radioactive (that is, mixed waste), then a completed Hazardous Waste label must be affixed to each container of mixed waste at the start of accumulation in addition to the Radioctive Waste tag.

- When a generator signs a Radioctive Waste tag and a Radioacative/Mixed Waste Disposal Requisition, he/she is certifying that the waste is properly characterized, that training has been completed, and that documentation is available to support chracterization information.

- Waste Certification will determine the classification of the waste based on the indicated constituent(s). 


\section{Appendix 3. Abbreviations and Acronyms}

COB City of Berkeley

DOE U.S. Department of Energy

DTSC California Department of Toxic Substances Control

DOT U.S. Department of Transportation

HWHF LBNL Hazardous Waste Handling Facility

LSAD LBNL Self-Assessment Database

MSDS Material Safety Data Sheet

MWSAA Mixed Waste Satellite Accumulation Area

NCAR Nonconformance and Corrective Action Report

NIOSH National Institutes of Occupational Safety and Health

NORM Naturally Occurring Radioactive Material

OAA LBNL Office of Assessment and Assurance

RCRA Resource Conservation and Recovery Act

RMA Radioactive Material Area

RWCA Radioactive Waste Collection Area

SAA Satellite Accumulation Area

TCLP Toxicity Characteristic Leaching Procedure

TSDF Treatment, Storage, and Disposal Facility

WAA Waste Accumulation Area 


\section{Appendix 4. Definitions}

Acutely Hazardous Wastes. Any wastes defined as acutely hazardous by $22 \mathrm{CCR}$, Chapter 11 , Article 4.

Certification. The person who signs his or her name on the Hazardous Waste Disposal Requisition and/or the Radioactive Waste Tag certifies that the contents of the hazardous, radioactive, or mixed waste package are described exactly and correctly by the Requisition/Tag. This description (and the signature) are legally binding.

Certify. To attest by signature, to the best of one's knowledge, that the information provided is correct.

Characterization. The detailed documentation necessary to certify that the waste is what it is claimed to be. Characterization can include process knowledge (see definition below), required analyses, or written documentation (log books, formulas, etc.).

Controlled Area (for Radiation Protection). An area where radioactive materials or elevated radiation fields may be present.

Corrosive Wastes. Aqueous wastes with $\mathrm{pH} \leq 2$ or $\geq 12.5$ (or nonaqueous wastes that produce a solution with these $\mathrm{pH}$ values when mixed with an equivalent weight of water). Corrosive wastes also include wastes that can corrode steel at a rate of 0.25 inch per year.

Cradle-to-Grave Tracking. The term for the system whereby carefully detailed records are maintained documenting the generation, storage, treatment, and disposal of all hazardous waste generated at a facility. These records essentially cover hazardous waste from the point of origin (generation) to its final offsite destination and disposal.

Discarded Material. Any material that is disposed of, burned, incinerated, accumulated, stored, treated, or recycled.

Dry Waste. Radioactive waste that has less than $1 \%$ free liquids.

Extremely Hazardous Waste. Any hazardous waste or mixture of hazardous wastes that, if human exposure should occur, may likely result in death, disabling personal injury, or serious illness caused by the hazardous waste or mixture of hazardous wastes because of its quantity, concentration, or chemical characteristics. (From 22 CCR 66260.10.)

\section{Hazardous Wastes.}

- Wastes that exhibit one or more of the criteria for identification of "hazardous waste" (22 CCR 66261.21-66261.24). These criteria are

$$
\begin{array}{ll}
- & \text { toxicity } \\
- & \text { ignitability } \\
- & \text { reactivity } \\
- & \text { corrosivity }
\end{array}
$$


- Wastes listed in the California Code of Regulations (22 CCR 66261) and the Code of Federal Regulations (40 CFR Part 261). These wastes include certain discarded commercial chemical products, off-specification products, container residues, and spill residues.

- Wastes listed as "dangerous" or "extremely hazardous" in the Washington Administrative Code, Chapter 173-303.

High-Level Waste. The highly radioactive waste material that results from the reprocessing of spent nuclear fuel, including liquid waste produced directly in reprocessing and any solid waste derived from the liquid that contains a combination of transuranic waste and fission products in concentrations requiring permanent isolation.

Identification. The description of the waste in a container. When you fill out the Hazardous Waste Label and the Hazardous Waste Disposal Requisition, you identify your waste.

Ignitable Wastes. Material that has any of the following properties:

- A liquid with a flash point of less than $60^{\circ} \mathrm{C}\left(140^{\circ} \mathrm{F}\right)$. Exception: Aqueous solutions containing less than $24 \%$ alcohol when they are used

- Solids that are capable of causing fire through friction, absorption of moisture, or spontaneous changes

- A flammable compressed gas. Examples: carbon monoxide, ethylene, hydrogen, methane

- A material defined as an oxidizer. Examples: nitric acid, perchloric acid, potassium permanganate, hydrogen peroxide, silver nitrate, ammonium persulfate, potassium nitrate, sodium nitrate, chromic acid

Low-Level Waste. Waste containing radioactivity that is not classified as high-level waste, transuranic waste, spent nuclear fuel, or byproduct material, as defined in DOE Orders 5820.2A and 5400.3. At Berkeley Lab, low-level waste is divided into the following categories for the purpose of safe handling:

- Low-specific-activity (LSA) alpha waste, solid. LSA solid alpha waste must have radioactivity levels below $100 \mathrm{nCi} / \mathrm{g}$. Low-level solid waste with activity levels above $100 \mathrm{nCi} / \mathrm{g}$ should be kept separate from LSA waste.

- Low-level alpha waste, liquid. Low-level liquid alpha waste must have radioactivity levels below $100 \mathrm{nCi} / \mathrm{ml}$.

- Low-level beta and gamma waste, solid. Low-level solid beta and gamma solid waste must have radioactivity levels below $0.3 \mathrm{mCi} / \mathrm{g}$. The exception is ${ }^{90} \mathrm{Sr}$, for which the beta and gamma levels must be below $0.005 \mathrm{mCi} / \mathrm{g}$. Nonradioactive material contaminated with radioactivity less than $0.001 \mathrm{mCi} / \mathrm{cm}^{2}$ (measured on the surface) is considered to be lowlevel beta or gamma solid waste. 
- Low-level beta and gamma waste, liquid. Low-level liquid beta and gamma waste must have radioactivity levels below $0.3 \mathrm{mCi} / \mathrm{ml}$. The exception is ${ }^{90} \mathrm{Sr}$, for which the beta and gamma levels must not exceed $5 \mu \mathrm{Ci} / \mathrm{ml}$.

Mixed Waste. Any radioactive waste that is also a hazardous waste.

Process Knowledge. The ability of the generator to characterize waste on the basis of knowing the chemical materials from which the waste was derived and the processes through which the waste was generated. Also includes the ability to verify the characterization with the documented procedures used and data accumulated during the waste-generation process.

Radioactive Material Area (RMA). An area where the potential exists for contamination from the presence of unencapsulated or unconfined radioactive materials or an area that is exposed to beams or other sources of particles (neutrons, protons, etc.) capable of causing activation.

Reactive Waste. A material that has the following properties:

- It is normally unstable and readily undergoes violent change.

- It reacts violently with water.

- It forms potentially explosive mixtures with water.

- It is a cyanide- or sulfied-bearing waste that is capable of generating toxic gases, vapors, or fumes

- It is capable of detonation or explosive reaction.

- It is defined as an explosive.

Satellite Accumulation Area (SAA). An area in an individual laboratory, shop, or other facility designated by the generator for the accumulation of waste, not to exceed 55 gallons of hazardous waste or 1 quart of extremely or acutely hazardous waste. The area must be at or near the point of waste generation. Waste can accumulate in SAAs for up to 275 days. Even a single small bottle of a hazardous waste is considered an SAA.

SAA Start Date. The date that waste is first placed in a container in the SAA.

Secondary Containment. A container designed to hold one or more containers for the collection of liquid waste in a laboratory or shop area. Examples of secondary containment include plastic tubs or buckets, photographic development trays, and pail skids.

Segregation. The practice of not placing chemically unrelated or incompatible materials in the same container.

Separation. The practice of keeping containers of incompatible wastes apart physically.

Solid Waste. Any discarded material (solid, liquid, or gas) that is not excluded.

Toxic Wastes. Wastes that pose a hazard to human health or the environment because of carcinogenicity, acute or chronic toxicity, bioaccumulative properties, or persistence in the environment. 
Transuranic (TRU) Waste. Waste, without regard to source or form, that is contaminated with alpha-emitting transuranium radionuclides (elements 93 and higher) with half-lives greater than 20 years and concentrations greater than $100 \mathrm{nCi} / \mathrm{g}$ at the time of assay. Radium sources and $\mathrm{U}-233$ are also considered to be TRU waste. Radioactive waste with quantities of transuranic radionuclides in concentrations of $100 \mathrm{nCi} / \mathrm{g}$ of waste or less is considered low-level waste and not TRU waste. Transuranic waste generated at Berkeley Lab will be shipped to the Hanford site and placed in interim storage pending eventual shipment to the Waste Isolation Pilot Project (WIPP) in New Mexico. All transuranic waste must meet the criteria of WIPP-DOE069, Transuranic Waste Acceptance Criteria for the WIPP.

Treatment. Any method, technique, or process designed to change the physical, chemical, or biological character or composition of any hazardous waste. (This definition is taken from 40 CFR 260.10 and 22 CCR 66260.10.) Neutralization and dilution are examples of processes that are considered treatments by federal and state regulations.

Waste Accumulation Area (WAA). An officially designated area for the accumulation and storage of large quantities of hazardous waste. Specific regulations apply to WAAs, including security, labeling and signage, contingency plans, and emergency equipment. Wastes can be accumulated in WAAs for up to 60 days.

WAA Receival or Accumulation Start Date. The date that a container transferred from an SAA to a WAA is received by the manager of the WAA, or the date waste is first placed in a container at a WAA collection point.

Waste Container. Anything that collects waste. Waste containers include drums, carboys, cans, bottles, boxes, plastic bags, metal transport containers, and any other container approved as appropriate for the type of waste handled.

Waste-Generating Organization. A program, facility, or group that generates hazardous, radioactive, or mixed waste.

Waste Generator. The individual or operation responsible for actually generating the hazardous, radioactive, or mixed waste within an organization. Berkeley Lab as a whole is viewed as a waste generator by environmental regulatory agencies. Within Berkeley Lab, each researcher, laboratory, shop, and facility, as a potential point of origin for hazardous, radioactive, or mixed waste, is a waste generator.

Waste Stream. Waste generated from an industrial process or application, laboratory experiment, or routine laboratory procedure with roughly constant and unchanging radioactive, mixed, or hazardous characteristics. 


\section{Appendix 5. Berkeley Lab Compliance Framework for Waste Accumulation at Generator Sites}

\section{Introduction}

Most of the hazardous, radioactive, and mixed wastes generated by Berkeley Lab scientific and support activities are accumulated in satellite areas until they are picked up and transported to the onsite Hazardous Waste Handling Facility (HWHF), where they are treated and/or packaged for transport to approved, offsite treatment, storage, and disposal facilities (TSDFs). The satellite areas include approximately 400 Satellite Accumulation Areas (SAAs), where small amounts of hazardous wastes are stored, approximately 120 Radioactive Waste Collection Areas, and approximately 25 Mixed Waste Satellite Accumulation Areas (MWSAAs).

Berkeley Lab has established policies for compliant accumulation of hazardous, radioactive, or mixed wastes at generator sites that minimize risks to the health and safety of Berkeley Lab staff and visitors, and greatly reduce the likelihood of accidental releases to the environment. Noncompliance with laws and regulations regarding waste accumulation could result in fines or penalties to the Laboratory, with possible disciplinary actions to responsible parties. The purpose of this document is to briefly outline the responsibilities of Berkeley Lab scientists, managers, and support staff in the matter of waste accumulation at generator sites, and to familiarize Berkeley $\mathrm{Lab}$ staff with their roles in maintaining a workplace that is free from unnecessary hazards relating to waste storage.

\section{Regulatory Framework}

Regulations regarding the storage of hazardous wastes in SAAs are found in Title 22, Division 4.5, Chapter 12 of the California Code of Regulations. Because mixed wastes are hazardous as well as radioactive, these regulations also govern the accumulation of mixed wastes in satellite areas. The regulations make it clear that the point of responsibility for waste accumulation in satellite areas is as follows:

- The waste generator is responsible for the maintenance of the waste accumulation site and for keeping detailed records of waste accumulation, as necessary to adequately and accurately characterize all waste.

- The facility/laboratory supervisor (or designee) is responsible for enforcing proper waste accumulation at the SAA or MWSAA.

At Berkeley Lab, the compliance policies in this manual govern the accumulation of hazardous waste (in SAAs), mixed waste (in MWSAAs) and radioactive wastes (in Radioactive Waste Collection Areas). Areas where hazardous, radioactive, and mixed wastes are accumulated must be operated and maintained by the waste generators, and the accountability for compliance in these 
areas is a clear line-management responsibility. The Berkeley Lab Environment, Health and Safety (EH\&S) Division, the Office of Assessment and Assurance (OAA), DOE, and other groups play supporting roles in the management, operation, and oversight of these areas.

\section{Enforcement Authority for Hazardous and Mixed Wastes}

The responsibility and authority for enforcement of regulations regarding the storage of waste in Berkeley Lab's SAAs and MWSAAs resides with the State of California Department of Toxic Substances Control (DTSC) and also, should it choose to exercise its authority, the U.S. Environmental Protection Agency. DTSC has delegated to Alameda County, and Alameda County has redelegated to the City of Berkeley $(\mathrm{COB})$ as the authority for local enforcement. Thus, the COB has the authority to make unannounced inspections of Berkeley Lab SAAs and MWSAAs and to prepare reports of violations to the Laboratory and its employees for any areas that are found to be out of compliance with the regulations.

For the purpose of determining administrative penalties, DTSC has divided violations into two types, Class I and Class II.

- Class I violations are significant deviations from statute or regulation that present a release or a significant threat of a release of hazardous waste to the environment and/or chronic nonconformance with the regulations. Fines for Class I violations can be as large as $\$ 25,000$ per day.

- Less significant Class II violations normally bring fines of up to $\$ 10,000$ per day for each violation, but fines as large as $\$ 25,000$ per day are possible.

- Noncompliant SAA or MWSAA operation can also lead to civil penalties of up to $\$ 25,000$ per day or criminal penalties involving fines and/or jail terms when responsible parties knowingly or willfully violate the statutes or regulations in accumulating or managing hazardous or mixed waste. Second or subsequent negligent violations can lead to civil penalties of up to $\$ 25,000$ per day or felony convictions involving large fines or jail terms, as can illegal treatment, storage, disposal, or transportation of hazardous waste by any person who knows or should reasonably know he or she was treating, storing, disposing, or transporting hazardous waste.

\section{Enforcement Authority for Radioactive Wastes}

Enforcement authority for the management of radioactive wastes at Berkeley Lab Radioactive Waste Collection Areas resides with the Department of Energy (DOE). Although DOE penalties do not include fines and/or criminal penalties, noncompliance with DOE orders and rules can result in the curtailment of research and support activities at the Laboratory.

\section{The Compliance Hierarchy for Waste Accumulation at Generator Sites}

To limit the institutional and individual liability in the case of noncompliance with regulations regarding waste accumulation at generator sites, Berkeley Lab has initiated a three-tiered hierarchy of violations, as depicted in Figure C-1. These three levels are described below. 


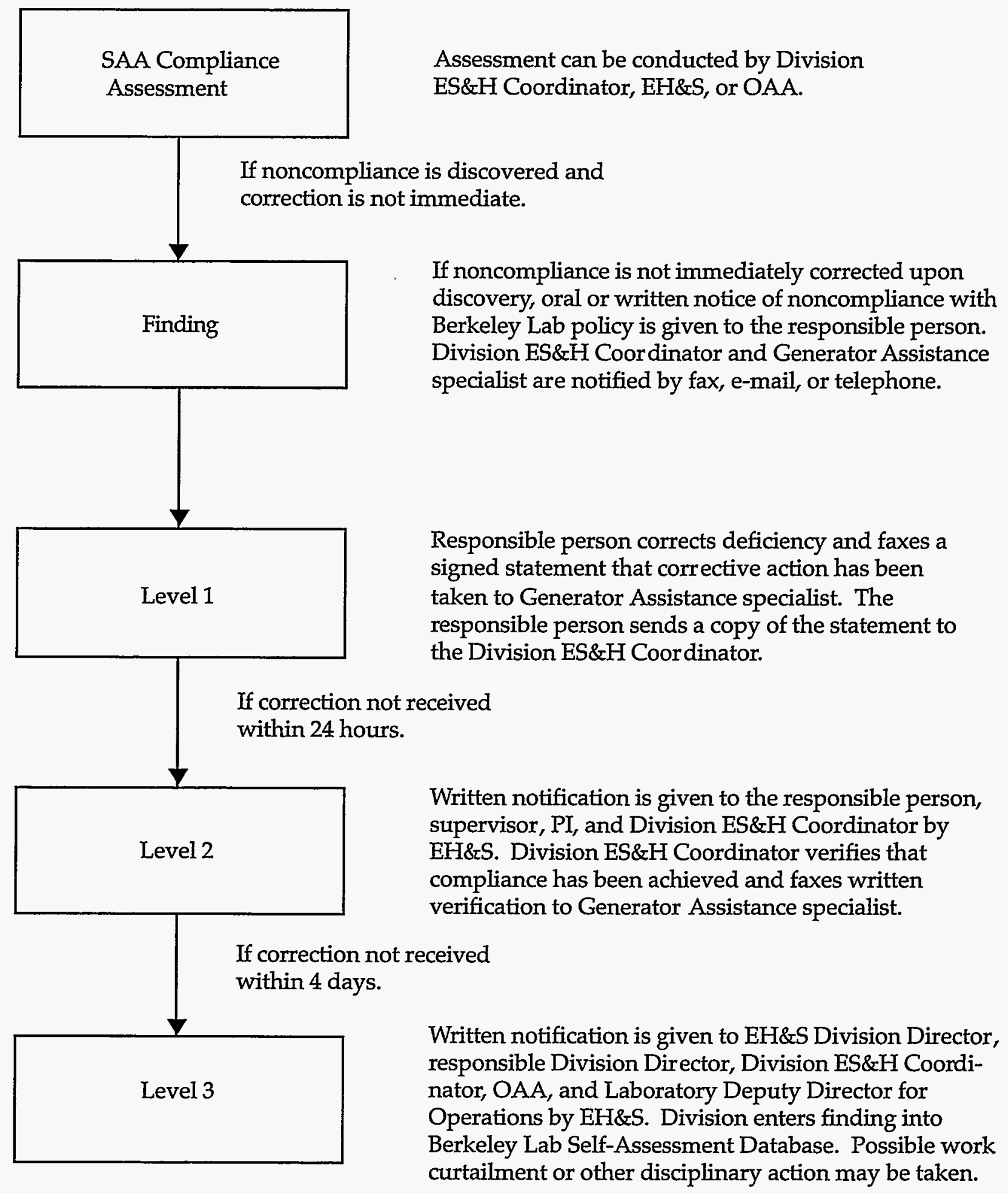

Figure C-1. Compliance hierarchy for waste accumulation at generator sites. 
Level 1 When an assessment by the responsible Division, EH\&S, or OAA reveals that a generator waste accumulation site is out of compliance with Berkeley Lab policy and the noncompliance is not immediately corrected, the person responsible for the accumulation site will be notified orally or in writing, and a notice will be faxed, telephoned, or e-mailed to both the EH\&S Generator Assistance specialist and Environment, Safety, and Health (ES\&H) Coordinator for the responsible division. This notice should be received on the day of discovery and should identify the generator site location, the date and time of the discovery of noncompliance, the responsible division, and the person responsible for the operation of the site of waste accumulation. The responsible person has 24 hours (one working day) to correct the deficiency and to fax a signed statement to the EH\&S Generator Assistance specialist and the ES\&H Coordinator for the responsible division that corrective actions have been taken

Level 2 If a fax confirming that compliance has been achieved is not received within 24 hours (one working day), the EH\&S Generator Assistance specialist escalates the problem to Level 2. A written notice of the deficiency is faxed to the responsible person, his/her supervisor, the responsible Principal Investigator, and the ES\&H Coordinator for the responsible division. In addition, an indication of noncompliance is entered into the Generator Assistance database for tracking. The responsible Division ES\&H Coordinator has four working days to determine that compliance has been achieved, and to fax written verification of the correction to the EH\&S Generator Assistance specialist.

Level 3 In the event that four working days pass without verification from the responsible Division ES\&H Coordinator that a Level 2 infraction has been corrected, the EH\&S Generator Assistance specialist escalates the problem to Level 3. After discussion with the responsible Division ES\&H Coordinator, a written notice is faxed to the EH\&S Division Director, detailing the nature of the problem. Copies are faxed to the responsible Division Director, the responsible Division ES\&H Coordinator, and OAA, which informs the Laboratory Deputy Director for Operations. The responsible division enters the finding into the Berkeley Lab Self-Assessment Database (LSAD) for tracking. Ensuing discussions between the EH\&S Division Director, the responsible Division Director, and the Laboratory Deputy Director for Operations focus on the need, if any, for work curtailment or other disciplinary action until compliance is achieved. It is anticipated that Level 3 will be reached only in the most extraordinary of conditions.

\section{Oversight Responsibility at Berkeley Lab}

EH\&S is responsible for maintaining a current view of regulatory issues, formulating Berkeley Lab policy to assure regulatory compliance, and providing documentation, training materials, guidance, and assistance to the Laboratory's hazardous, radioactive, and mixed waste generators.

When the $\mathrm{COB}$ (or DOE) wishes to inspect generator waste accumulation sites at the Laboratory, an EH\&S Division Generator Assistance specialist attends the inspection. The Generator Assistance specialist also takes part in scoping meetings prior to any inspection and in formal post-inspection close-outs, where any possible findings are discussed. This practice promotes factual accuracy in the findings and generates a full understanding of any outstanding issues by all 
parties. A database of findings from COB, DOE, or EH\&S inspections and all Level 2 or Level 3 violations is maintained by the Waste Minimization and Generator Assistance Team Leader to provide information for lessons learned analysis.

Berkeley Lab divisions routinely monitor their own performance in ES\&H issues through the Berkeley Lab Self-Assessment Program. In addition, the EH\&S Division and the DOE Site Office provide oversight of ES\&H matters at Berkeley Lab through periodic functional appraisals. If not corrected immediately, these discoveries of nonconformance are treated in the same ways as violations discovered by COB. A notice reporting the noncompliance is sent to the EH\&S Generator Assistance specialist, who enters the deficiency into the Compliance Hierarchy process, as described above.

EH\&S Generator Assistance specialists conduct quarterly quality assurance walkarounds to establish the general level of compliance across the Laboratory's generator accumulation areas; these walkarounds also give the Generator Assistance specialists first-hand knowledge of the types of problems that may be contributing to any persistent noncompliance. The walkarounds cover at least $10 \%$ of Berkeley Lab's SAAs, MWSAAs, and Radioactive Waste Collection Areas in any quarter and are meant to provide a site-wide view of waste-accumulation compliance at Berkeley Lab generator sites.

\section{EH\&S Division Waste Generator Training Program}

Generators of hazardous, radioactive, and/or mixed waste must be trained in proper handling procedures for waste to be accepted by the HWHF. All waste generators should complete Training for Hazardous Waste Generators (EHS-601) within 30 days of arriving at the Laboratory. Furthermore, generators of radioactive and/or mixed waste at the Laboratory should also complete Training for Radioactive/Mixed Waste Generators (EHS-621) within 30 days of arriving at Berkeley Lab. Training for Hazardous Waste Generators (EHS-601) is accomplished by watching a 12-minute video entitled "Environmental Compliance, Hazardous Waste, Part 1," studying this guidebook, Guidelines for Generators to Meet HWHF Acceptance Requirements for Hazardous, Radioactive, and Mixed Wastes at Berkeley Lab (PUB-3092), and passing a written test. Generators of radioactive and/or mixed waste view an additional 8-minute video, read the appropriate sections in PUB3092, and answer additional examination questions. All materials have been distributed to each Division's ES\&H Coordinator so generators can be trained at their convenience. Completed tests are forwarded to EH\&S Training, where they are scored. The names and employee ID numbers of all Berkeley Lab staff who successfully pass the test are recorded in Berkeley Lab's training database, System for Training and Assessment Records.

After exams are scored, EH\&S Training sends a memo to each trainee, listing any questions that were missed and the page in PUB-3092 where the correct information can be found. Any trainee who fails is given a second opportunity to pass the test, and credit for the course is not given until successful completion of the exam. The EH\&S Training Unit also informs the appropriate Division Safety Coordinator of failures, so the information can be forwarded to the trainee's supervisor. Trainees who fail a second time should contact their EH\&S Generator Assistance specialist for assistance.

Site-specific generator training is also available to supplement Training for Hazardous Waste Generators and Training for Radioactive/Mixed Waste Generators courses. This training is called Site-Specific Haz Waste Generator Training (EHS-602) and Site-Specific Rad/Mixed Waste Generator Training (EHS-622). Such special training sessions can always be arranged with the 
EH\&S Generator Assistance specialist at any time, and may include question-and-answer periods, site consultations, or follow-ups to resolve particularly difficult issues surrounding compliant operations.

Refresher training for hazardous, radioactive, and/or mixed waste generators is given to individuals or groups on an as-needed basis, as indicated from the compliance history for Berkeley Lab waste generators. In addition, refresher training will also be required when there are substantial changes in the generator guidelines or procedures. Refresher training may include formal classroom presentations by the EH\&S Generator Assistance specialist and/or consultations at the generator waste accumulation site. Records on the refresher training are kept in the Berkeley Lab training database as well.

When revisions are made to PUB-3092, the new revision is distributed to everyone who has had waste generator training.

Berkeley Lab waste generators can get advice about their SAAs, MWSAAs, or Radioactive Waste Collection Areas by calling their EH\&S Generator Assistance specialist. In most cases, questions can be answered directly over the phone, or by reference to one or more passages in PUB-3092. In cases where simple answers are not available, the EH\&S Generator Assistance specialist will provide onsite consultations to resolve any further issues or give further assistance. 


\section{Appendix 6. Governing Documents and References}

\section{Governing Documents}

United States Environmental Protection Agency, Title 40 of the Code of Federal Regulations (40 CFR)

United States Department of Transportation, 49 CFR

Occupational Safety and Health Administration, $29 \mathrm{CFR}$

United States Department of Energy Orders 5820.2A, 5400.3, and 5480.11

California Code of Regulations (CCR) Title 22

California Department of Health Services Hazardous Waste Control Law (excerpt from Health and Safety Code, Division 20)

EPA SW-846, Test Methods for Evaluating Solid Waste, Physical/Chemical Methods

Washington Administrative Code, Chapter 173-303, Dangerous Waste Regulations

Health and Safety Manual, Berkeley Lab (PUB-3000)

Waste Analysis Plan (Section III of the Part B Permit)

Hanford Radioactive Solid Waste Packaging, Storage, and Disposal Requirements, WHC-EP-0063-3

Transuranic Waste Acceptance Criteria for the WIPP, WIPP-DOE-069

Master Emergency Plan, Berkeley Lab (PUB-237), revised

Waste Minimization and Pollution Prevention Awareness Plan, Berkeley Lab (PUB-3106), September 1995

Chemical Hygiene and Safety Plan, Berkeley Lab (PUB-5341)

\section{References}

Guidelines for Waste Accumulation Areas (WAAs), Berkeley Lab (PUB-3093)

Medical and Biohazardous Waste Generator's Guide, Berkeley Lab (PUB-3095)

Occurrence Reporting, Berkeley Lab (LBID-1694 Rev.) 